VANESSA GOMES CRUZ OGAWA

PROPOSTA DE IDENTIFICAÇÃO DOS PARÂMETROS DO MODELO DE BATERIA PARA USO NA MODELAGEM DE SISTEMAS DE PARTIDA DE VEÍCULOS AUTOMOTIVOS

São Paulo 
VANESSA GOMES CRUZ OGAWA

\title{
PROPOSTA DE IDENTIFICAÇÃO DOS PARÂMETROS DO MODELO DE BATERIA PARA USO NA MODELAGEM DE SISTEMAS DE PARTIDA DE VEÍCULOS AUTOMOTIVOS
}

\author{
Dissertação apresentada à Escola \\ Politécnica da Universidade de São Paulo \\ para obtenção do Título de Mestre em \\ Engenharia.
}

Área de Concentração: Sistemas de Potência

Orientador: Prof. Dr. Luiz Lebensztajn

São Paulo 
Este exemplar foi revisado e alterado em relação à versão original, sob responsabilidade única do autor e com a anuência de seu orientador.

São Paulo, 05 de julho de 2011.

Assinatura do autor

Assinatura do orientador

FICHA CATALOGRÁFICA

Ogawa, Vanessa Gomes Cruz

Proposta de identificação dos parâmetros do modelo de ba teria para uso na modelagem de sistemas de partida de veículos automotivos / V.G.C. Ogawa. -- ed.rev. -- São Paulo, 2011.

$76 \mathrm{p}$.

Dissertação (Mestrado) - Escola Politécnica da Universidade de São Paulo. Departamento de Engenharia de Energia e Automação Elétricas.

1. Baterias elétricas 2. Otimização não linear 3. Identificação de sistemas I. Universidade de São Paulo. Escola Politécnica. Departamento de Engenharia de Energia e Automação Elétricas II. t. 
Dedico esse trabalho à minha mãe e ao meu pai (que estará sempre em meu coração) por todo o esforço que fizeram para que eu chegasse muito mais longe do que eles próprios conseguiram. 


\section{AGRADECIMENTOS}

Ao professor Luiz Lebensztajn, pela orientação e pelo constante estímulo e incentivo transmitidos durante todo o trabalho.

Ao meu marido Márcio Hideki Ogawa, pelo amor, compreensão e apoio durante o tempo que dediquei a esse trabalho.

A minha mãe que sempre incentivou meus estudos e esforçou-se muito para que eu conseguisse concluí-los.

Ao meu tutor e amigo Flávio Roberto Hernandes Miguel que me ensinou grande parte do que sei sobre baterias, alternadores e veículos de uma forma geral e me orienta na resolução dos problemas enfrentados no dia-a-dia da empresa.

Aos meus gerentes Rogério Vollet e Dalicio Guiguer e ao meu diretor Plinio Cabral Jr. por terem permitido minhas saídas durante o horário de expediente para a realização desse trabalho e pela confiança que depositaram em mim desde quando fui admitida na empresa.

E a todos os amigos, colegas e familiares que tiveram a compreensão necessária quando precisei me ausentar para a execução desse trabalho e que colaboraram direta ou indiretamente para sua conclusão. 


\section{RESUMO}

O objetivo desse trabalho foi investigar o modelo matemático para baterias de chumbo-ácido, usada em aplicações veiculares, mais adequado para a condição de descarga, que ocorre durante o teste de Cold Crank, e propor uma metodologia para identificar os parâmetros da bateria, a partir de ensaios experimentais. A simulação do teste de Cold Crank foi a motivação para o início da pesquisa. Dentre os diversos modelos pesquisados, foram selecionados aqueles que representam a dinâmica da bateria durante a descarga e que são baseados em circuitos elétricos. O modelo de Jackey foi escolhido, por possuir um circuito equivalente com adequada complexidade para o objetivo estudado. Após algumas simplificações e usando a $1^{\text {a }}$ Lei de Kirchhoff, definiu-se a equação da bateria, que calcula a tensão nos terminais para um dado valor de corrente de descarga constante. Adotaram-se ainda algumas leis de formação propostas por Jackey e uma forma alternativa para a descrição de $R_{1}$. Alguns parâmetros da equação da bateria foram calculados usando a curva de tensão em aberto (OCV) em função do estado de carga (SOC), a equação da variação do estado de carga em função do tempo (SOC(t)) e o circuito simplificado para o instante inicial. Para os demais parâmetros, uma metodologia de resolução foi apresentada e implementada em ambiente MatLab®. Através da utilização de curvas de descarga experimentais e com o auxílio dos algoritmos de otimização genético e de busca local, os parâmetros desconhecidos foram estimados de forma a minimizar o erro entre os valores calculados e os valores experimentais. Por fim, foi apresentada a variação dos parâmetros em função da corrente de descarga. Com o uso das curvas que aproximam essa variação, alguns exemplos foram gerados para mostrar que os valores calculados continuam coerentes, tanto em forma quanto em escala, quando comparados com valores experimentais para outros níveis de corrente. Dessa forma, o objetivo do trabalho foi alcançado uma vez que a metodologia aplicada apresentou bons resultados mesmo com o número limitado de curvas de descarga experimentais.

Palavras-chave: Baterias elétricas. Otimização não linear. Identificação de sistemas. 


\begin{abstract}
The aim of this study was to investigate the most suitable lead-acid battery model, used in vehicular application, to the discharge condition which occurs during a Cold Crank test, and to propose a methodology to identify the battery parameters from experimental tests. The Cold Crank simulation was the motivation for this research. Among the various studied models, were selected those that describe the battery dynamic during a discharge process and that are based on electrical circuits. Jackey model was chosen because it has an equivalent circuit with suitable complexity to the aim. After some simplifications and using $1^{\text {st }}$ Kirchhoff's Law, the battery equation was defined, which calculates the terminal voltage for a given constant discharge current. Also, it was adopted some laws proposed by Jackey and an alternative way to describe $R_{1}$. Some parameters from battery equation were defined using the open circuit voltage (OCV) as function of state of charge (SOC), the equation of SOC variation as function of time and simplified circuit for the initial time. For the others parameters, a solving methodology was introduced and implemented in Matlab® environment. Usage of experimental discharge curves and with the help of genetic and local search algorithms, the unknown parameters were estimated in order to minimize the error between calculated and experimental values. Finally, it was presented the parameters variation as function of discharge current. With the use of curves that approximate this variation, some examples were generated to show that the calculated values remain consistent in both shape and range when compared to experimental values for others current levels. In this way, the aim was reached since methodology produced good results even with limited number of experimental discharge curves.
\end{abstract}

Keywords: Electrical batteries. Non linear optimization. System identification. 


\section{LISTA DE ILUSTRAÇÕES}

Figura 1.1 - Esquema simplificado do sistema de partida de um veículo.

Figura 3.1 - Diagrama do sistema de partida de um veículo automotivo com motor de combustão interna.

Figura 3.2 - Elementos de uma bateria de chumbo-ácido.

Figura 3.3- Diferentes estruturas de grades que formam os eletrodos de uma bateria de chumbo-ácido.

Figura 4.1 - Modelo simples para bateria de chumbo-ácido..................................18

Figura 4.2 - Modelo caixa preta para bateria de chumbo-ácido...............................18

Figura 4.3 - Modelo para bateria de chumbo-ácido ...............................................19

Figura 4.4 - Modelo para bateria de chumbo-ácido implementado no Simulink ${ }^{\circledR}$....21

Figura 4.5 - Circuito equivalente do modelo de Jackey .22

Figura 4.6 - Circuito equivalente de um eletrodo .23

Figura 4.7 - Circuito equivalente de uma célula. 24

Figura 4.5 - Circuito equivalente do modelo de Jackey 25

Figura 4.8 - Modelo simplificado para bateria de chumbo-ácido considerando apenas os componentes relevantes durante o processo de descarga. 26

Figura 4.9 - Modelo simplificado para bateria de chumbo-ácido usando fonte de corrente. 26

Figura 4.10 - Modelo simplificado para bateria de chumbo-ácido válido no instante inicial. .34

Figura 4.11 - Fluxo da metodologia para a resolução da equação da bateria. 37

Figura 4.12 - Tela da ferramenta Optimtool no MatLab®: Parâmetros que foram alterados para o uso da função de otimização ga. 
Figura 4.13 - Tela da ferramenta Optimtool no MatLab®: Parâmetros que foram alterados para o uso da função de otimização fmincon.

Figura 4.14 - Exemplo dos pontos de medição que serão tomados da curva experimental e da resolução da equação da bateria para cálculo do erro.

Figura 4.15 - Fluxo da metodologia para a resolução da equação da bateria para um valor de corrente de descarga qualquer. .52 


\section{LISTA DE GRÁFICOS}

Gráfico 3.1 - Variação da resistência interna de um modelo de bateria de chumboácido em função da temperatura de operação. ...................................................14

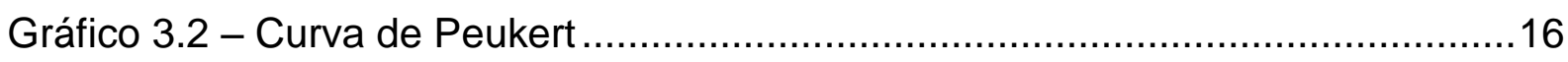
Gráfico 4.1 - Exemplo da variação da tensão nos terminais da bateria $V_{2}$ em função do tempo para uma bateria de chumbo-ácido submetida ao processo de descarga constante. .28

Gráfico 4.2 - Variação da tensão de circuito aberto (OCV) em função do estado de carga $(\mathrm{SOC})$ de baterias de chumbo-ácido comercialmente usadas em veículos automotivos. 31

Gráfico 4.3 - Variação do estado de carga (SOC) de uma bateria de chumbo-ácido (63Ah) em função do tempo para um processo descarga de 10A. .33

Gráfico 4.4 - Variação da tensão nos terminais da bateria $V_{2}$ em função do tempo para uma bateria de chumbo-ácido (63Ah) submetida à processos de descarga constante 100A. 42

Gráfico 4.5 - Variação da tensão nos terminais da bateria $V_{2}$ em função do tempo para uma bateria de chumbo-ácido (63Ah) submetida à processos de descarga constante 50A. .42

Gráfico 4.6 - Variação da tensão nos terminais da bateria $V_{2}$ em função do tempo para uma bateria de chumbo-ácido (63Ah) submetida à processos de descarga constante 10A.

Gráfico 4.7 - Variação da tensão nos terminais da bateria $V_{2}$ em função do tempo para uma bateria de chumbo-ácido (63Ah) submetida à processos de descarga constante 3.15A. 
Gráfico 4.8 - Variação da tensão nos terminais da bateria em função do tempo para uma bateria de chumbo-ácido submetida ao processo de descarga constante 100A Comparação entre valor calculado pela metodologia descrita na subseção 4.4 e valor medido experimentalmente. 46

Gráfico 4.9 - Variação da tensão nos terminais da bateria em função do tempo para uma bateria de chumbo-ácido submetida ao processo de descarga constante 50A Comparação entre valor calculado pela metodologia descrita na subseção 4.4 e valor medido experimentalmente.

Gráfico 4.10 - Variação da tensão nos terminais da bateria em função do tempo para uma bateria de chumbo-ácido submetida ao processo de descarga constante 10A - Comparação entre valor calculado pela metodologia descrita na subseção 4.4 e valor medido experimentalmente.

Gráfico 4.11 - Variação da tensão nos terminais da bateria em função do tempo para uma bateria de chumbo-ácido submetida ao processo de descarga constante 3,15A - Comparação entre valor calculado pela metodologia descrita na subseção 4.4 e valor medido experimentalmente. 47

Gráfico 4.12 - Variação do parâmetro $A_{0}$ em função da corrente de descarga $\mathrm{i}_{2}$ com curva de aproximação cúbica

Gráfico 4.13 - Variação do parâmetro $R_{10}$ em função da corrente de descarga $\mathrm{i}_{2}$ com curva de aproximação cúbica. 49

Gráfico 4.14 - Variação do parâmetro $\tau_{1}$ em função da corrente de descarga i $\mathrm{i}_{2}$ com curva de aproximação linear. .50

Gráfico 4.15 - Variação do parâmetro $k$ em função da corrente de descarga $i_{2}$ com curva de aproximação linear. .50 
Gráfico 4.16 - Variação do parâmetro $R_{00}$ em função da corrente de descarga $i_{2}$ com curva de aproximação cúbica..

Gráfico 4.17 - Comparativo entre curvas de descarga experimentais de 10A e 50A e curvas de descarga calculadas de 15A, 20A e 30A. .53

Gráfico 4.18 - Comparativo entre curvas de descarga experimentais de 50A e 100A e curvas de descarga calculadas de $60 \mathrm{~A}$ e $70 \mathrm{~A}$ .53 


\section{LISTA DE TABELAS}

Tabela 1.1 - Exemplo de requisitos do Teste de Partida a Frio ...............................

Tabela 1.2 - Exemplo de requisitos para Rotação de Partida .................................3

Tabela 4.1 - Especificação da bateria usada na obtenção das curvas de descarga 41

Tabela 4.2 - Detalhes sobre as curvas de descarga obtidas experimentalmente.....44

Tabela 4.3 - Resultados da Equação da Bateria .........................................45 


\section{LISTA DE ABREVIATURAS E SIGLAS}

Association des Constructeurs Européens de l'Automobile - Associação dos Fabricantes Europeus de Automóveis Absorbed Glass Mat - Placa de Vibro Absorvente Normas Automotivas

NMMA National Marine Manufacturers Association - Associação Nacional dos Fabricantes Navais

OCV Open Circuit Voltage - Tensão de Circuito Aberto

$O D E$ Ordinary Differential Equation - Equação Diferencial Ordinária

$R C$ 


\section{SUMÁRIO}

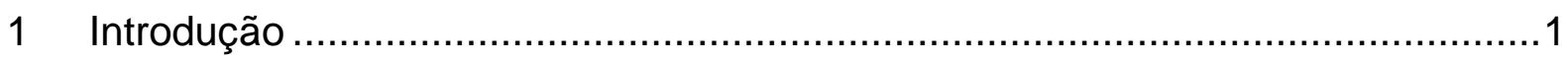

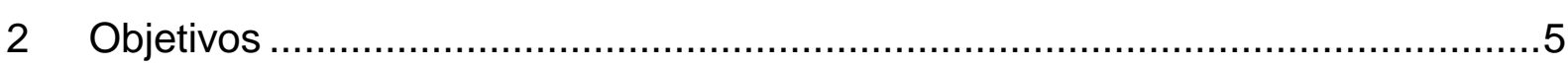

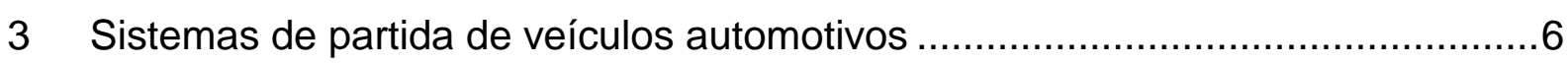

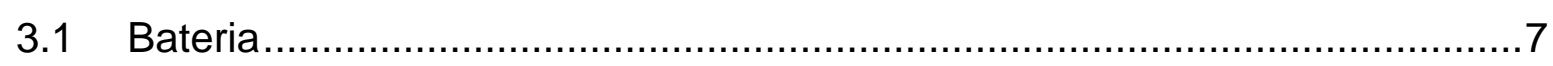

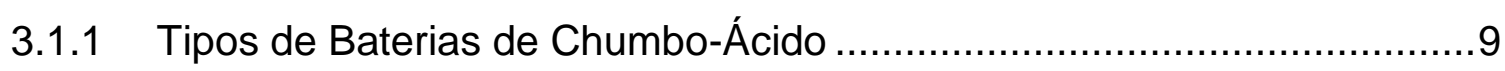

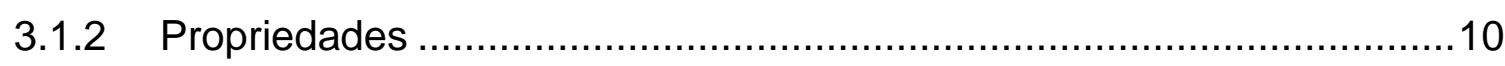

3.1.2.1 Capacidade Nominal ............................................................. 10

3.1.2.2 Corrente de Partida à Frio ...........................................................11

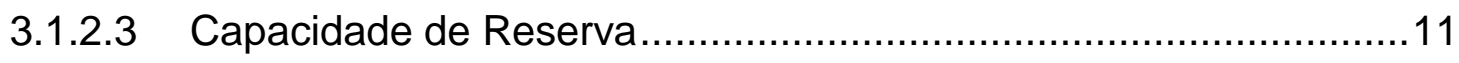

3.1.2.4 Tensão Nominal ................................................................11

3.1.2.5 Tensão de Circuito Aberto......................................................12

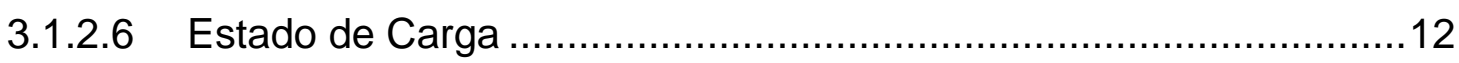

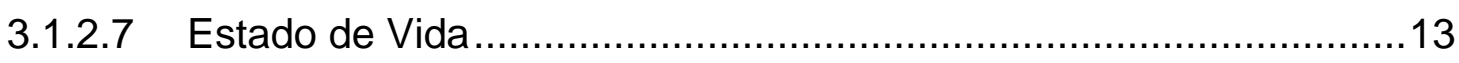

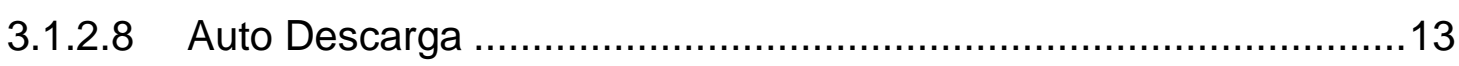

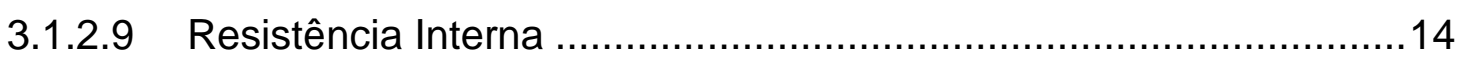

3.1.2.10 Profundidade de Descarga ........................................................14

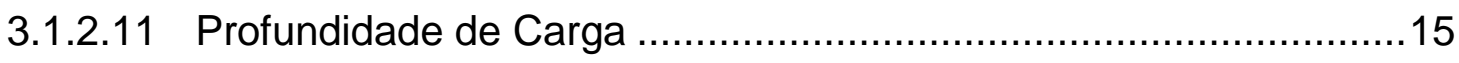

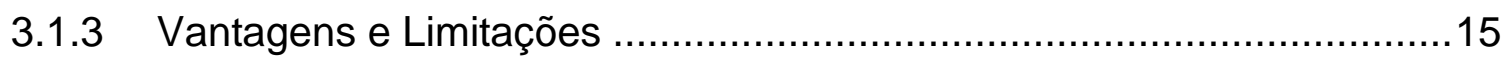

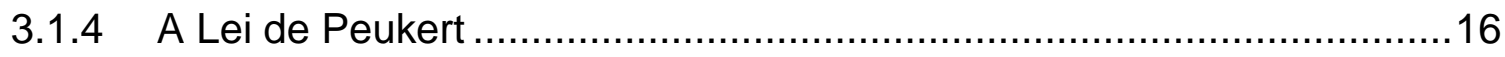

4 Modelo matemático da bateria ...................................................................

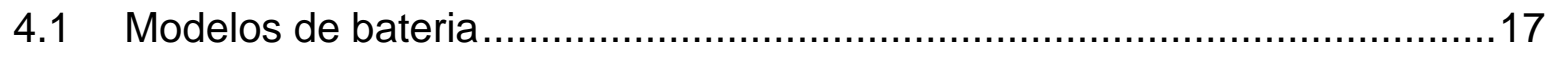

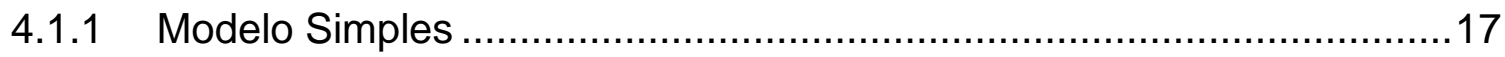

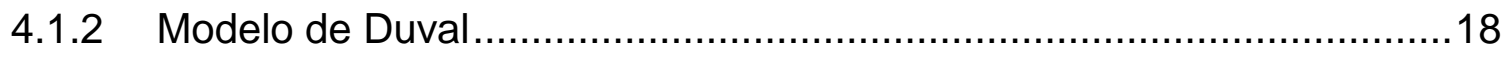

4.1.3 Modelo de Schintag, Reimann e Krüger .............................................19

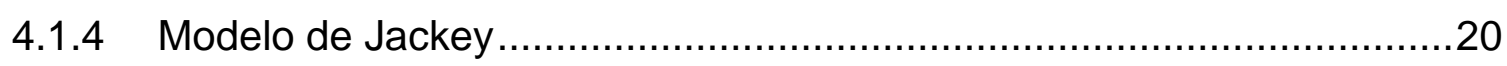




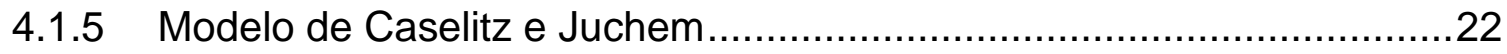

4.1.6 Modelo de Esfahanian, Torabi e Mosahebi ........................................23

4.2 Modelo de bateria escolhido para o trabalho - Modelo de Jackey ...............24

4.3 Definição dos parâmetros desconhecidos .................................................28

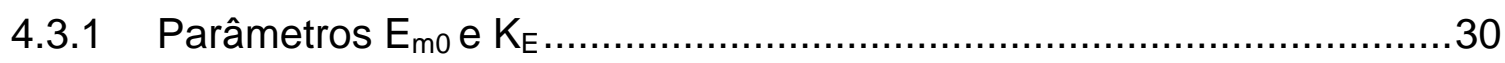

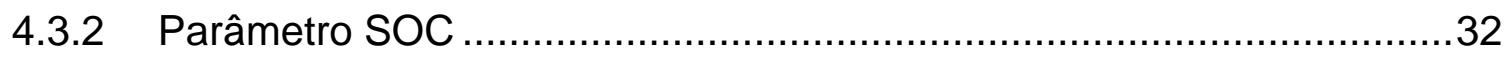

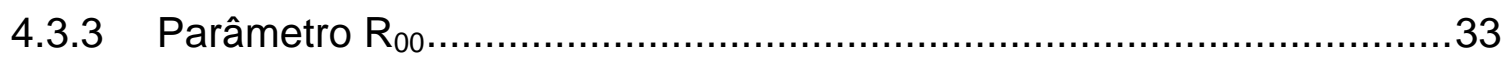

4.4 Metodologia para a resolução da equação da bateria ................................34

4.4.1 Descrição do método de otimização ……………………………........38

4.4.2 Curvas de Descarga Experimentais ……............................................41

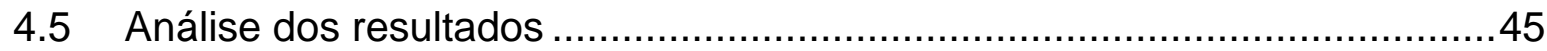

4.5.1 Variação dos parâmetros do modelo da bateria em função da corrente

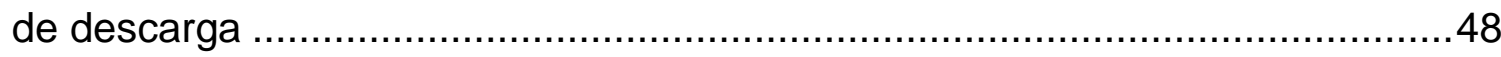

4.5.2 Exemplo de utilização do modelo da bateria .......................................51

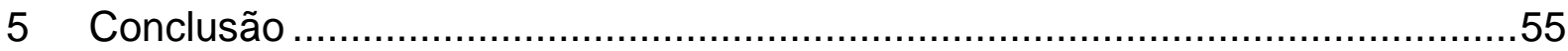

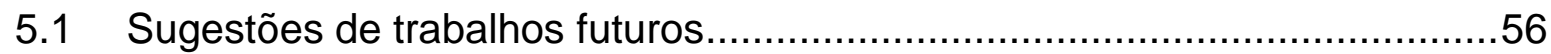

APÊNDICE A - ANÁLISE DAS PRINCIPAIS CARACTERÍSTICAS DOS DO MOTOR

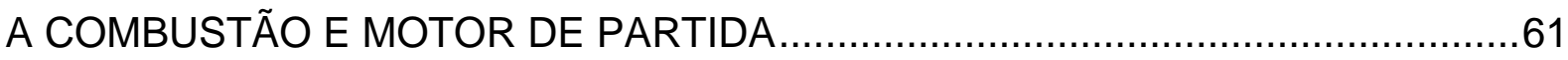

APÊNDICE B - DESENVOLVIMENTO DA EQUAÇÃO DA BATERIA …...................74

APÊNDICE C - ALGORITMO PARA CÁLCULO DA EQUAÇÃO DA BATERIA .......75 


\section{Introdução}

O desenvolvimento de um veículo envolve diversas etapas. Dentre elas estão os testes de validação para comprovar que o novo projeto atende à legislação de trânsito dos países nos quais será vendido e aos requisitos internos definidos pela montadora para garantir a qualidade desejada.

Esses testes de validação são classificados nas áreas de elétrica, durabilidade, segurança, motores (e itens relacionados como transmissão e módulo de controle do motor), ruído e vibração, ar condicionado e sistema de arrefecimento (e itens relacionados como sensores de temperatura). Eles podem ser executados em cada uma das peças do veículo individualmente ou nos veículos protótipos através de simulação, através de experimentos práticos ou de ambas as formas, com o objetivo de confirmar os resultados simulados e o cumprimento com os requisitos específicos determinados previamente para cada componente.

Um dos principais ensaios, classificado na área Elétrica, é o teste de validação do sistema de partida, composto por bateria, motor de partida e cabo de ligação. Esse teste, conhecido por Cold Crank, é realizado através de um experimento prático em veículos protótipos. Por isso ocorre numa fase já bem avançada do projeto, na qual o protótipo é bastante representativo do veículo que entrará em produção, que muitas vezes dificulta e limita as ações corretivas quando são necessárias.

O nome Cold Crank está sendo escrito em inglês por não possuir uma tradução exata que mantenha seu significado original. Comumente, é chamado de Teste de Partida a Frio. Porém existe uma sutil diferença entre o Teste de Cold Crank e o Teste de Cold Start (Teste de Partida a Frio), explicada a seguir.

O Teste de Partida a Frio tem por finalidade averiguar se o veículo tem condições de funcionar em temperaturas baixas (que variam entre $-10^{\circ} \mathrm{C}$ e $-30^{\circ} \mathrm{C}$ ), consideradas como condição crítica para que um motor a combustão inicie seu funcionamento. As 
seguintes características podem interferir em seu resultado (Zhong; Henein; Bryzik, 2007):

- Propriedades do combustível;

- Temperatura e pressão do ar de admissão do motor;

- Relação de compressão do combustível;

- Vazamento ou blow-by;

- Rotação de partida;

- Quantidade de injeção de combustível;

- Projeto da câmara de combustão.

Esse teste verifica se o veículo entrou em funcionamento dentro do tempo máximo pré-estabelecido para cada faixa de temperatura. A tabela 1.1 apresenta um exemplo de requisitos para o Teste de Partida a Frio para um motor movido a gasolina de acordo com a variação de temperatura do óleo lubrificante do motor.

Tabela 1.1 - Exemplo de requisitos do Teste de Partida a Frio

\begin{tabular}{cc}
\hline $\begin{array}{c}\text { Temperatura do óleo } \\
\text { lubrificante do motor }\end{array}$ & $\begin{array}{c}\text { Tempo máximo } \\
\text { para a partida }\end{array}$ \\
\hline$-30^{\circ} \mathrm{C}$ a $-25^{\circ} \mathrm{C}$ & $\leq 30$ segundos \\
$-25^{\circ} \mathrm{C} \mathrm{a}-20^{\circ} \mathrm{C}$ & $\leq 20$ segundos \\
$-20^{\circ} \mathrm{C} \mathrm{a}-10^{\circ} \mathrm{C}$ & $\leq 5$ segundos \\
$-10^{\circ} \mathrm{C} \mathrm{a}+10^{\circ} \mathrm{C}$ & $\leq 3$ segundos \\
$+10^{\circ} \mathrm{C} \mathrm{a}+60^{\circ} \mathrm{C}$ & $\leq 1,5$ segundos \\
\hline
\end{tabular}

Para que o tempo máximo de partida seja atingido, é necessário controlar cada um dos fatores, que interferem no resultado e que foram descritos anteriormente, para que atendam isoladamente aos critérios pré-estabelecidos. A rotação de partida recebe um destaque especial dentre esses fatores. Ela depende da temperatura ambiente, do sistema de partida especificado e das características do motor a combustão. Para minimizar seu efeito negativo no tempo máximo de partida, uma determinada rotação mínima deve ser garantida após um tempo pré-estabelecido. A tabela 1.2 (extraído de GENERAL MOTORS, 1998) apresenta um exemplo de requisitos para a rotação de partida para um motor movido a gasolina, válido para $20^{\circ} \mathrm{C}$ de temperatura do óleo lubrificante. 
Tabela 1.2 - Exemplo de requisitos para Rotação de Partida

(extraído de GENERAL MOTORS, 1998)

\begin{tabular}{cc}
\hline $\begin{array}{c}\text { Tempo após virar a chave } \\
\text { para dar partida }\end{array}$ & Rotação Mínima \\
\hline Após 5 segundos & $\geq 100 \mathrm{rpm}$ \\
Após 25 segundos & $\geq 80 \mathrm{rpm}$ \\
\hline
\end{tabular}

O Teste de Cold Crank é realizado para averiguar se a rotação mínima de partida está sendo atingida após o tempo pré-estabelecido, o que contribuirá para que a partida a frio do veículo seja satisfatória.

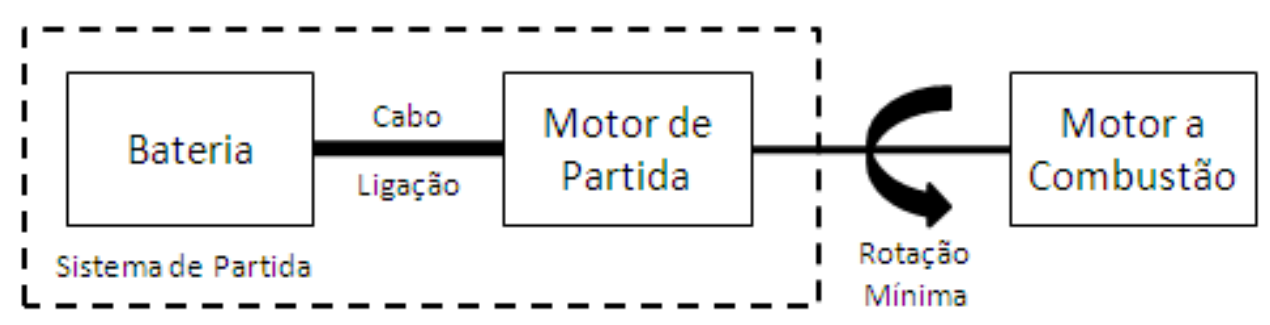

Figura 1.1 - Esquema simplificado do sistema de partida de um veículo.

Antes do início do teste, alguns preparativos devem ser realizados (GENERAL MOTORS, 1998):

- O tanque de combustível e a linha de alimentação devem ser esvaziados para evitar que o motor a combustão comece a funcionar (a finalidade do teste é medir a rotação do motor a combustão após ser acelerado pelo motor de partida).

- O motor a combustão precisa ter funcionado por uma distância mínima. Em linguagem coloquial diz-se que o motor precisa estar amaciado. Exemplo: tipicamente deseja-se que o motor tenha funcionado por no mínimo $2000 \mathrm{~km}$.

- O óleo lubrificante usado deve ser adequado para a temperatura de teste. Exemplo: $10 \mathrm{~W} 40$ para teste a $-20^{\circ} \mathrm{C} / 5 \mathrm{~W} 30$ para teste a $-30^{\circ} \mathrm{C} /$ entre outros.

- Instrumentos devem ser instalados para monitorar a temperatura do óleo lubrificante, a rotação do motor a combustão e a tensão da bateria durante a execução do teste. 
Além disso, a temperatura ambiente para a execução do teste deve ser escolhida como a temperatura mais baixa considerada para o projeto, pois essa é a condição mais desfavorável para o motor a combustão, já que a viscosidade do óleo lubrificante aumenta contribuindo para o aumento do torque resistente inicial do motor a combustão. Para a execução do teste, a temperatura desejada é atingida colocando-se o veículo numa câmara fria.

A temperatura ambiente dependerá dos mercados nos quais o veículo será vendido. Para o mercado brasileiro, considerar como a mais baixa temperatura ambiente $-10^{\circ} \mathrm{C}$ é bastante razoável tendo em vista nossas condições climáticas históricas. Já para o mercado russo, o mais adequado é considerar como a mais baixa temperatura ambiente $-30^{\circ} \mathrm{C}$.

Conforme exemplificado anteriormente na Tabela 1.2 (extraído de GENERAL MOTORS, 1998), o critério de avaliação principal do teste é verificar se a rotação mínima foi atingida após o tempo pré-estabelecido. O segundo critério é verificar se durante todo o teste a tensão da bateria esteve acima do valor mínimo préestabelecido. Se ambos os critérios são atendidos, considera-se que o sistema de partida especificado para o veículo é suficiente uma vez que a rotação mínima de partida está sendo atendida (GENERAL MOTORS, 1998). 


\section{Objetivos}

A motivação desse trabalho foi propor um método de simulação para o Teste de Cold Crank. Como se trata de uma simulação multidisciplinar, que envolve vasto conhecimento em motores a combustão, motores elétricos e na execução do teste de Cold Crank, essa proposta foi dividida nas seguintes partes:

1. Estudo do modelo da bateria;

2. Estudo do modelo do motor de partida;

3. Estudo do modelo do motor a combustão;

4. União dos modelos de forma a representar a dinâmica de funcionamento do sistema de partida juntamente com a carga, que é o motor a combustão;

5. Validação do modelo através da comparação com resultados obtidos de experimentos práticos.

O objetivo desse trabalho foi a realização da parte 1 , que consistiu na investigação do modelo matemático mais adequado para a bateria. Nesse estudo, usaram-se modelos já propostos por outros autores, adequados para a condição de Cold Crank, e curvas de descarga, realizadas num modelo de bateria popularmente comercializado, para a identificação dos parâmetros desconhecidos do modelo.

As demais partes citadas não foram estudadas nesse trabalho e são sugeridas na subseção 5.1 como sugestões para trabalhos futuros. 


\section{Sistemas de partida de veículos automotivos}

A figura 3.1 (extraído de $\mathrm{BOSCH}, 1988$ ) ilustra os componentes do sistema de partida, importantes para a proposta de método de simulação do Cold Crank.

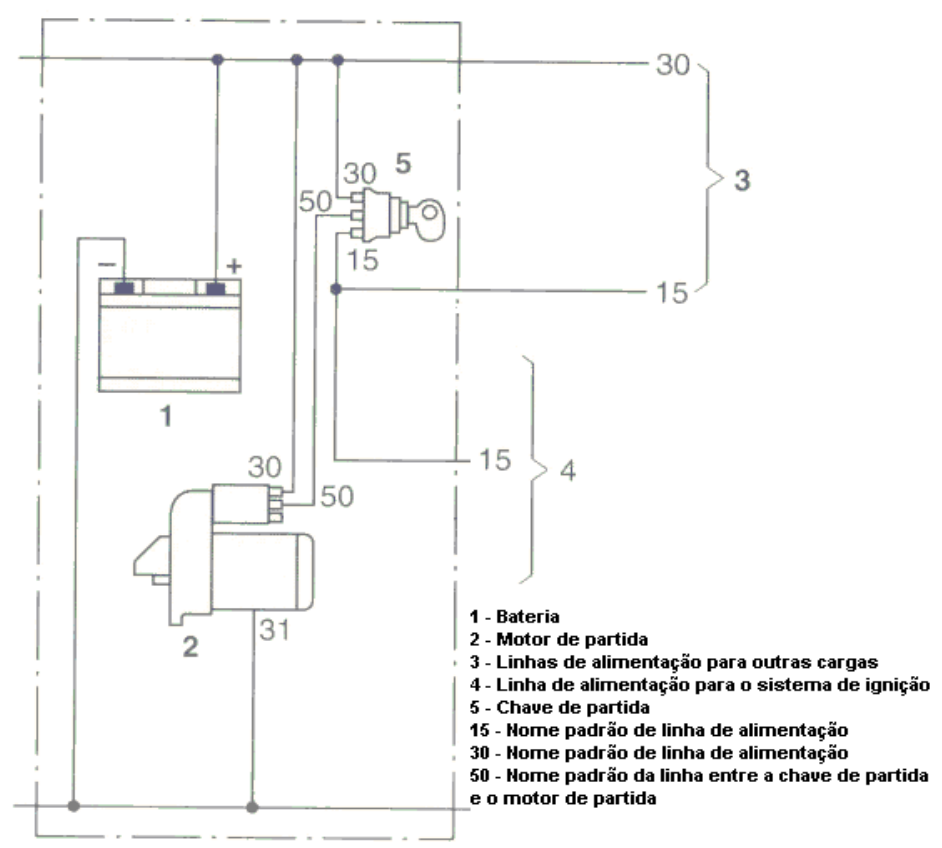

Figura 3.1 - Diagrama do sistema de partida de um veículo automotivo com motor de combustão interna (extraído de BOSCH, 1988).

A ênfase é dada aos componentes descritos a seguir uma vez que são os principais responsáveis pela partida do veículo:

- Bateria de chumbo-ácido de $12 \mathrm{~V}$;

- Motor de partida elétrico CC série com fuso de avanço e alavanca de comando.

O motor a combustão interna é a carga do sistema de partida. Os principais tipos são: motor de ignição por centelha ou motor diesel.

A subseção 3.1 apresenta as principais características da bateria. O apêndice A apresenta detalhes sobre as principais características do motor de partida e do motor a combustão. 


\subsection{Bateria}

A bateria de chumbo-ácido foi inventada em 1859 por Raymond Gaston Planté usando condutores de chumbo (anodo) e dióxido de chumbo (catodo), separados por um material isolante (madeira ou borracha porosa) e mergulhados numa solução de ácido sulfúrico (MARTINS, 1999). Seu uso em veículos automotivos que utilizam motores a combustão iniciou-se por volta de 1900 para permitir a ignição elétrica dos veículos (JOHNSTON, 1996).

Sua finalidade é transformar energia química em energia elétrica e vice-versa. Ou seja, o processo de transformação é reversível fazendo com que a bateria possa ser carregada e descarregada por centenas de vezes $(\mathrm{BOSCH}, 2007)$.

O termo descarga, que será usado diversas vezes nesse trabalho, representa a condição na qual a bateria fornece energia elétrica. Nessa situação, a bateria fornece energia elétrica para algum receptor, como uma lâmpada por exemplo. $O$ termo carga representa a condição na qual a bateria recebe energia elétrica e a armazena em forma de energia química. Nessa situação, é a bateria que funciona como um receptor. As equações (1), (2) e (3) apresentam as equações químicas que representam os processos de carga e descarga da bateria (Bocchi; Ferracin; Biaggio, 2000)

$$
\begin{aligned}
& \text { Reação no Catodo: } \mathrm{PbO}_{2}+4 \mathrm{H}^{+}+\mathrm{SO}_{4}^{2-}+2 e^{-} \underset{\text { carga }}{\stackrel{\text { descarga }}{\rightleftarrows}} \mathrm{PbSO}_{4}+2 \mathrm{H}_{2} \mathrm{O} \\
& \text { Reação no Anodo: } \mathrm{Pb}+\mathrm{SO}_{4}^{2-} \underset{\text { carga }}{\stackrel{\text { descarga }}{\rightleftarrows}} \mathrm{PbSO}_{4}+2 e^{-} \\
& \text {Reação Global: } \mathrm{Pb}+\mathrm{PbO}_{2}+2 \mathrm{H}_{2} \mathrm{SO}_{4} \underset{\text { carga }}{\stackrel{\text { descarga }}{\longrightarrow}} 2 \mathrm{PbSO}_{4}+2 \mathrm{H}_{2} \mathrm{O}
\end{aligned}
$$

Esse tipo de bateria é composto dos seguintes elementos ilustrados na figura 3.2 (extraído de Bocchi; Ferracin; Biaggio, 2000):

- Eletrodo Positivo: formado por grades revestidas com pasta de dióxido de chumbo; 
- Eletrodo Negativo: formado por grades revestidas com pasta de chumbo puro esponjoso;

- Separadores: material isolante que separa os eletrodos positivos dos eletrodos negativos;

- Solução eletrolítica: solução de ácido sulfúrico que permite a reação química entre os eletrodos;

- Caixa de polipropileno: acomoda os eletrodos e a solução eletrolítica;

- Pólos: feito de chumbo fundido ou forjado, eles fazem o contato final entre a bateria e a carga a ser alimentada.

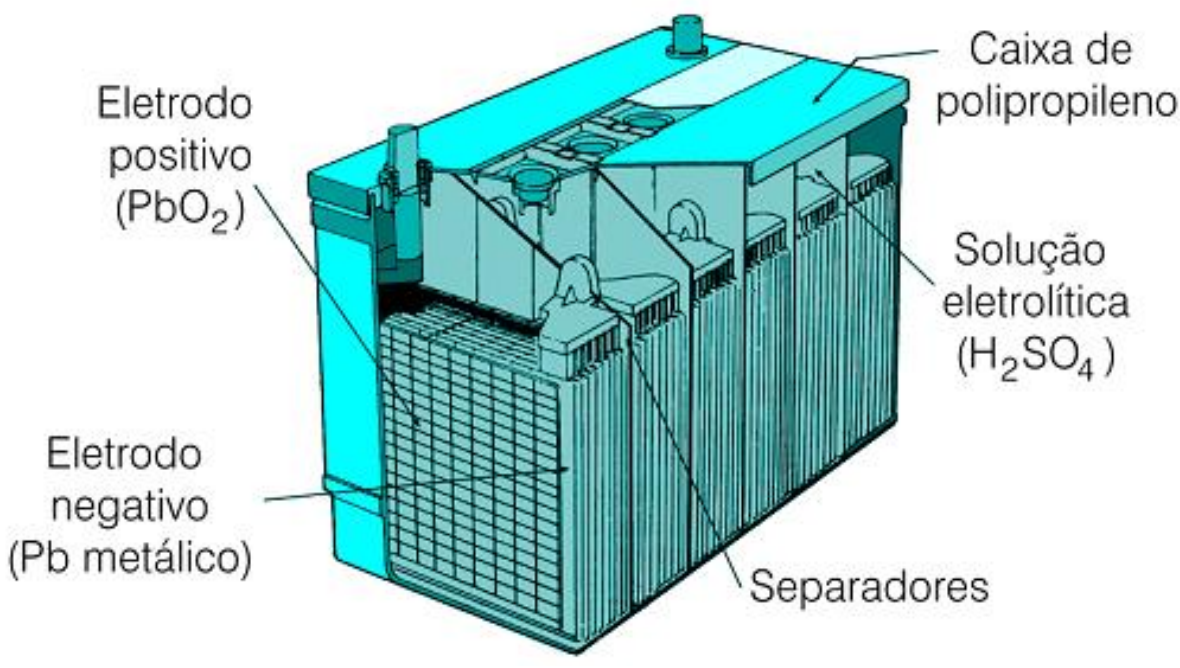

Figura 3.2 - Elementos de uma bateria de chumbo-ácido (extraído de BOCCHI; Ferracin; Biaggio, 2000).

As grades que formam os eletrodos podem ser feitas de liga de chumbo-antimônio ( $\mathrm{PbSb}$ ), liga de chumbo-cálcio ( $\mathrm{PbCa}$ ) ou liga de chumbo-cálcio-prata (PbCaAg) e devem atender aos seguintes requisitos (KIEHNE, 2000):

- Estabilidade mecânica: depende do método de fabricação - grade fundida ou grade expandida (mais durável e com maior desempenho);

- Resistência à corrosão: quando a grade for usada no eletrodo positivo;

- Capacidade de armazenamento de energia: depende da quantidade de pasta de chumbo adicionada às grades. 

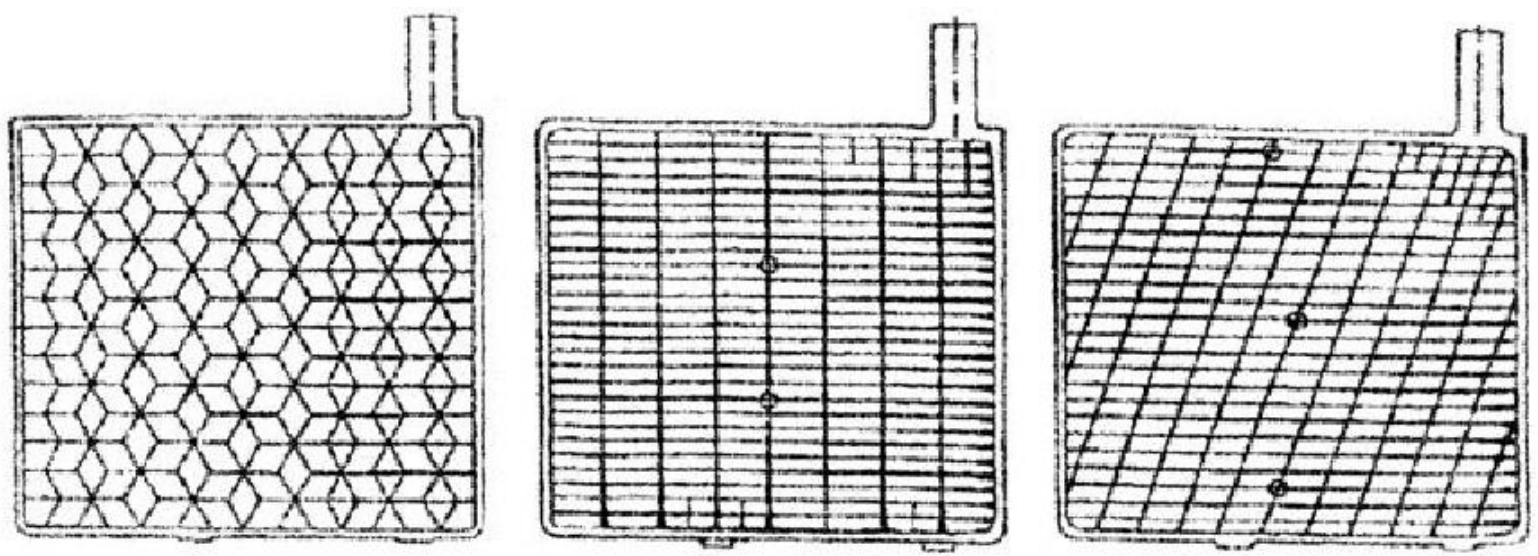

Figura 3.3- Diferentes estruturas de grades que formam os eletrodos de uma bateria de chumbo-ácido (extraído de KIEHNE, 2000).

\subsubsection{Tipos de Baterias de Chumbo-Ácido}

Existem dois tipos principais de baterias de chumbo-ácido: FLA - Flooded Lead Acid Batteries (Baterias de Chumbo-Ácido Inundado) e VRLA - Valve Regulated Lead Acid Batteries (Baterias de Chumbo-Ácido de Válvula Regulada) (KIEHNE, 2000).

Na bateria FLA os eletrodos ficam imersos no eletrólito (que é uma solução líquida).

A bateria VRLA é considerada de baixa manutenção uma vez que não é necessário adicionar água em suas células, possui válvula de segurança para alívio de pressão, usa quantidade menor de ácido do que a bateria convencional e possui maior capacidade. As baterias VRLA são ainda classificadas em AGM - Absorbed Glass Mat (Placa de Vibro Absorvente) e SLA - Sealed Lead Acid Batteries (Baterias Seladas de Chumbo-Ácido). O eletrólito da bateria AGM está absorvido em placas finas de fibra de vidro enquanto que na bateria SLA ele está em forma de gel. Ambos os modelos são bastante resistentes a temperaturas altas e não vazam. $\mathrm{A}$ grade da bateria AGM é feita de chumbo apenas enquanto que a bateria SLA usa liga de chumbo-antimônio (LINDEN, 2002). 


\subsubsection{Propriedades}

As propriedades das baterias de chumbo-ácido foram padronizadas pela norma IEC95-1:1988 (KIEHNE, 2000). As principais propriedades são:

\subsubsection{Capacidade Nominal}

É a carga elétrica que a bateria consegue fornecer em determinadas condições. Esse valor é medido em ampère-hora [Ah] e depende dos seguintes fatores (BOSCH, 2007).

- Quantidade de material ativo usado na bateria (quantidade de pasta de chumbo usada nas placas);

- Nível de corrente de descarga e processo de descarga em função do tempo;

- Densidade, temperatura e nível de estratificação do eletrólito;

- Idade da bateria.

A capacidade nominal pode ser medida seguindo padrões específicos conhecido como C-rate. Os mais comuns são C20 e C5:

- C20: capacidade de fornecer corrente durante 20 horas em temperatura ambiente sem que o valor da tensão entre os pólos seja inferior a 10,5V. Exemplo: se uma bateria tem capacidade de fornecer corrente de $2 \mathrm{~A}$ por hora, o C20 dessa bateria é $20 \mathrm{~h} \times 2 \mathrm{~A}=40 \mathrm{Ah}$.

- C5: capacidade de fornecer corrente durante 5 horas em temperatura ambiente sem que o valor da tensão entre os pólos seja inferior a 10,5V. Exemplo: se uma bateria tem capacidade de fornecer corrente de $2 \mathrm{~A}$ por hora, o $\mathrm{C} 5$ dessa bateria é $5 \mathrm{~h} \times 2 \mathrm{~A}=10 \mathrm{Ah}$. 


\subsubsection{Corrente de Partida à Frio}

É a corrente elétrica que pode ser fornecida pela bateria, em temperaturas baixas, durante a partida do veículo. Depende das características descritas abaixo $(\mathrm{BOSCH}$, 2007):

- Número de placas;

- Área geométrica da superfície das placas;

- Espaçamento entre as placas e material do separador, que interferem na velocidade das reações químicas.

Esse parâmetro é conhecido por CCA - Cold Crank Ampère (Corrente de Partida à Frio) e é medido em ampères [A]. De acordo com a norma IEC95-1:1988, a temperatura de $-18^{\circ} \mathrm{C}$ deve ser usada como referência para sua medição.

\subsubsection{Capacidade de Reserva}

Também conhecido como RC - Reserve Capacity (Capacidade de Reserva), é o tempo (em minutos) durante o qual uma bateria, completamente carregada, pode fornecer corrente elétrica (padronizada em $25 \mathrm{~A}$ em $27^{\circ} \mathrm{C}$ de acordo com a norma IEC95-1:1988) mantendo a tensão em seus terminais superior a 10,5V $(1,75 \mathrm{~V}$ por célula) (BOSCH, 2007).

\subsubsection{Tensão Nominal}

É a tensão teórica da bateria, resultado da multiplicação do número de células pelo valor nominal de tensão de cada célula. As baterias de chumbo-ácido comuns, usadas em veículos automotivos, possuem seis células com um valor nominal de $2 \mathrm{~V}$ por célula. Logo, a tensão nominal da bateria é de $12 \mathrm{~V}(\mathrm{BOSCH}, 2007)$.

Existem também outros padrões de tensão nominal para alguns modelos de baterias de chumbo-ácido tais como (Battery Space): 
- $4 \mathrm{~V}$ e 6V: usadas em brinquedos elétricos, luzes de emergência, carrinhos de golfe, alguns modelos de scooters, entre outros;

- $24 \mathrm{~V}$ e $36 \mathrm{~V}$ : usadas em bicicletas elétricas, alguns modelos de motos, carrinhos de golfe, cortadores de grama, entre outros.

\subsubsection{Tensão de Circuito Aberto}

É a tensão medida nos terminais da bateria quando ela está num circuito aberto, ou seja, não está conectada em nenhum circuito. Esse valor é conhecido como OCV Open Circuit Voltage (Tensão de Circuito Aberto) e é função da temperatura e da concentração do eletrólito. Para medi-la corretamente, é preciso deixar a bateria em repouso para que o OCV atinja um valor estável ou executar um procedimento de descarga rápida para eliminar o valor da tensão superficial, gerada após um processo de carga ou descarga por conta das perdas resistivas e da polarização das placas (BOSCH, 2007; LINDEN, 2002).

\subsubsection{Estado de Carga}

O estado de carga da bateria indica o percentual de energia acumulada (carga) que a bateria possui. Popularmente conhecido como SOC - State of Charge (Estado de Carga), é medido através da gravidade específica do eletrólito e também pode ser estimado através da tensão de circuito aberto OCV, medida nos pólos da bateria (BOSCH, 2007).

Tabela 3.1 - Exemplo da relação entre OCV e SOC (extraído de CADEX, 2003)

\begin{tabular}{cc}
\hline Tensão de Circuito Aberto (OCV) & Estado de Carga (SOC) \\
\hline $12,65 \mathrm{~V}$ & $100 \%$ \\
$12,45 \mathrm{~V}$ & $75 \%$ \\
$12,24 \mathrm{~V}$ & $50 \%$ \\
$12,06 \mathrm{~V}$ & $25 \%$ \\
$11,89 \mathrm{~V}$ ou menor & Descarregada \\
\hline
\end{tabular}




\subsubsection{Estado de Vida}

Também conhecido como SOH - State of Health (Estado de Vida), é a medição percentual da condição da bateria comparada com condições ideais. Esse valor é $100 \%$ quando a bateria está nova e diminui de acordo com seu uso pois a cada ciclo de carga ou descarga uma pequena quantidade de massa ativa se desprende das placas reduzindo a capacidade da bateria. Como não representa uma medição física, não existe ainda um consenso sobre sua determinação. Mas de forma geral, é possível relacioná-lo com as seguintes variáveis (BOSCH, 2007; LINDEN, 2002):

- Resistência, capacitância e impedância internas;

- Capacidade;

- Auto descarga;

- Habilidade para aceitar carga;

- Número de ciclos de carga / descarga;

- Tipo de separador utilizado;

- Densidade da pasta de revestimento das grades;

- Profundidade de descarga.

\subsubsection{Auto Descarga}

Mesmo que nenhum receptor esteja ligado à bateria, as reações químicas continuam ocorrendo. Por isso, a bateria perde energia com o passar do tempo. A auto descarga é provocada por impurezas metálicas usadas para endurecer as grades de chumbo. Seu valor é dado em percentual de carga perdida num período de 30 dias e aumenta à medida que os seguintes fatores aumentam $(\mathrm{BOSCH}, 2007$; CADEX, 2003).

- Temperatura;

- Idade da bateria;

- Umidade;

- Quantidade de impurezas metálicas (tecnologia de fabricação das grades). 


\subsubsection{Resistência Interna}

É a resistência ôhmica da bateria e determina a quantidade de energia que pode ser entregue num determinado intervalo de tempo. Varia em função da temperatura: quanto maior é a temperatura, menor é a resistência interna da bateria e vice-versa (CADEX, 2003). Varia também em função do projeto das grades, da porosidade, espessura e tipo de separador e do método de conexão entre as células (LINDEN, 2002).

É medida em ohms e costuma ser baixo (da ordem de dezenas de mili-ohms) para baterias de chumbo-ácido, conforme ilustra gráfico 3.1. Porém aumenta por causa da corrosão e sulfatação das grades. Essa grandeza também é refletida pela constante de Peukert, que será discutida na subseção 3.1.4 (LINDEN, 2002).

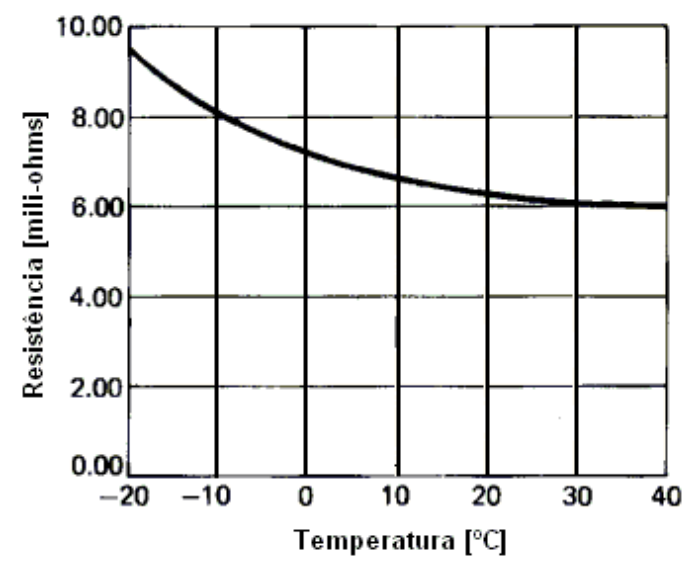

Gráfico 3.1 - Variação da resistência interna de um modelo de bateria de chumbo-ácido em função da temperatura de operação (extraído de LINDEN, 2002).

\subsubsection{Profundidade de Descarga}

Representa o percentual da capacidade nominal da bateria que foi perdida durante um processo de descarga. É conhecido como DOD - Depth of Discharge (Profundidade de Descarga) e possui relação direta com o tempo de vida da bateria (CADEX, 2003). 
O tempo de vida é estimado de acordo com a quantidade de ciclos de carga / descarga. De acordo com a profundidade de descarga, temperatura de operação e capacidade nominal da bateria, essa quantidade pode variar entre 150 (descarga completa) e 8000 (descarga parcial) ciclos, conforme padrão SAE J240 (CADEX, 2003).

\subsubsection{Profundidade de Carga}

Representa o percentual de energia acumulada (carga) que a bateria possui para um dado valor de corrente de descarga. É conhecido como DOC - Depth of Charge (Profundidade de Carga) (Guo, 2010).

\subsubsection{Vantagens e Limitações}

A bateria de chumbo-ácido é barata e de simples fabricação, está disponível em diferentes tamanhos, sua manutenção é simples porque possui tecnologia conhecida e confiável e seus componentes podem ser reciclados. Também possui capacidade para alta taxa de descarga, característica útil durante a partida do veículo, e o valor de auto descarga é o menor dentre os tipos de bateria recarregáveis conhecidas (CADEX, 2003; LINDEN, 2002).

A bateria de chumbo-ácido não pode ser estocada na condição descarregada e nem deve ser descarregada completamente durante seu funcionamento, pois cada ciclo de descarga completa faz com que a bateria de chumbo ácido perca parte de sua capacidade. Possui restrições de transporte, uma vez que é considerada carga perigosa por possuir chumbo. Sua temperatura ideal de operação é ${ }^{2} 5^{\circ} \mathrm{C}$ pois a cada $8^{\circ} \mathrm{C}$ de aumento na temperatura de operação, a vida útil da bateria é reduzida pela metade (CADEX, 2003). 


\subsubsection{A Lei de Peukert}

Foi apresentada em 1897 pelo cientista alemão W. Peukert e descreve a relação empírica existente entre a taxa de descarga da bateria e sua capacidade, descrita na equação (4) (CADEX, 2003).

$$
t=\frac{C *\left(\frac{C}{R}\right)^{K-1}}{I^{K}}
$$

Em que:

- $\mathrm{t}[\mathrm{h}]=$ tempo da descarga

- $\quad \mathrm{C}[\mathrm{Ah}]=$ capacidade nominal da bateria considerando a taxa de descarga em $R$ horas

- $\mathrm{R}[\mathrm{h}]=$ tempo de descarga da bateria (normalmente usa-se o padrão $\mathrm{C} 20=$ 20h)

- $\quad[A]=$ corrente de descarga

- $\mathrm{K}=$ número de Peukert

O número de Peukert $(\mathrm{K})$ varia exponencialmente e reflete a resistência interna da bateria. Para baterias de chumbo-ácido esse número fica entre 1,1 e 1,3 e aumenta de acordo com a idade da bateria (CADEX, 2003).

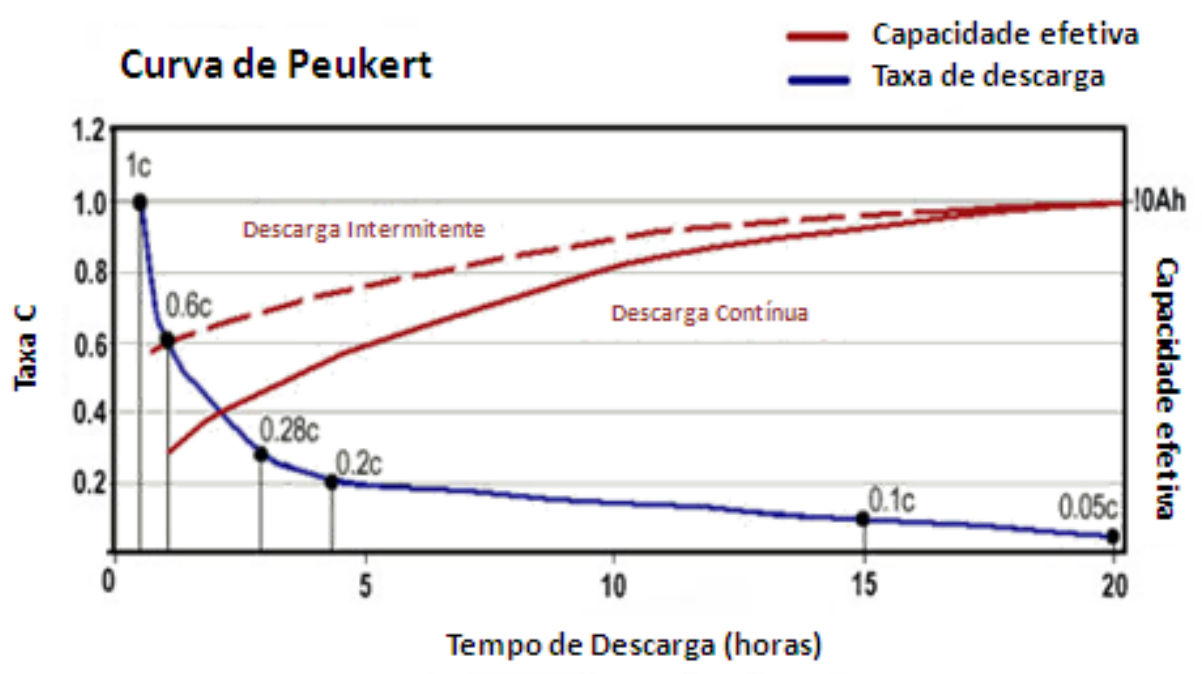

Gráfico 3.2 - Curva de Peukert (extraído de CADEX, 2003). 


\section{Modelo matemático da bateria}

\subsection{Modelos de bateria}

Existem diversos estudos, como o estudo de Duval, o estudo de Schintag, Reimann e Krüger, o estudo de Jackey, o estudo de Caselitz e Juchem, e o estudo de Esfahanian, Torabi e Mosahebi, que apresentam possíveis modelos matemáticos que representam a dinâmica de funcionamento de uma bateria de chumbo-ácido em diversas condições.

Para esse trabalho, o modelo deve representar a dinâmica da bateria na condição de descarga, ou seja, condição na qual a bateria funciona como fonte de energia e converte sua energia química em elétrica. Além disso, o modelo deve ser baseado num circuito elétrico equivalente para que seja de fácil entendimento e manuseio pelos profissionais da área elétrica, tanto engenheiros como técnicos.

Nas subseções 4.1.1 a 4.1.6, os modelos encontrados a partir da leitura de artigos e manuais de baterias são apresentados de forma resumida bem como a escolha do modelo mais adequado para esse trabalho.

\subsubsection{Modelo Simples}

O modelo mais simples para a bateria é composto por uma fonte de alimentação contínua e um resistor, conforme ilustra figura 4.1.

Ele é utilizado em situações nas quais a variação do estado de carga (SOC) não é relevante, uma vez que a impedância interna desse modelo é sempre constante. Isso significa que ele não é capaz de representar com grande fidelidade o processo de descarga no qual o estado de carga (SOC) da bateria varia ao longo do tempo (GUO, 2010). 


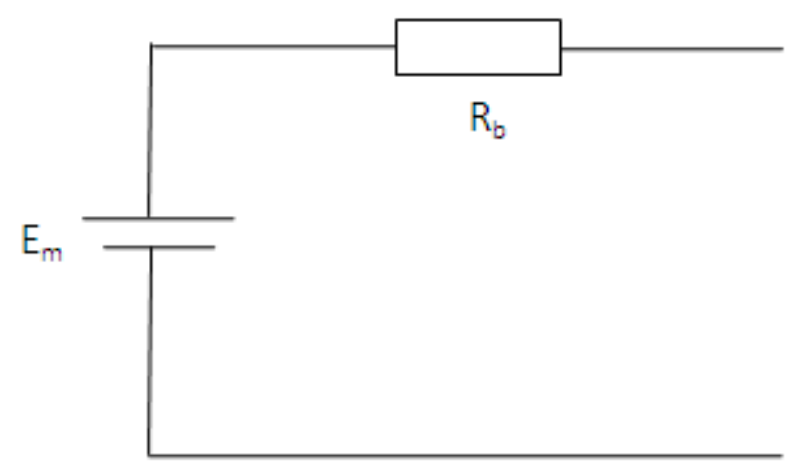

Figura 4.1 - Modelo simples para bateria de chumbo-ácido.

\subsubsection{Modelo de Duval}

Duval (1995) desenvolveu um modelo de bateria do tipo caixa preta para ser usado num software de simulação da arquitetura elétrica do veículo.

Esse modelo baseia-se no comportamento elétrico da bateria, que descreve como varia a tensão nos terminais da bateria, e no comportamento da capacidade da bateria, que descreve como varia seu estado de carga (SOC).

Algumas equações de estado são consideradas para descrever esses comportamentos e dependem dos seguintes fatores: $U$ - tensão nos terminais da bateria, I - corrente de descarga, Q - energia que está sendo entregue à carga, SOC - estado de carga, $T$ - temperatura média do eletrólito, que é considerada uma informação primordial para uma boa estimativa do comportamento da bateria.

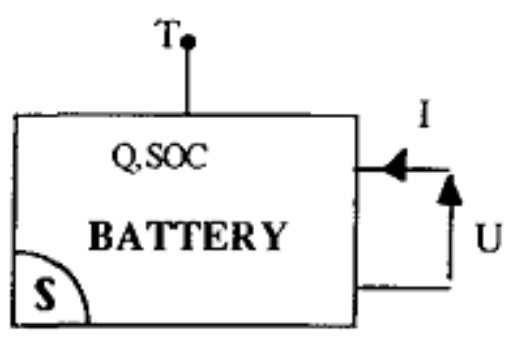

Figura 4.2 - Modelo caixa preta para bateria de chumbo-ácido (extraído de Duval, 1995). 
Segundo Duval (1995), esse modelo apresenta boa predição em estados estacionários sob descarga, ou seja, em situações nas quais é requerida da bateria uma corrente de descarga constante ao longo do tempo.

Sua principal desvantagem é o extenso protocolo experimental que deve ser levantado e utilizado para a identificação dos parâmetros do modelo, que envolve diversos ciclos de carga e descarga da bateria.

\subsubsection{Modelo de Schintag, Reimann e Krüger}

Schintag, Reimann e Krüger (2001) desenvolveram um algoritmo que descreve a tensão de saída nos terminais da bateria em função de sua resistência interna, que é subdividida em resistência base e resistência de carga, ilustradas na figura 4.3 (extraído de Schintag; Reimann; Krüger, 2001), ambas corrigidas pela temperatura. A resistência base é determinada pelos parâmetros da bateria: capacidade nominal (C20), corrente de partida a frio (CCA), temperatura da bateria e estado de carga (SOC). A resistência de carga é determinada pelo histórico de descarga que a bateria possui.

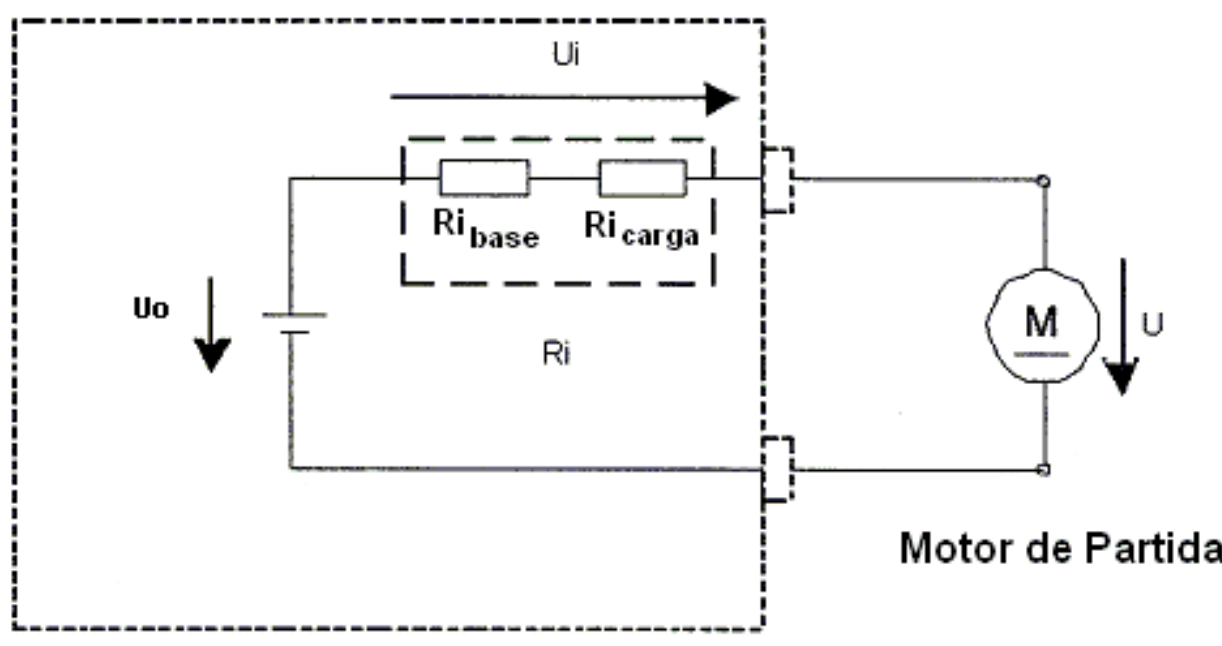

Bateria

Figura 4.3 - Modelo para bateria de chumbo-ácido (extraído de Schintag; Reimann; Krüger, 2001). 
A finalidade desse algoritmo é simular a bateria num teste de partida a frio, conferindo repetibilidade e confiabilidade ao teste.

Segundo Schintag, Reimann e Krüger (2001), esse modelo apresenta bons resultados quando comparados com uma bateria real, uma vez que os erros estão dentro do desvio esperado para esse teste.

Entretanto, o artigo que apresenta esse modelo não mostra todos os detalhes necessários para sua implementação. Detalhes adicionais foram solicitados aos autores. Porém, direitos autorais da empresa à qual os autores estão vinculados impedem a divulgação, o que inviabiliza o uso nesse trabalho.

\subsubsection{Modelo de Jackey}

Jackey (2007) desenvolveu um modelo no Simulink ${ }^{\circledR}$ com o objetivo de ser rápido, simples e efetivo para uso em simulações do sistema elétrico de forma geral.

Esse modelo é dividido em três partes: modelo térmico, que monitora a temperatura do eletrólito, modelo de carga e capacidade, que monitora o estado de carga (SOC) e a profundidade de descarga (DOD) da bateria, e o modelo do circuito da bateria, que simula o circuito equivalente em função da corrente e de outros parâmetros nãolineares. 


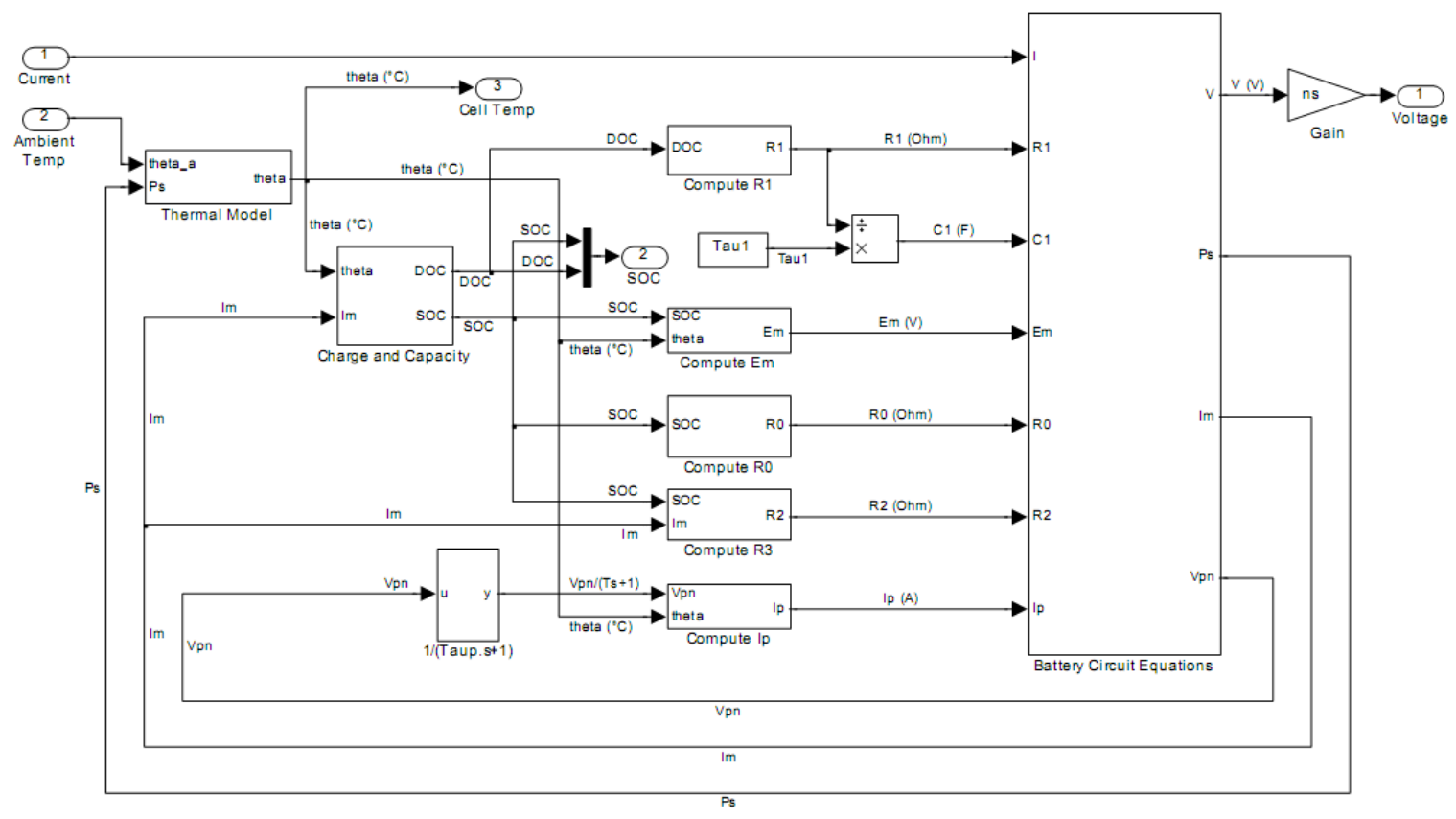

Figura 4.4 - Modelo para bateria de chumbo-ácido implementado no Simulink® (extraído de Jackey, 2007).

O circuito equivalente, do modelo apresentado na figura 4.4 (extraído de Jackey, 2007), é apresentado na figura 4.5 (extraído de Jackey, 2007). Esse circuito é composto pelo "Circuito Principal", que simula a dinâmica da bateria sob a maioria das condições, e pelo "Circuito Parasita", que simula o comportamento da bateria no fim da carga.

Os parâmetros do circuito são obtidos com o auxilio de algoritmos de otimização e curvas de descarga e carga experimentais.

Sua principal vantagem é a excelente precisão, uma vez que a curva de descarga da bateria simulada a partir desse modelo aproxima-se bastante da curva de descarga de uma bateria real (com erro da ordem de 3,2\%). 


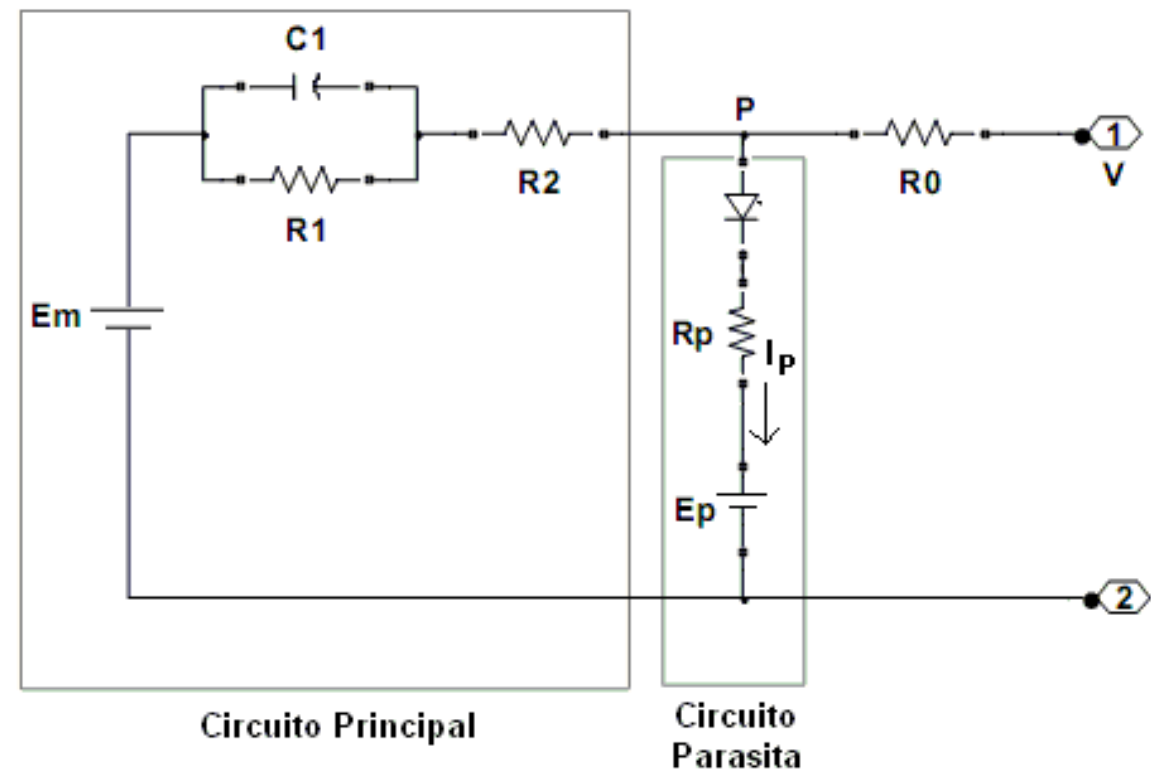

Figura 4.5 - Circuito equivalente do modelo de Jackey (extraído de Jackey, 2007).

\subsubsection{Modelo de Caselitz e Juchem}

Caselitz e Juchem (1998) desenvolveram um software que representa a estrutura física e eletroquímica das baterias a partir dos seguintes dados de entrada: geometria da bateria, quantidade de substâncias nos eletrodos e porosidade dos separadores e eletrodos no estado carregado.

Nesse software, o comportamento dinâmico da bateria pode ser representado pelo processo físico e eletroquímico que acontece no eletrodo de uma única célula, conforme ilustra figura 4.6 (extraído de Caselitz; Juchem, 1998). A descrição matemática desse sistema envolve o estabelecimento de variáveis de estado, como porosidade, potencial do eletrodo e concentração do ácido, que compõem as equações de equilíbrio. As equações de equilíbrio, por sua vez, fazem parte do sistema de equações diferenciais que serão discretizadas e resolvidas dentro do software.

Sua vantagem é a capacidade de representar a bateria, sob todas as condições de funcionamento e numa larga faixa de temperatura, com uma boa proximidade dos resultados experimentais. Entretanto, é um modelo bastante complexo que requer o 
conhecimento de dados químicos da bateria, que não estão disponíveis para a execução desse trabalho.

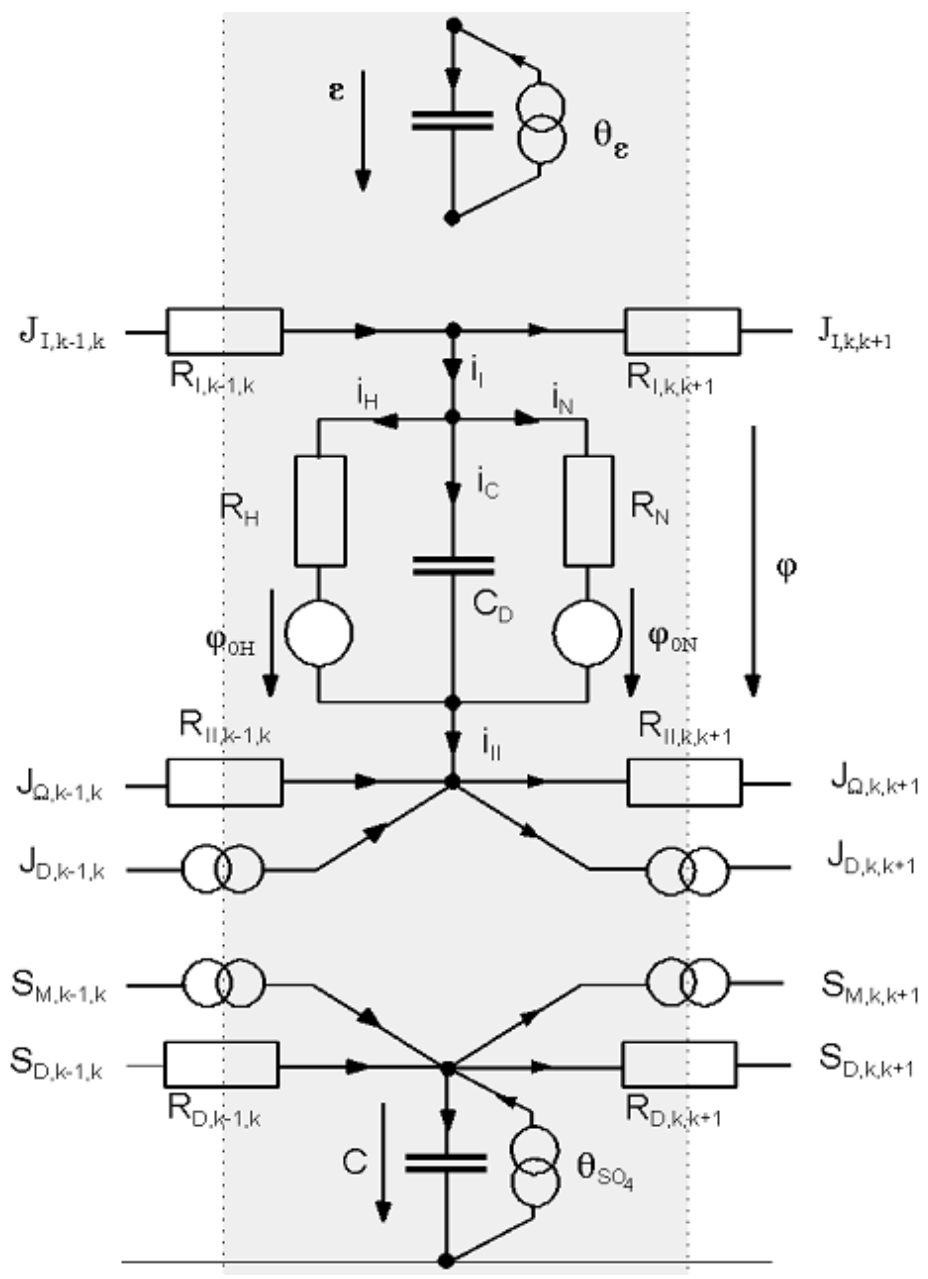

Figura 4.6 - Circuito equivalente de um eletrodo (extraído de Caselitz; Juchem, 1998).

\subsubsection{Modelo de Esfahanian, Torabi e Mosahebi}

Esfahanian, Torabi e Mosahebi (2008) desenvolveram um modelo de bateria baseado em CFD (Computation Fluid Dynamics - Dinâmica Computacional dos Fluidos) e em EMC (Equivalent Circuit Model - Modelo do Circuito Equivalente). $\mathrm{O}$ método EMC é o responsável pela modelagem de cada fenômeno da bateria através do uso de componentes elétricos como resistores e capacitores. Como resultado os parâmetros dinâmicos da bateria são obtidos. O método CFD é responsável pela resolução das equações que representam a dinâmica da bateria usando técnicas numéricas avançadas em função do tempo e espaço. Dessa forma, dados como 
concentração do ácido e distribuição de potencial ao longo da célula podem ser obtidos.

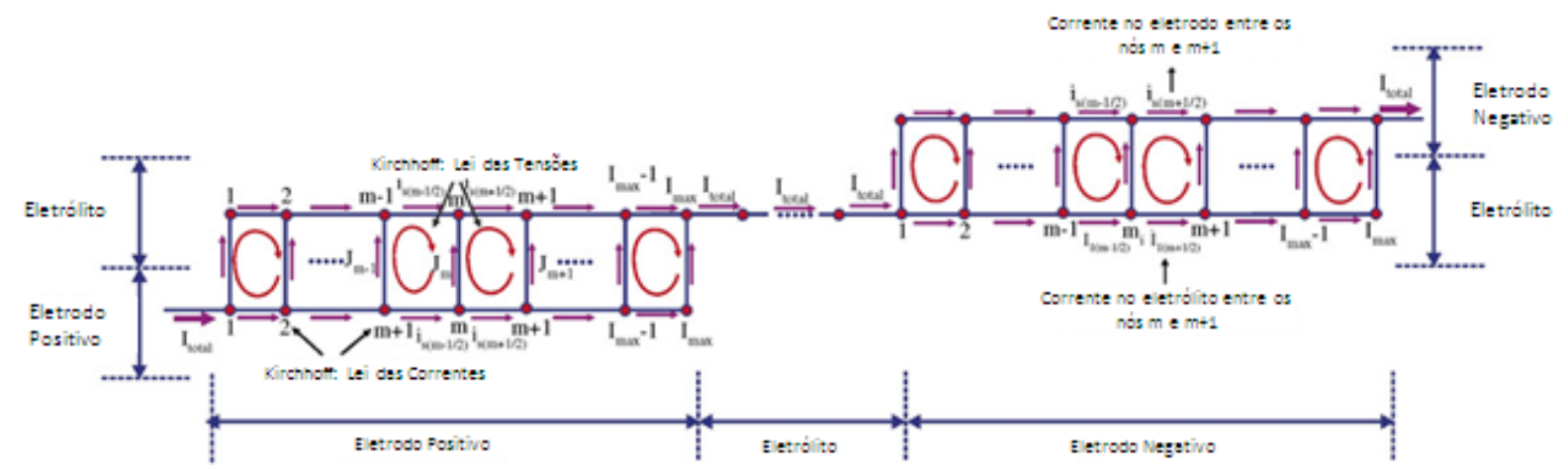

Figura 4.7 - Circuito equivalente de uma célula (extraído de Esfahanian, 2008).

A principal vantagem desse modelo é a rapidez de sua execução permitindo que seja utilizado em simulações em tempo real. Sua desvantagem é uso de equações que consideram as reações químicas e eletroquímicas que ocorrem na bateria, cujos dados não estão disponíveis para a execução desse trabalho.

\subsection{Modelo de bateria escolhido para o trabalho - Modelo de Jackey}

Dentre os modelos apresentados na subseção 4.1, o modelo de Jackey mostrou-se o mais simples de ser aplicado a partir da análise de seu circuito equivalente. De forma simplificada, apenas o modelo do circuito da bateria será utilizado nesse trabalho conforme ilustra figura 4.5 (extraído de Jackey, 2007). 


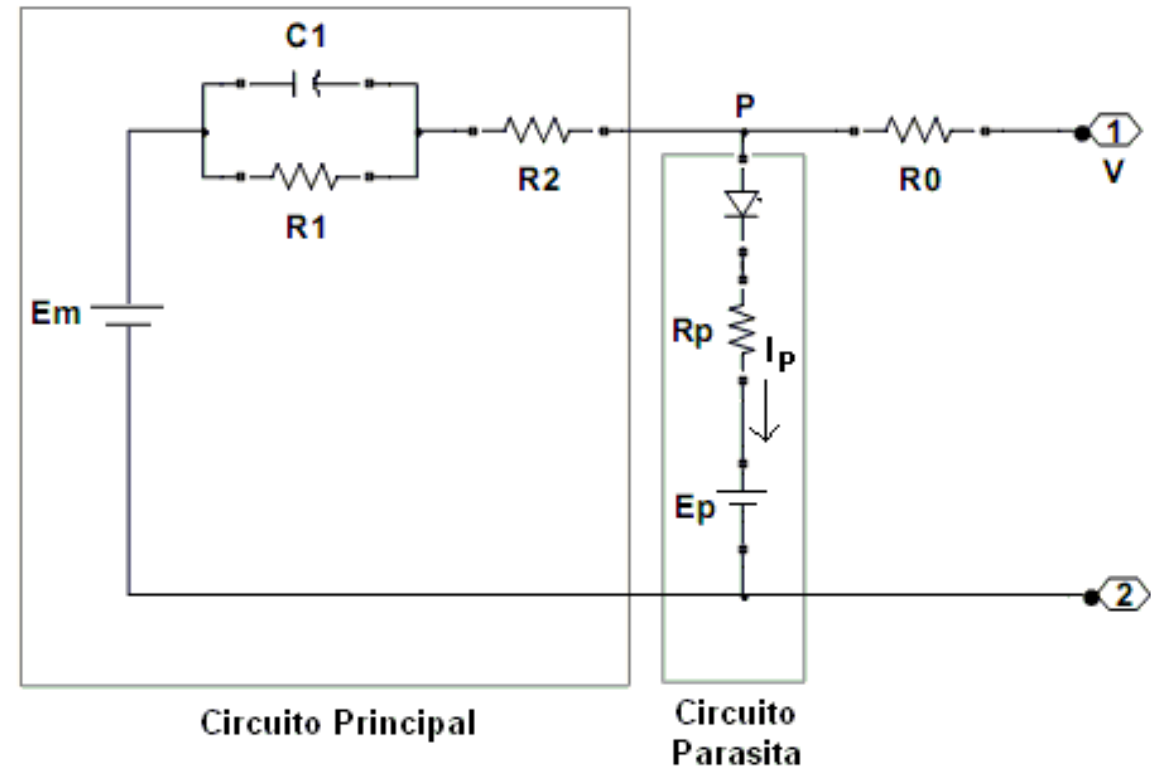

Figura 4.8 - Circuito equivalente do modelo de Jackey (extraído de Jackey, 2007).

A seguir tem-se a descrição de cada um dos componentes desse circuito:

- $E_{m}$ : força eletromotriz, em outras palavras tensão de circuito aberto (OCV) que é considerada constante quando a bateria está carregada e varia com a temperatura e estado de carga (SOC); medida em volts [V];

- $R_{0}$ : resistência vista pelos terminais da bateria que é considerada constante para todas as temperaturas e varia com o estado de carga (SOC); medida em ohms $[\Omega]$;

- $R_{1}$ : resistência que varia com a profundidade de carga (DOC) e aumenta exponencialmente conforme a bateria se descarrega; medida em ohms $[\Omega]$;

- $C_{1}$ : capacitância que simula o atraso da tensão; medida em farads [F]; o circuito paralelo formado por $R_{1}$ e $C_{1}$ representa a impedância da transferência de carga;

- $R_{2}$ : resistência que aumenta exponencialmente conforme o estado de carga (SOC) aumenta e varia com a corrente que flui através do "Circuito Principal"; além disso, afeta a bateria durante a carga e torna-se insignificante durante a descarga; medida em ohms $[\Omega]$; 
- $I_{P}$ : perda por corrente parasita quando a bateria está sendo carregada que depende da temperatura do eletrólito e da tensão do "Circuito Parasita"; esse valor é muito pequeno na maioria das condições exceto durante a carga sob alto estado de carga (SOC); medida em ampères [A].

Como o foco desse trabalho é o processo de descarga da bateria (teste de Cold Crank), as seguintes simplificações devem ser feitas:

- $\mathrm{R} 2 \rightarrow$ será desconsiderado porque se torna insignificante durante a descarga;

- "Circuito Parasita" $\rightarrow$ será desconsiderado porque não possui valor significativo durante a descarga.

Dessa forma, o circuito equivalente simplificado, considerando a corrente de descarga constante conhecida $i_{2}$ que está sendo consumida da bateria é apresentado nas figuras 4.8 e 4.9 .

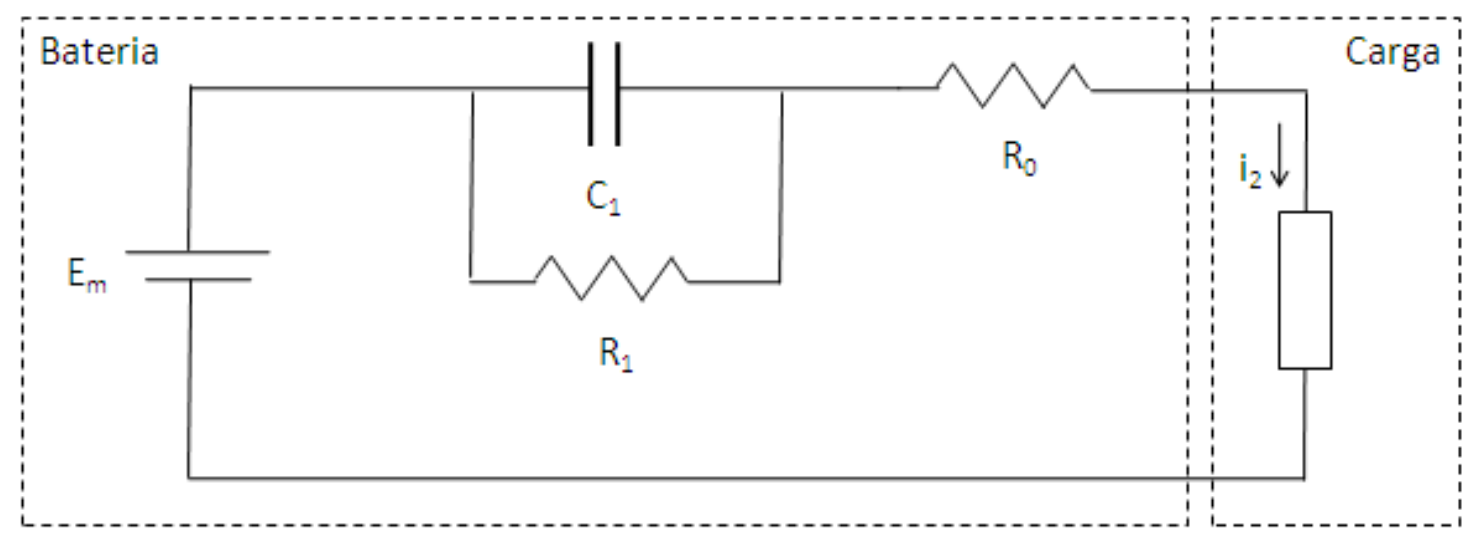

Figura 4.9 - Modelo simplificado para bateria de chumbo-ácido considerando apenas os componentes relevantes durante o processo de descarga.

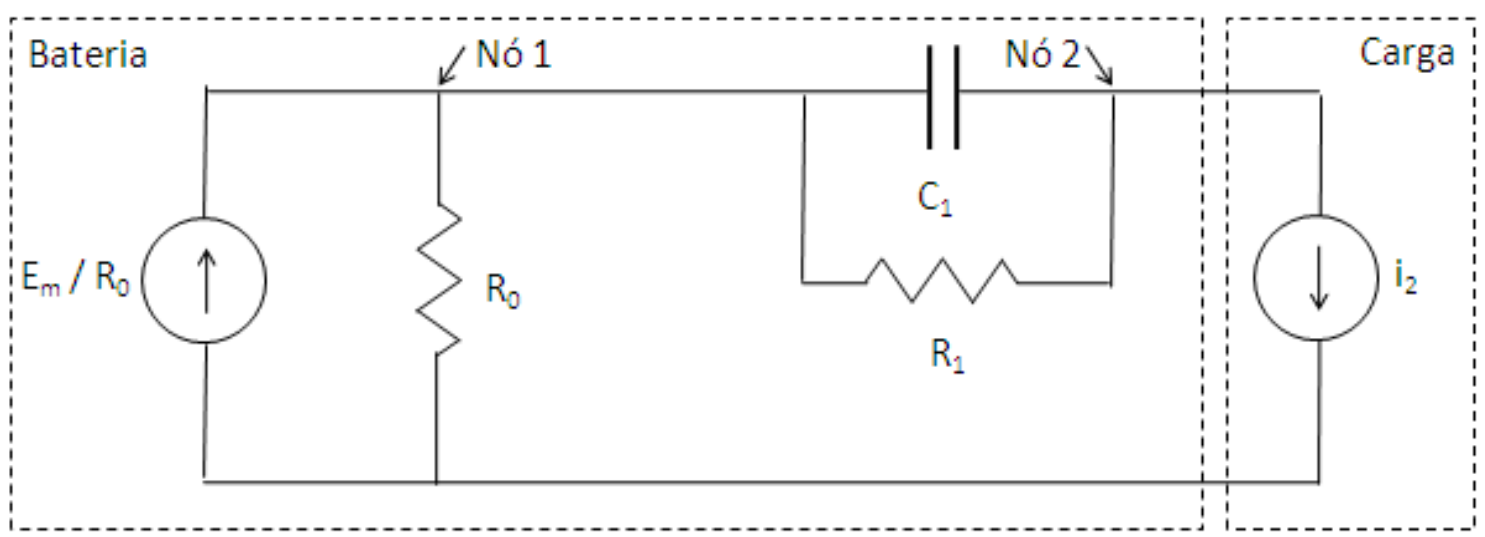

Figura 4.10 - Modelo simplificado para bateria de chumbo-ácido usando fonte de corrente. 
Resolvendo o circuito da figura 4.9, através da $1^{\text {a }}$ Lei de Kirchhoff, se obtêm as equações (5) e (6) para os nós 1 e 2 do circuito.

$$
\begin{gathered}
N o ́ ~ \\
1 \rightarrow \frac{E_{m}}{R_{0}}-\frac{V_{1}}{R_{0}}-\frac{\left(V_{1}-V_{2}\right)}{R_{1}}-C_{1} \frac{d}{d t}\left(V_{1}-V_{2}\right)=0 \\
N \text { ó } 2 \rightarrow \frac{\left(V_{1}-V_{2}\right)}{R_{1}}+C_{1} \frac{d}{d t}\left(V_{1}-V_{2}\right)-i_{2}=0
\end{gathered}
$$

Reescrevendo as equações diferenciais (5) e (6) da forma $M(t, y) y^{\prime}=f(t, y)$, chega-se na equação (7), aqui chamada de Equação da Bateria. $\mathrm{O}$ desenvolvimento completo encontra-se no apêndice B.

$$
\left[\begin{array}{cc}
-C_{1} & C_{1} \\
C_{1} & -C_{1}
\end{array}\right]\left[\begin{array}{c}
\dot{V}_{1} \\
\dot{V}_{2}
\end{array}\right]=\left[\begin{array}{c}
-\frac{E_{m}}{R_{o}} \\
i_{2}
\end{array}\right]+\left[\begin{array}{cc}
\left(\frac{1}{R_{0}}+\frac{1}{R_{1}}\right) & -\frac{1}{R_{1}} \\
-\frac{1}{R_{1}} & \frac{1}{R_{1}}
\end{array}\right]\left[\begin{array}{l}
V_{1} \\
V_{2}
\end{array}\right]
$$

Resolvendo a equação da bateria (7) tem-se o valor de tensão no nó 1 e no nó 2 ( $V_{1}$ e $V_{2}$ respectivamente) em função dos parâmetros $\left[C_{1} E_{m} R_{0} R_{1}\right]$ que são desconhecidos. Para cada conjunto $\left[C_{1} E_{m} R_{0} R_{1}\right]$ existe pelo menos um par $\left[\begin{array}{ll}V_{1} & V_{2}\end{array}\right]$ que satisfaz a equação da bateria. Esses valores $\left[V_{1} V_{2}\right]$ variam em função do tempo uma vez que a bateria está sendo descarregada com a corrente constante $i_{2}$ e representam a dinâmica de funcionamento da bateria durante um processo de descarga. O gráfico 4.1, obtido a partir de um experimento prático, ilustra a tensão $V_{2}$ que é a tensão nos terminais da bateria durante um processo de descarga usando corrente constante. 


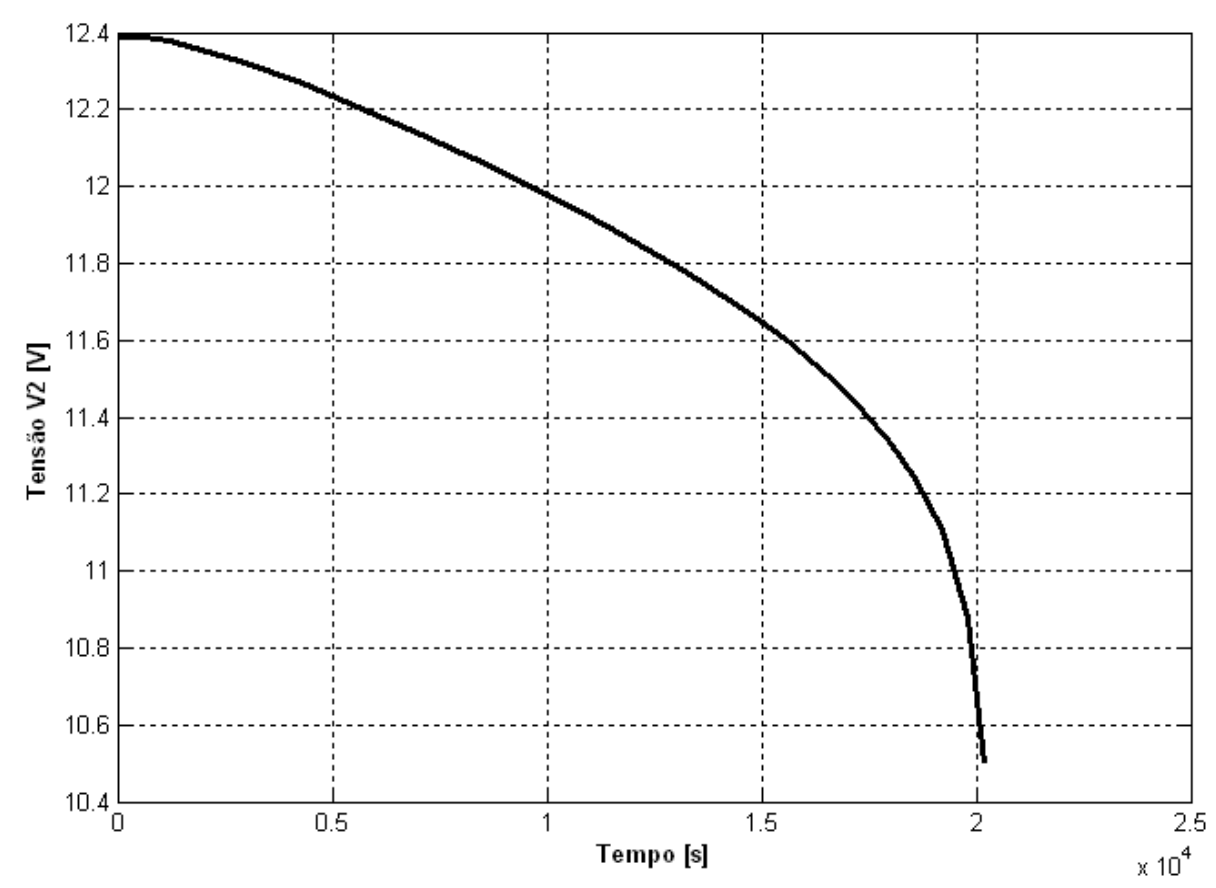

Gráfico 4.1 - Exemplo da variação da tensão nos terminais da bateria $V_{2}$ em função do tempo para uma bateria de chumbo-ácido submetida ao processo de descarga constante.

Na subseção 4.3 explicam-se detalhes da metodologia de obtenção dos parâmetros desconhecidos $\left[\begin{array}{llll}C_{1} & E_{m} & R_{0} & R_{1}\end{array}\right]$. E na subseção 4.4 explica-se a metodologia para a resolução da equação (7) em função desses parâmetros.

\subsection{Definição dos parâmetros desconhecidos}

Os parâmetros desconhecidos $\left[\begin{array}{llll}C_{1} & E_{m} & R_{0} & R_{1}\end{array}\right]$ da equação da bateria (7) possuem leis de formação, conforme explicado por Jackey, apresentadas nas equações (8), (9), (10) e (11) (Jackey, 2007).

$$
\begin{gathered}
E_{\boldsymbol{m}}=\boldsymbol{E}_{\boldsymbol{m} 0}-\boldsymbol{K}_{\boldsymbol{E}}(273+\boldsymbol{\theta})(\mathbf{1}-\boldsymbol{S O C}) \\
\boldsymbol{R}_{\mathbf{0}}=\boldsymbol{R}_{\mathbf{0 0}}\left[\mathbf{1}+\boldsymbol{A}_{\mathbf{0}}(\mathbf{1}-\boldsymbol{S O C})\right] \\
\boldsymbol{C}_{\mathbf{1}}=\frac{\boldsymbol{\tau}_{\mathbf{1}}}{\boldsymbol{R}_{\mathbf{1}}} \\
R_{1}=-R_{10} \ln (\mathrm{DOC})
\end{gathered}
$$


Em que:

- $E_{m 0}$ : tensão de circuito aberto (OCV) para SOC = $100 \%$, dada em volts;

- $K_{E}:$ constante dada em volts / ํㅜ;

- $\theta$ : temperatura do eletrólito dada em ${ }^{\circ} \mathrm{C}$;

- $S O C$ : estado de carga da bateria dado em \%;

- $R_{00}$ : resistência vista pelos terminais da bateria para SOC $=100 \%$, dada em ohms;

- $A_{0}:$ constante;

- $\tau_{1}$ : constante de tempo do circuito principal, dada em segundos;

- $R_{10}$ : resistência do circuito principal, dada em ohms;

- $D O C$ : profundidade de carga dada em \%;

Adicionalmente para o parâmetro $\left[R_{1}\right]$, uma nova lei de formação é proposta nesse trabalho, apresentada na equação (12). Os resultados da equação da bateria (7) usando essa proposta são avaliados na subseção 4.5. Portanto, a equação (11) proposta por Jackey será descartada e o parâmetro $\left[R_{1}\right]$ será calculado a partir da equação (12).

$$
R_{1}=R_{10} e^{(1-k \cdot S O C)}
$$

Em que:

- $k$ : constante.

Usando as leis das equações (8), (9), (10) e (12), os parâmetros desconhecidos passam a ser divididos em dois grupos:

- Grupo A: $\left[\begin{array}{llll}E_{m 0} & K_{E} & S O C_{t>0} & R_{00}\end{array}\right]$ parâmetros que podem ser estimados a priori sem necessidade de procedimentos de otimização, cujos detalhes são explicados nas subseções 4.3.1 a 4.3.3; 
- Grupo B: $\left[\begin{array}{lllll}A_{0} & R_{10} & \tau_{1} & S O C_{t=0} & k\end{array}\right]$ parâmetros que não podem ser estimados pois não são conhecidas suas leis de formação; por isso, só podem ser estimados através de procedimentos iterativos que usam metodologias de otimização numérica, cujos detalhes são explicados na subseção 4.4.1; dessa forma, o resultado da equação da bateria (7) será em função desses parâmetros desconhecidos, cuja estimativa inicial é explicada na subseção 4.4 .

Assim a equação da bateria (7) pode ser rescrita na forma apresentada na equação (13) e sua solução será em função do conjunto $\left[\begin{array}{llllll}A_{0} & R_{10} & \tau_{1} & S O C_{t=0} & k\end{array}\right]$.

$$
\begin{aligned}
{\left[\begin{array}{cc}
-\frac{\tau_{1}}{R_{1}} & \frac{\tau_{1}}{R_{1}} \\
\frac{\tau_{1}}{R_{1}} & -\frac{\tau_{1}}{R_{1}}
\end{array}\right]\left[\begin{array}{l}
\dot{V}_{1} \\
\dot{V}_{2}
\end{array}\right]=\left[\begin{array}{c}
-\frac{\left[E_{m 0}-K_{E}(273+\theta)(1-S O C)\right]}{R_{00}\left[1+A_{0}(1-S O C)\right]} \\
i_{2}
\end{array}\right]+} \\
+\left[\begin{array}{cc}
\left(\frac{1}{R_{00}\left[1+A_{0}(1-S O C)\right]}+\frac{1}{R_{10} e^{(1-k . S O C)}}\right) & -\frac{1}{R_{10} e^{(1-k . S O C)}} \\
-\frac{1}{R_{10} e^{(1-k . S O C)}} & \frac{1}{R_{10} e^{(1-k . S O C)}}
\end{array}\right]\left[\begin{array}{l}
V_{1} \\
V_{2}
\end{array}\right]
\end{aligned}
$$

\subsubsection{Parâmetros $E_{m 0}$ e $K_{E}$}

A curva OCV versus SOC, apresentada no gráfico 4.2, mostra que o estado de carga da bateria $(\mathrm{SOC})$ varia de forma aproximadamente linear em função da tensão. Considerando essa aproximação, é possível extrair a equação da reta na forma $y(x)=a x+b$ que relaciona essas duas grandezas. Nesse trabalho, usase a bateria 6 (curva vermelha do gráfico 4.2) que representa a bateria de 63Ah (valor nominal) / 68,6 $\mathrm{Ah}^{1}$ (valor real).

\footnotetext{
${ }^{1}$ A capacidade nominal dessa bateria, divulgada comercialmente, é 63Ah. A capacidade real é $68,6 \mathrm{Ah}$, cujo valor está sendo utilizado nos cálculos desse trabalho.
} 


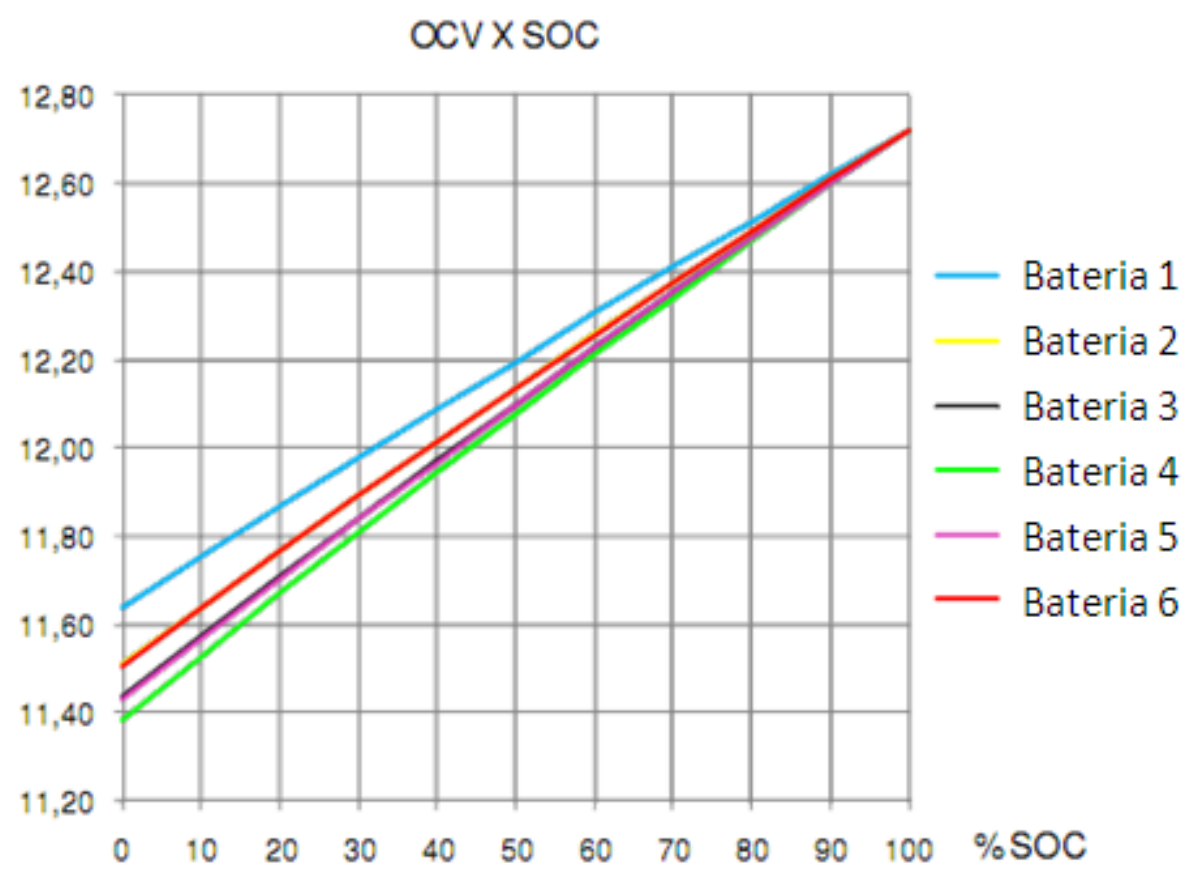

Gráfico 4.2 - Variação da tensão de circuito aberto (OCV) em função do estado de carga (SOC) de baterias de chumbo-ácido comercialmente usadas em veículos automotivos.

Usando os pontos obtidos do gráfico, chega-se à equação (14):

$$
\begin{gathered}
\text { Ponto 1: } y(0 \%)=11,5 \mathrm{~V} \quad \text { Ponto } 2: y(100 \%)=12,7 \mathrm{~V} \\
\therefore \text { tensão }=1,2 \mathrm{~V} . \mathrm{SOC}+11,5 \mathrm{~V} \rightarrow \text { SOC }=\frac{\text { tensão }-11,5 \mathrm{~V}}{1,2 \mathrm{~V}}
\end{gathered}
$$

Sabendo-se que a tensão $E_{m}$ representa a tensão OCV e usando a equação da reta (14), tem-se a relação indicada na equação (15).

$$
\text { tensão } O C V=E_{m}=1,2 \mathrm{~V} \cdot S O C+11,5 \mathrm{~V}
$$

Aplicando-se manipulações algébricas à equação (15) chega-se à equação (16).

$$
\begin{gathered}
E_{m}=1,2 \mathrm{~V} \cdot S O C+11,5 V \rightarrow \frac{E_{m}-11,5}{1,2}=S O C \rightarrow 1-\left(\frac{E_{m}-11,5}{1,2}\right)=1-S O C \\
\therefore E_{m}=12,7-1,2(1-S O C)
\end{gathered}
$$


Comparando-se a equação (16) com a equação (8), é possível obter os valores de $E_{m 0}$ e $K_{E}$, para o qual a temperatura de $\theta=25^{\circ} C$ será considerada no cálculo.

Equação (8): $E_{m}=E_{m 0}-K_{E}(273+\theta)(1-S O C)$

Equação (16): $E_{m}=12,7-1,2(1-S O C)$

$\therefore E_{m 0}=12,7 \mathrm{~V}$

$\therefore K_{E}(273+\theta)=1,2 \rightarrow K_{E}=\frac{1,2}{(273+25)} \rightarrow K_{E}=0,004027$

\subsubsection{Parâmetro SOC}

As equações (8), (9) e (12) mostram que o valor do estado de carga (SOC) é extremamente relevante para o cálculo de $E_{m}$, a tensão de circuito aberto (OCV) da bateria, para o cálculo de $R_{0}$, resistência vista pelos terminais da bateria, e para o cálculo de $R_{1}$, resistência de transferência de carga.

O SOC, que varia ao longo do tempo em função da corrente de descarga $i_{2}$, pode ser calculado a partir da equação (17) (Xiao; Shi; He, 2010).

$$
\operatorname{SOC}(t)=\operatorname{SOC}(0)-\frac{1}{Q} \int_{0}^{t} i_{2}(t) d t
$$

Em que:

- $i_{2}$ : corrente de descarga;

- $\Delta t$ : variação do tempo (em horas);

- $Q$ : capacidade real da bateria utilizada como referência nesse trabalho; 
- $S O C_{t=0}$ : é um parâmetro desconhecido e, por isso, o resultado da resolução da equação da bateria (13) será em sua função, cuja estimativa inicial é explicada na subseção 4.4 .

Como ilustração, o gráfico 4.3 apresenta o valor do SOC calculado a partir da equação (17), em função do tempo, admitindo-se que a corrente de descarga foi mantida fixa $i_{2}=10 \mathrm{~A}$, considerando SOC $(\mathrm{t}=0)=100 \%$ e $Q=68,6 \mathrm{Ah}$.

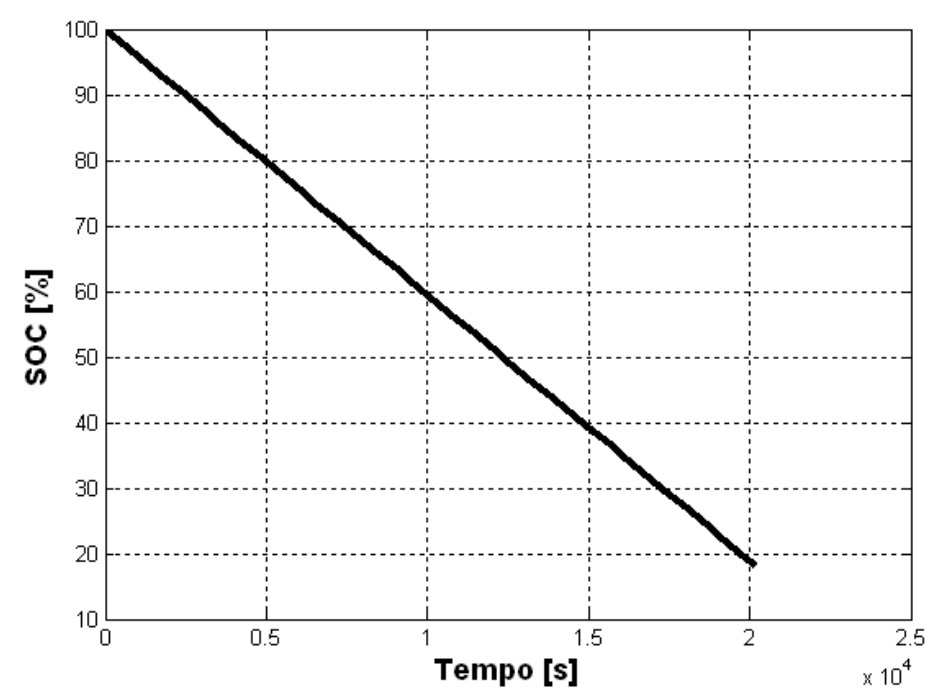

Gráfico 4.3 - Variação do estado de carga (SOC) de uma bateria de chumbo-ácido (63Ah) em função do tempo para um processo descarga de $10 \mathrm{~A}$.

\subsubsection{Parâmetro $R_{00}$}

No instante inicial, o modelo simplificado da bateria representado na figura 4.8 pode ser escrito tal qual ilustra figura 4.10. A ausência do capacitor nesse circuito é explicada pelo fato desse componente comportar-se com um curto-circuito assim que a chave é fechada (instante $\mathrm{t}_{0_{+}}$). Conseqüentemente, nenhuma corrente circulará pelo resistor $R_{1}$ que também foi removido do modelo. 


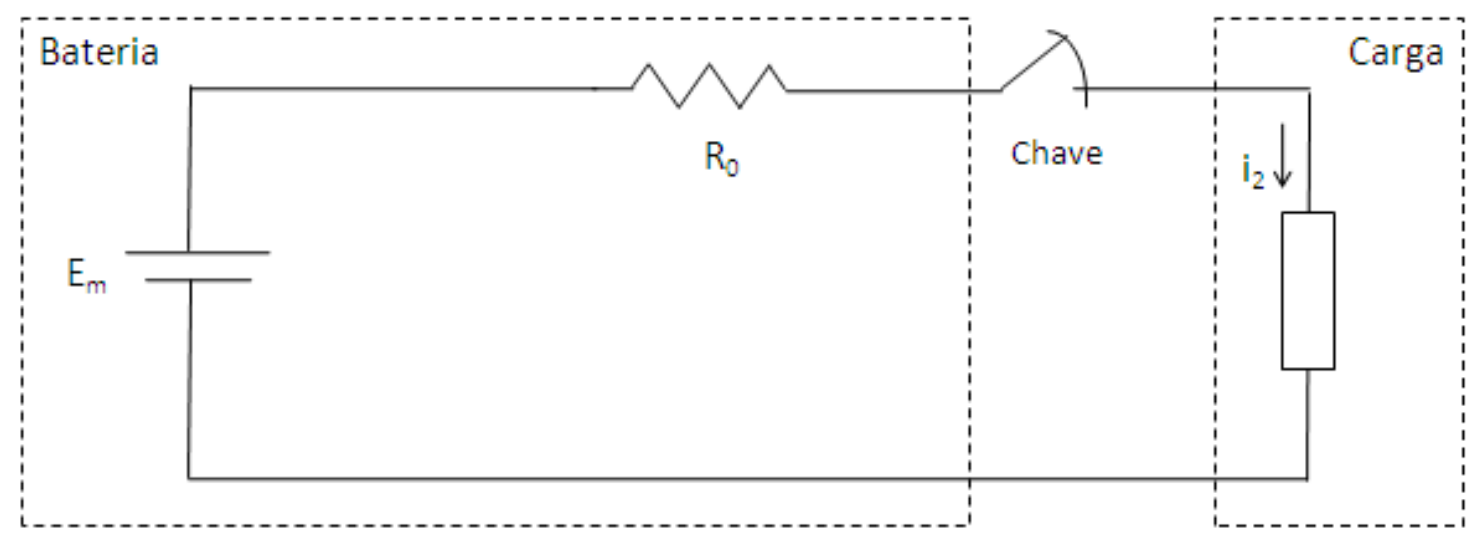

Figura 4.11 - Modelo simplificado para bateria de chumbo-ácido válido no instante inicial.

Analisando a figura 4.10 , obtemos a equação (18) considerando que $V_{2}, E_{m}$ e $i_{2}$ são valores conhecidos no instante inicial.

$$
R_{0}\left(t_{0+}\right)=\frac{V_{2}\left(t_{0+}\right)-E_{m}\left(t_{0+}\right)}{i_{2}}
$$

Substituindo o valor de $R_{0}\left(t_{0+}\right)$ e $A_{0}$ na equação

$R_{0}=R_{00}\left[1+A_{0}(1-S O C)\right]$, temos a equação (19) que calcula o valor de $R_{00}$.

$$
R_{00}=\frac{R_{0}\left(t_{0+}\right)}{\left[1+A_{0}(1-S O C)\right]}
$$

\subsection{Metodologia para a resolução da equação da bateria}

Analisando-se a matriz massa, descrita na equação (20), da equação da bateria (13), nota-se que seu determinante é nulo.

$$
M(t)=\left[\begin{array}{cc}
-\frac{\tau_{1}}{R_{1}} & \frac{\tau_{1}}{R_{1}} \\
\frac{\tau_{1}}{R_{1}} & -\frac{\tau_{1}}{R_{1}}
\end{array}\right]
$$


Ou seja, a matriz massa é singular. Com isso, a equação diferencial é classificada como DAE (Differential-Algebraic Equation - Equação Diferencial-Algébrica).

O MatLab® possui uma família de funções para a resolução de equações diferenciais. Essas funções são conhecidas por funções ODE (Ordinary Differential Equation - Equação Diferencial Ordinária) e são baseadas nos métodos de RungeKutta que são métodos iterativos para aproximar a solução de equações diferenciais (MATLAB, 2008). Nessa família, encontram-se as funções que suportam equações do tipo DAE:

- ODE15s: usa o algoritmo Runge-Kutta chamado NDF (Numerical Differentiation Formula - Fórmula de Diferenciação Numérica), indicada para problemas nos quais algumas variáveis do modelo variam rapidamente e outras variam lentamente e indicada como primeira função a ser usada na resolução de equações diferenciais pois o grau de complexidade computacional é pequeno se comparado ao de outras funções (MATLAB, 2008);

- ODE23t: usa o algoritmo Runge-Kutta chamado Regra Trapezoidal usando um interpolador livre, indicada para problemas nos quais algumas variáveis do modelo variam rapidamente e outras variam lentamente e indicada para situações onde uma solução sem amortecimento numérico é aceitável (MATLAB, 2008).

A equação da bateria (13) será resolvida usando a função ODE15s como estratégia inicial, já que sua complexidade computacional é menor e, conseqüentemente, é executada pelo MatLab® de forma mais rápida.

Esse cálculo produzirá um resultado em função do conjunto $\left[\begin{array}{lllll}A_{0} & R_{10} & \tau_{1} & S O C_{t=0} & k\end{array}\right]$ escolhido aleatoriamente, já que o valor desses parâmetros é desconhecido. Dessa forma, a definição de um erro conforme ilustra equação (21) é conveniente para permitir que o conjunto ótimo seja escolhido para os parâmetros. O uso de um algoritmo de otimização numérica será usado para minimizar esse erro aproximando os valores de $V_{2 \_ \text {calculado }}$ e $V_{2 \_ \text {esperado }}$. 


$$
\operatorname{Erro}=\frac{\sum_{t_{\text {inicial }}}^{t_{\text {final }}}\left(V_{2_{-} \text {esperado }}(t)-V_{2_{-} \text {calculado }}(t)\right)^{2}}{n}
$$

Em que:

- $V_{2 \_ \text {esperado }}$ : valor obtido a partir de uma curva de descarga experimental;

- $\quad V_{2}$ calculado: valor obtido a partir da resolução da equação da bateria (13) para um dado conjunto $\left[\begin{array}{llllll}A_{0} & R_{10} & \tau_{1} & S O C_{t=0} & k\end{array}\right]$ escolhido aleatoriamente;

- $\quad n$ : número de amostras.

Assim, a metodologia para a resolução da equação da bateria é definida conforme fluxo apresentado na figura 4.11. O código fonte implementado em Matlab® é apresentado no apêndice $\mathrm{C}$. 


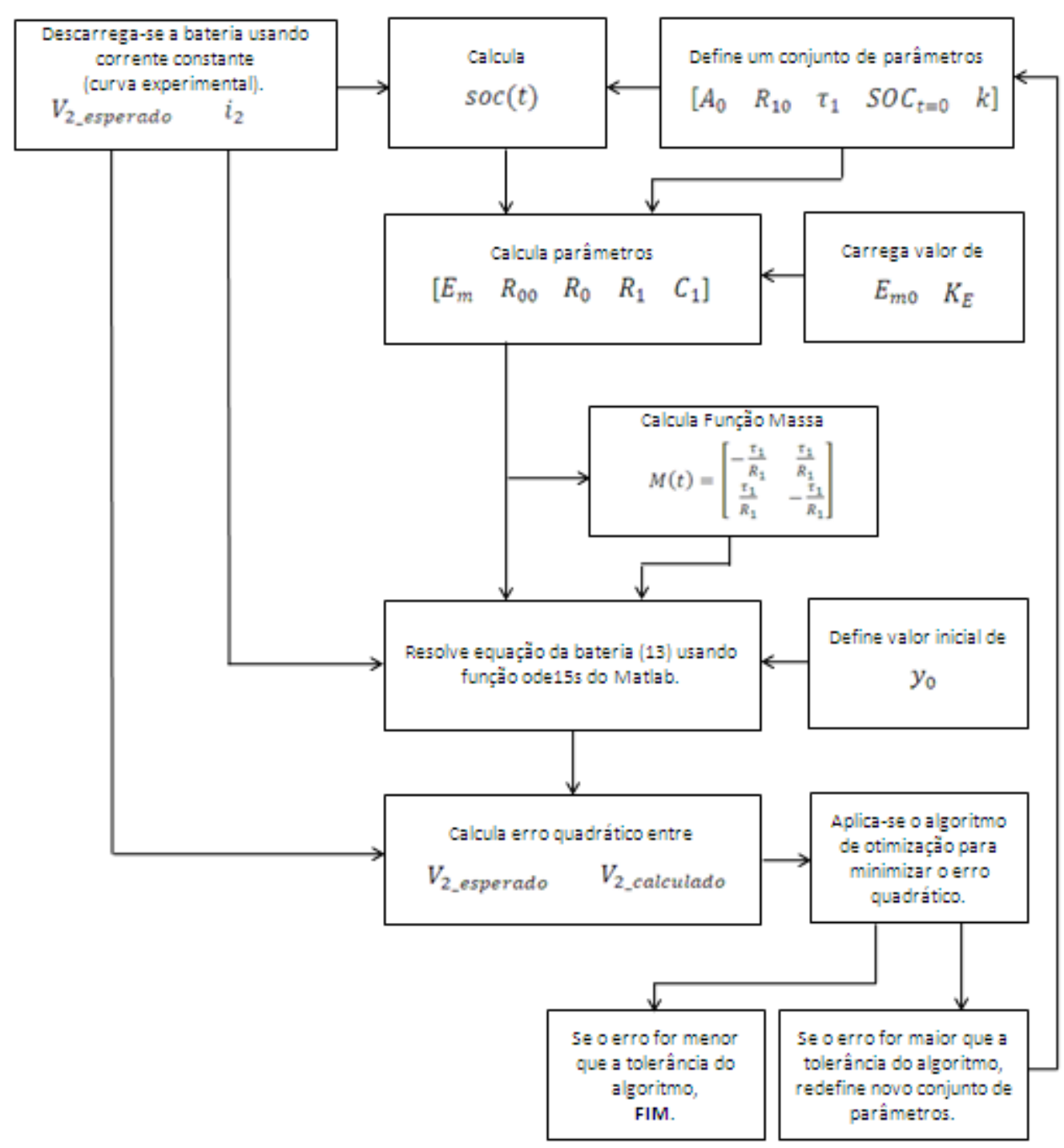

Figura 4.12 - Fluxo da metodologia para a resolução da equação da bateria.

Com a definição do método para a resolução da equação da bateria, apresenta-se na subseção 4.4.1 os detalhes do método de otimização utilizado e na subseção 4.4.2 as curvas de descarga obtidas experimentalmente e que serão usadas para o cálculo do erro quadrático. Na seqüência, os resultados obtidos na resolução da equação da bateria (13) são apresentados e discutidos na subseção 4.5 . 


\subsubsection{Descrição do método de otimização}

A resolução da equação da bateria (13), seguindo a metodologia descrita na subseção 4.4, envolve um problema de minimização com restrição pois cada uma das variáveis do conjunto $x=\left[\begin{array}{lllll}A_{0} & R_{10} & \tau_{1} & S O C_{t=0} & k\end{array}\right]$ possui um valor mínimo e um valor máximo admissível. Essas restrições precisam ser estabelecidas de forma coerente para permitir que o algoritmo de otimização, implementado na obtenção do menor erro quadrático, gere um conjunto que tenha sentido físico. Dessa forma, os seguintes limites são adotados nesse trabalho:

Função que será otimizada:

$\min$ erro $=f(x)=\sum_{t_{\text {inicial }}}^{t_{\text {final }}}\left(V_{2_{\text {calculado }}}(x(t))-V_{2_{\text {esperado }}}(t)\right)^{2}$

Sujeita às restrições: $\quad x \geq\left[\begin{array}{lllll}0,001 & 0,0001 & 100 & 0,5 & 0,01\end{array}\right]$

$$
x \leq\left[\begin{array}{lllll}
20 & 10 & 100000 & 1 & 20
\end{array}\right]
$$

Os limites foram definidos a partir da aplicação da metodologia para a resolução da equação da bateria usando diferentes limites para as variáveis. Os limites foram alterados de ambas as formas: reduzindo a escala de variação dos parâmetros e aumentando a escala de variação dos parâmetros, até que se conhecesse, aproximadamente, os valores mínimos e máximos possíveis para cada parâmetro.

A ferramenta Optimtool do MatLab® possui um conjunto de algoritmos de otimização. Nesse trabalho, é necessário o uso de um algoritmo que suporte problemas não lineares com restrições. As categorias disponíveis para esse tipo de problema são.

- Algoritmos de busca local:

Encontram o mínimo local da função objetivo próximo ao ponto inicial $x_{0}$, a partir da informação de gradientes da função objetivo (MATLAB, 2008). 
- Algoritmos de busca direta:

Métodos que não precisam de informação sobre o gradiente da função objetivo para funcionar. Esse algoritmo define um conjunto de pontos ao redor do ponto atual, em busca do ponto para o qual a função objetivo é menor. E assim sucessivamente até obter a solução ótima (MATLAB, 2008).

- Algoritmo genético:

Método baseado na seleção natural que modifica repetidamente a população de soluções. A cada passo, o algoritmo genético seleciona indivíduos da população atual, de forma aleatória, como pais e usa-os para produzirem os filhos da próxima geração. Após sucessivas gerações, a população evolui na direção da solução ótima. Para criar as próximas gerações, os pais são submetidos a uma ou mais das seguintes regras (MATLAB, 2008):

- Seleção: seleciona indivíduos da população atual para formarem a próxima geração.

- Cruzamento (ou recombinação genética): combina dois indivíduos da população atual para formarem os filhos da próxima geração.

- Mutação: aplica mudanças aleatórias nos indivíduos da população atual e os utiliza como filhos da próxima geração.

Difere dos algoritmos de otimização convencionais pois não é baseado na derivada da função, gera uma população de candidatos à solução a cada iteração, e não apenas um candidato único, e não usa cálculo determinístico (MATLAB, 2008).

\section{- Algoritmo Simulated Anneling:}

Método que modela o processo físico de aquecimento de um material seguido de um resfriamento lento para minimizar a energia do sistema. A cada iteração, um novo ponto é gerado aleatoriamente. A distância desse novo ponto para o ponto atual é baseado na distribuição de probabilidade com uma escala proporcional à temperatura. $O$ algoritmo aceita novos pontos menores que o objetivo e também alguns pontos maiores que o objetivo, para escapar de pontos mínimos locais e 
ser capaz de explorar globalmente as soluções possíveis. O algoritmo sistematicamente diminui a temperatura o que faz reduzir a extensão da busca e converge para o ponto mínimo procurado (MATLAB, 2008).

Como o conjunto de parâmetros $\left[\begin{array}{llllll}A_{0} & R_{10} & \tau_{1} & S O C_{t=0} & k\end{array}\right]$ é completamente desconhecido, a seguinte estratégia foi adotada:

1) Usar o algoritmo genético que não solicita valor para $x_{0}$; representado pela função ga da ferramenta Optimtool do Matlab®.

2) Usar o algoritmo de busca local usando como $x_{0} \circ$ valor obtido no passo 1;

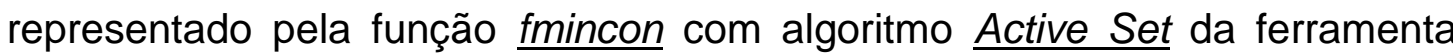
Optimtool do Matlabß.

A função fmincon usa o método de programação quadrática seqüencial, que é considerado o estado da arte dentre os métodos não lineares, e é baseado nas equações de Karush-Kuhn-Tucker (KKT), que são condições necessárias para encontrar o ponto ótimo da função objetivo (MATLAB, 2008).

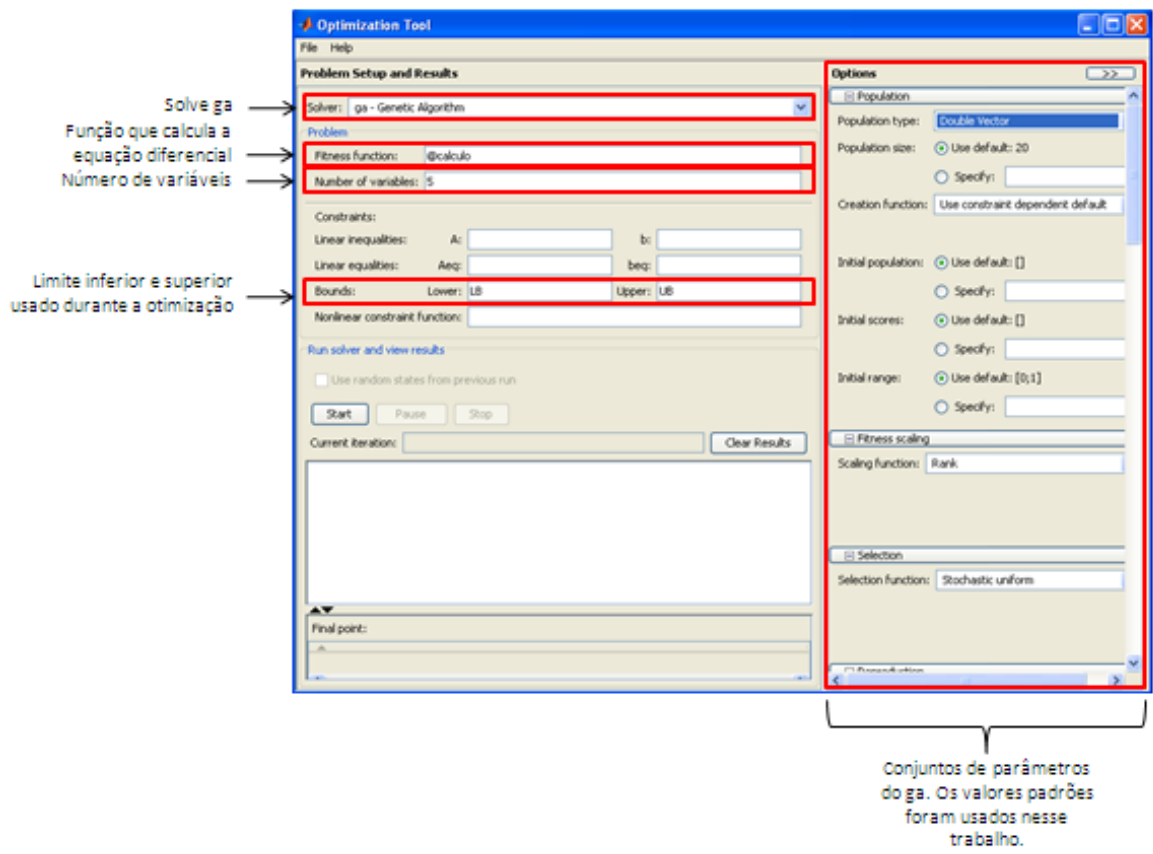

Figura 4.13 - Tela da ferramenta Optimtool no MatLab®: Parâmetros que foram alterados para o uso da função de otimização ga. 


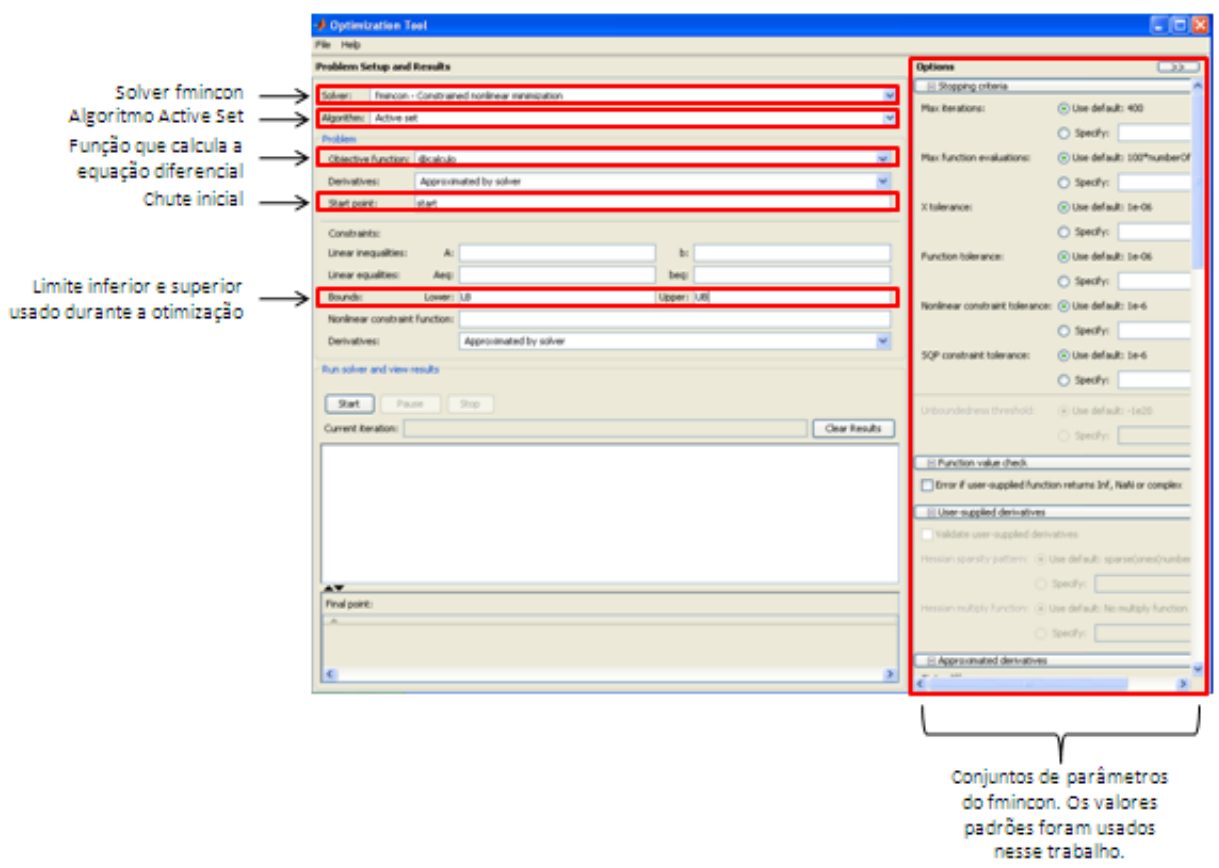

Figura 4.14 - Tela da ferramenta Optimtool no MatLab®: Parâmetros que foram alterados para o uso da função de otimização fmincon.

\subsubsection{Curvas de Descarga Experimentais}

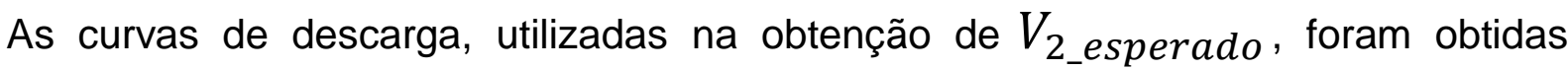
experimentalmente para quatro diferentes valores de corrente: 3,15A / 10A / 50A / $100 \mathrm{~A}$.

As curvas foram obtidas no Laboratório Elétrico do Campo de Provas da General Motors do Brasil usando a bateria com as especificações descritas na tabela $4.1 \mathrm{e}$ usando temperatura ambiente de $25^{\circ} \mathrm{C}$.

Tabela 4.1 - Especificação da bateria usada na obtenção das curvas de descarga

\begin{tabular}{cc}
\hline Especificação & Valor \\
\hline Capacidade Nominal & $63 \mathrm{Ah}$ \\
Capacidade Real & $68,6 \mathrm{Ah}$ \\
Corrente de partida a frio & $675 \mathrm{~A} \mathrm{SAE}$ \\
Tipo de bateria & FLA \\
\hline
\end{tabular}

Os resultados medidos experimentalmente, para cada um dos valores de corrente de descarga, são apresentados nos gráficos 4.4 a 4.7. 


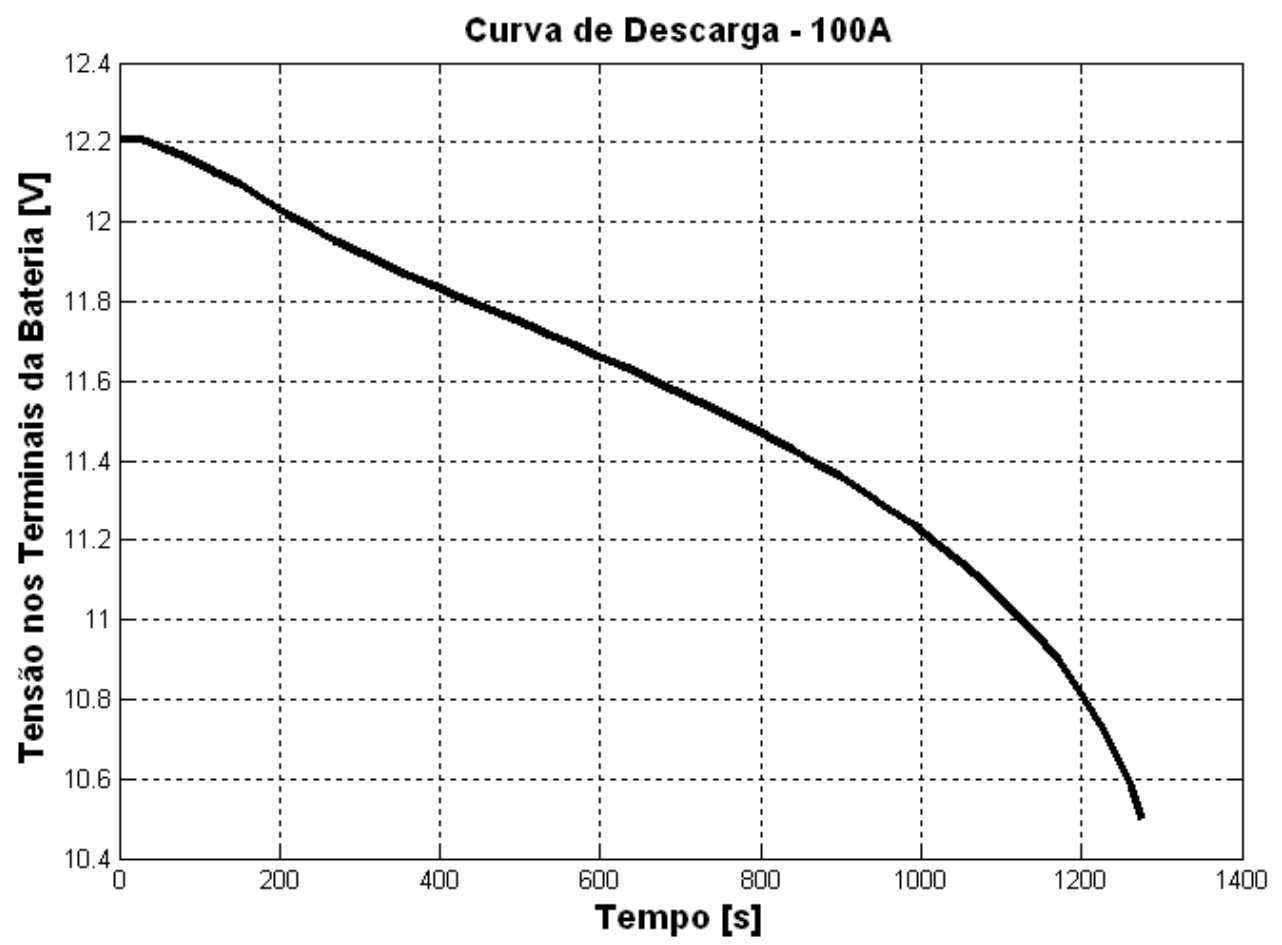

Gráfico 4.4 - Variação da tensão nos terminais da bateria $V_{2}$ em função do tempo para uma bateria de chumbo-ácido (63Ah) submetida à processos de descarga constante $100 \mathrm{~A}$.

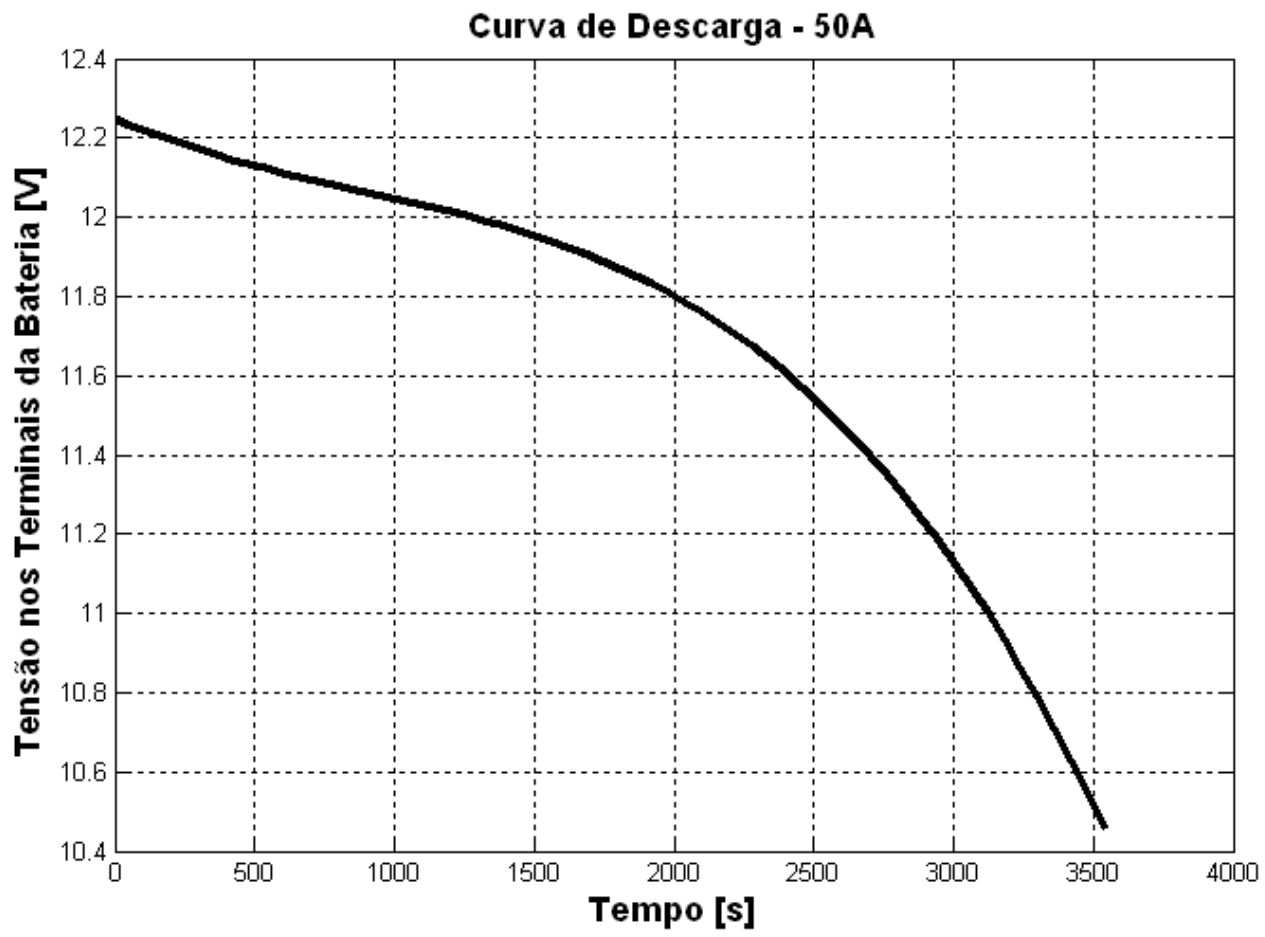

Gráfico 4.5 - Variação da tensão nos terminais da bateria $V_{2}$ em função do tempo para uma bateria de chumbo-ácido (63Ah) submetida à processos de descarga constante $50 \mathrm{~A}$. 


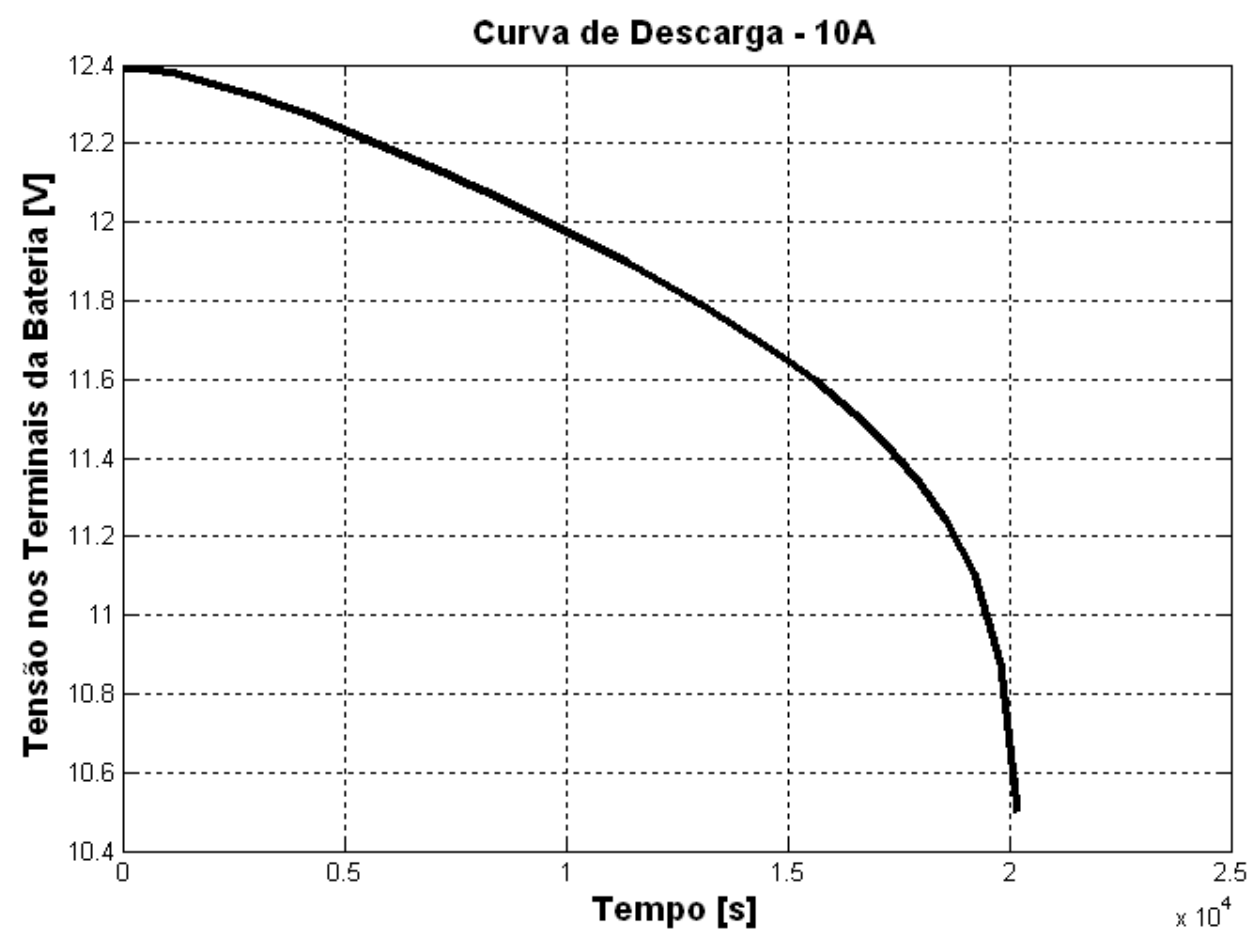

Gráfico 4.6 - Variação da tensão nos terminais da bateria $V_{2}$ em função do tempo para uma bateria de chumbo-ácido (63 Ah) submetida à processos de descarga constante $10 \mathrm{~A}$.

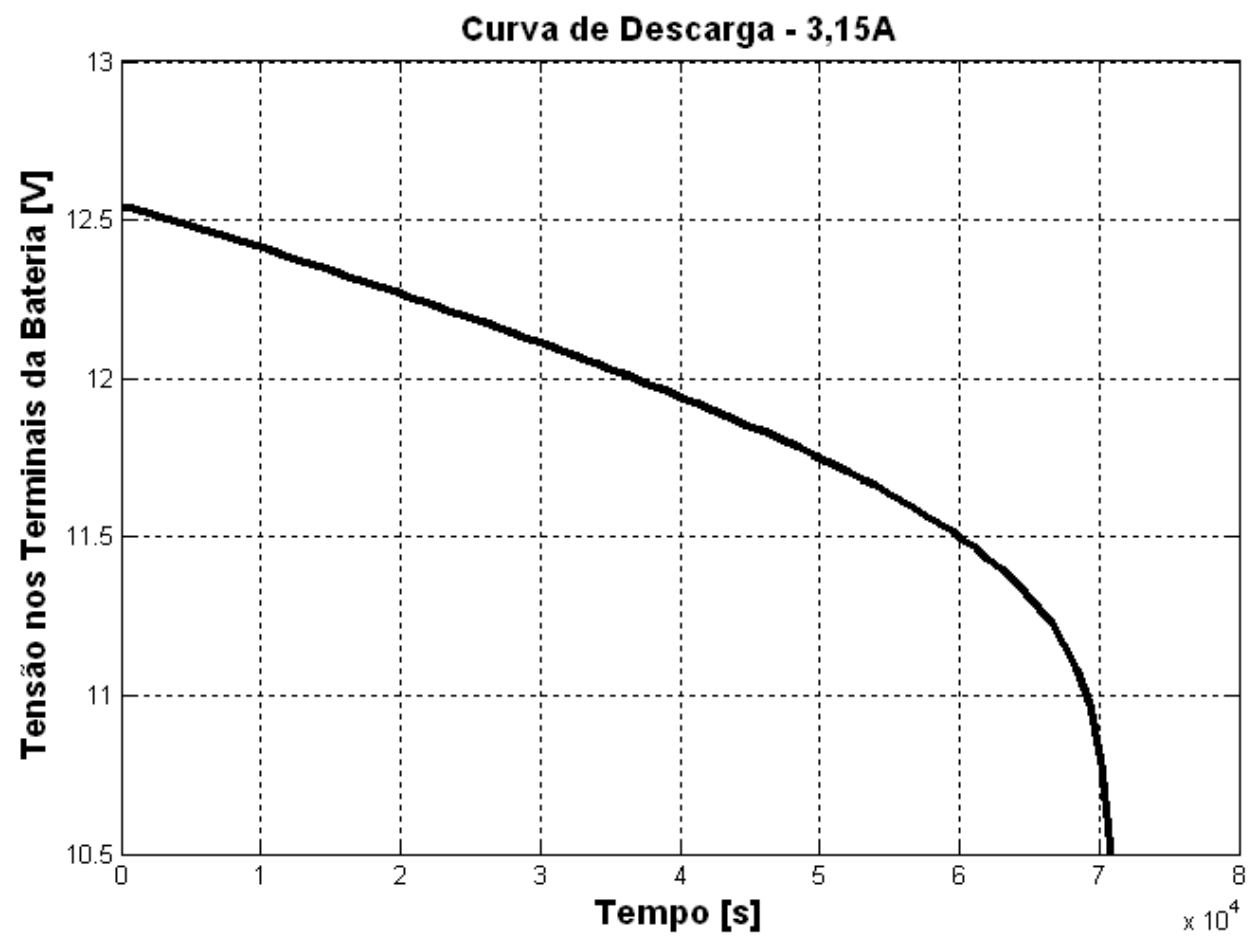

Gráfico 4.7 - Variação da tensão nos terminais da bateria $V_{2}$ em função do tempo para uma bateria de chumbo-ácido (63Ah) submetida à processos de descarga constante $3.15 \mathrm{~A}$. 
As curvas de descarga experimentais disponíveis serão usadas como $V_{2 \_ \text {esperado }}$ na resolução da equação da bateria (13) para que a metodologia possa ser aplicada. O tempo de duração total de cada experimento, o intervalo de leitura e o número de amostras estão descritos na tabela 4.2.

Tabela 4.2 - Detalhes sobre as curvas de descarga obtidas experimentalmente

\begin{tabular}{cccc}
\hline Corrente de descarga & $\begin{array}{c}\text { Tempo total do } \\
\text { experimento }\end{array}$ & Intervalo de leitura & Número de amostras \\
\hline $100 \mathrm{~A}$ & $1276 \mathrm{~s}$ & $30 \mathrm{~s}$ & 44 \\
$50 \mathrm{~A}$ & $3540 \mathrm{~s}$ & $60 \mathrm{~s}$ & 60 \\
$10 \mathrm{~A}$ & $20208 \mathrm{~s}$ & $600 \mathrm{~s}$ & 35 \\
$3,15 \mathrm{~A}$ & $70886 \mathrm{~s}$ & $900 \mathrm{~s}$ & 80 \\
\hline
\end{tabular}

Um dos parâmetros da função ODE15s, que será usada na resolução da equação diferencial - equação da bateria (9), é o intervalo de amostragem. Esse intervalo será parametrizado usando o tempo total do experimento apresentado na tabela 4.2. A figura 4.14 ilustra que para o cálculo do erro é preciso fazer uma comparação

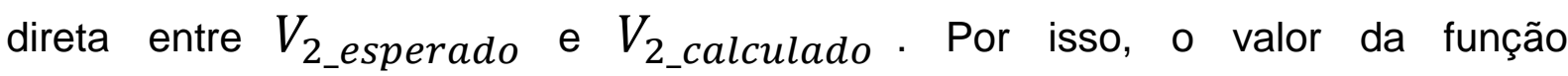

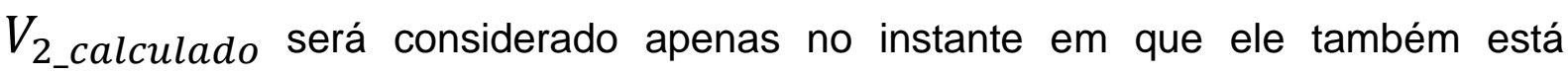
disponível para $V_{2 \_ \text {esperado }}$.

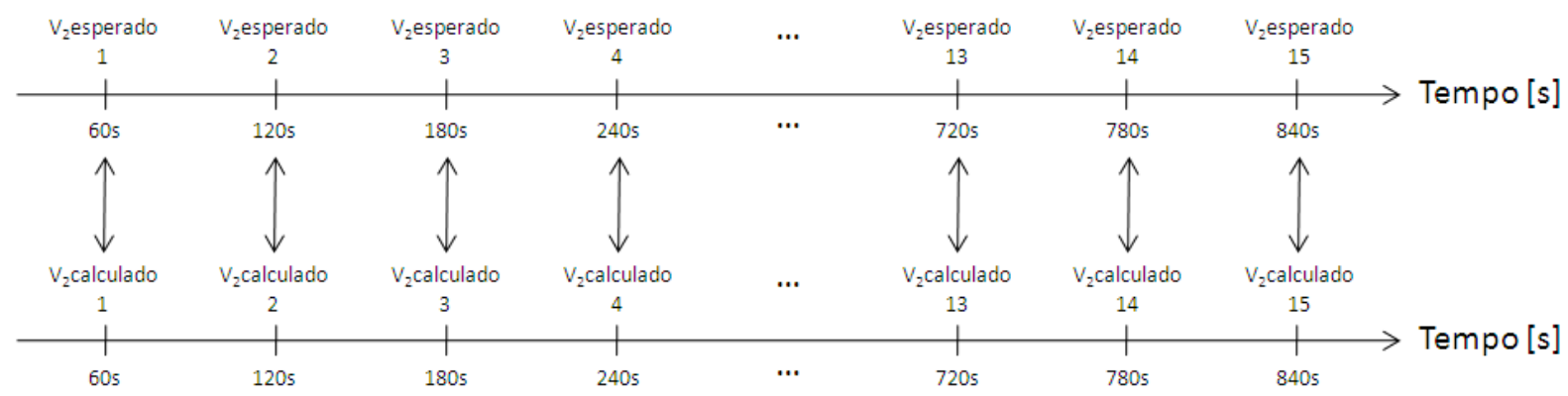

Figura 4.15 - Exemplo dos pontos de medição que serão tomados da curva experimental e da resolução da equação da bateria para cálculo do erro. 


\subsection{Análise dos resultados}

A metodologia para a resolução da equação da bateria, ilustrada na figura 4.11 , foi aplicada duas vezes da seguinte forma:

1) Usando o algoritmo genético.

2) Usando algoritmo de busca local e $x_{0}=\left[\begin{array}{lllll}A_{0} & R_{10} & \tau_{1} & S O C_{t=0} & k\end{array}\right]$, resultado obtido no passo 1.

Como resultado, a tabela 4.3 e os gráficos $4.8,4.9,4.10$ e 4.11 apresentam 0 conjunto de parâmetros que produzem o menor erro.

Tabela 4.3 - Resultados da Equação da Bateria

\begin{tabular}{ccccccc}
\hline Descarga & $\boldsymbol{A}_{\mathbf{0}}$ & $\boldsymbol{R}_{\mathbf{1 0}}[\Omega]$ & $\boldsymbol{\tau}_{\mathbf{1}}\left[\mathbf{1 0} \mathbf{S}^{\mathbf{s}}\right]$ & $\boldsymbol{S O C} \boldsymbol{t}_{\boldsymbol{t}=\mathbf{0}}$ & $\boldsymbol{k}$ & $\boldsymbol{E r r o}$ \\
\hline$i_{2}=100 \mathrm{~A}$ & 14,62791 & 0,6749 & 0,059675 & 0,807477 & 14,62896 & $0,02 \%$ \\
$i_{2}=50 \mathrm{~A}$ & 0,1 & 0,143289 & 0,689214 & 0,739249 & 10,11023 & $0,25 \%$ \\
$i_{2}=10 \mathrm{~A}$ & 0,174361 & 0,104859 & 0,787185 & 0,819089 & 9,883446 & $0,61 \%$ \\
$i_{2}=3,15 \mathrm{~A}$ & 0,100069 & 0,14015 & 1,01095 & 0,901288 & 7,931977 & $0,31 \%$ \\
\hline
\end{tabular}




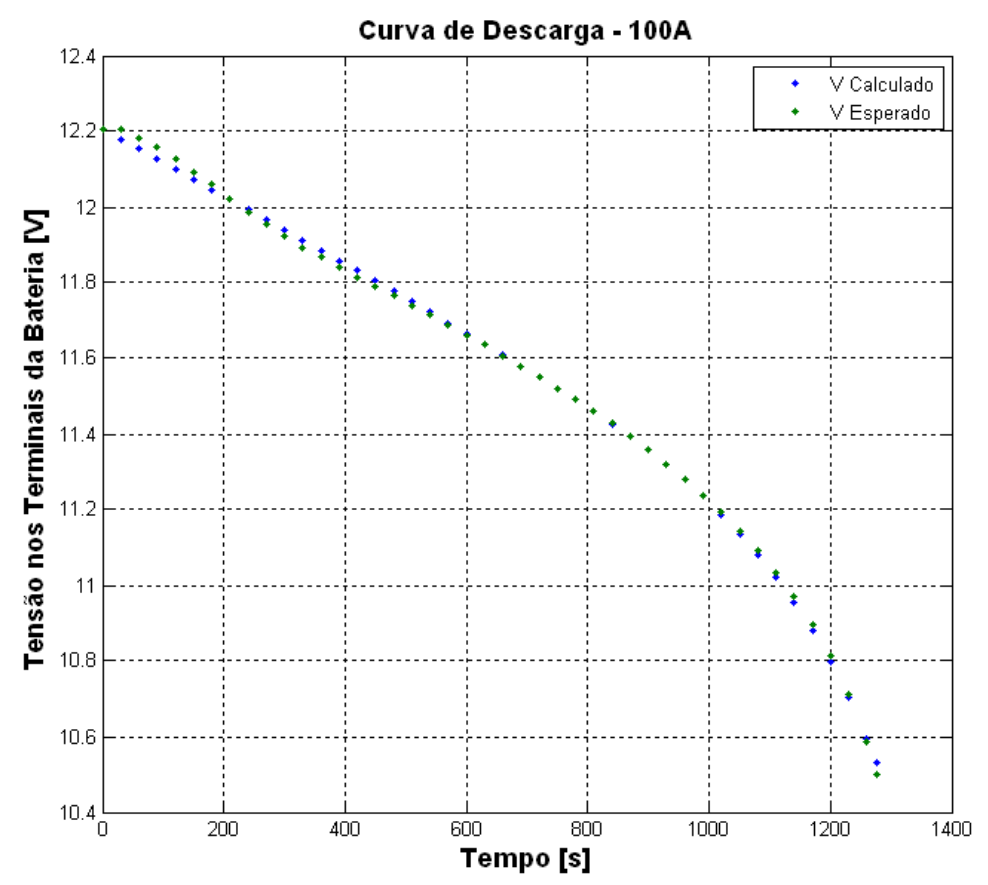

Gráfico 4.8 - Variação da tensão nos terminais da bateria em função do tempo para uma bateria de chumbo-ácido submetida ao processo de descarga constante $100 \mathrm{~A}$ - Comparação entre valor calculado pela metodologia descrita na subseção 4.4 e valor medido experimentalmente.

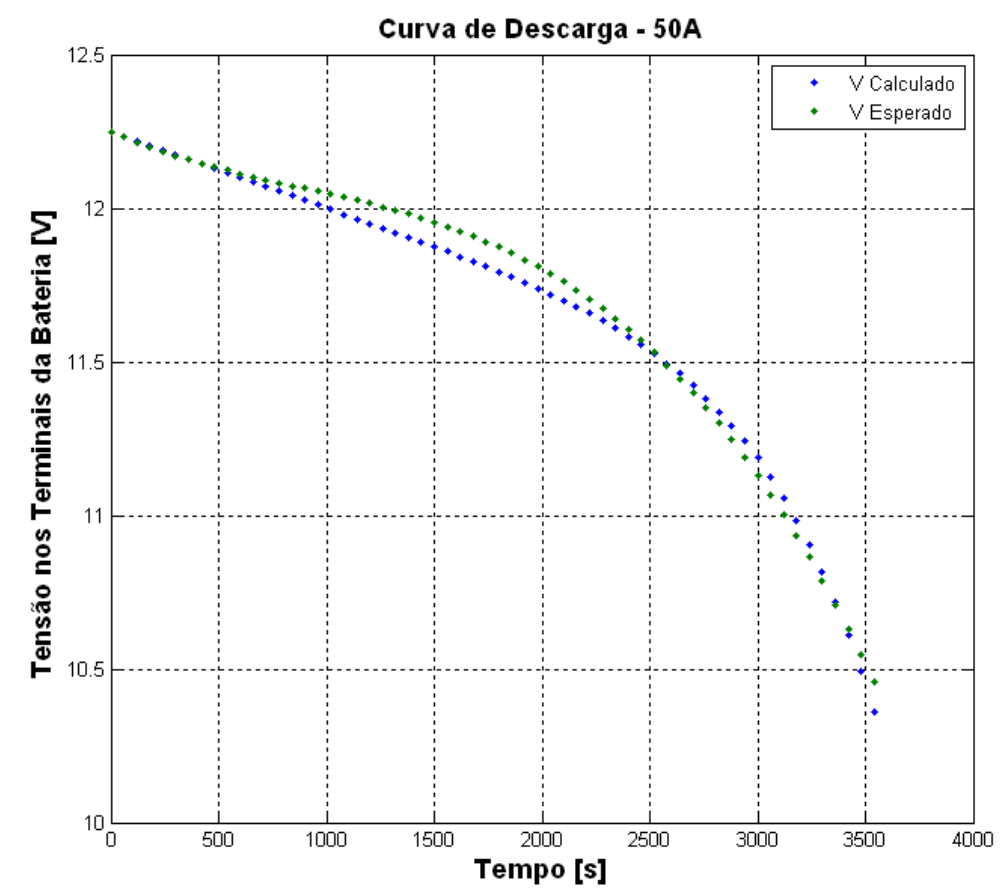

Gráfico 4.9 - Variação da tensão nos terminais da bateria em função do tempo para uma bateria de chumbo-ácido submetida ao processo de descarga constante $50 \mathrm{~A}$ - Comparação entre valor calculado pela metodologia descrita na subseção 4.4 e valor medido experimentalmente. 


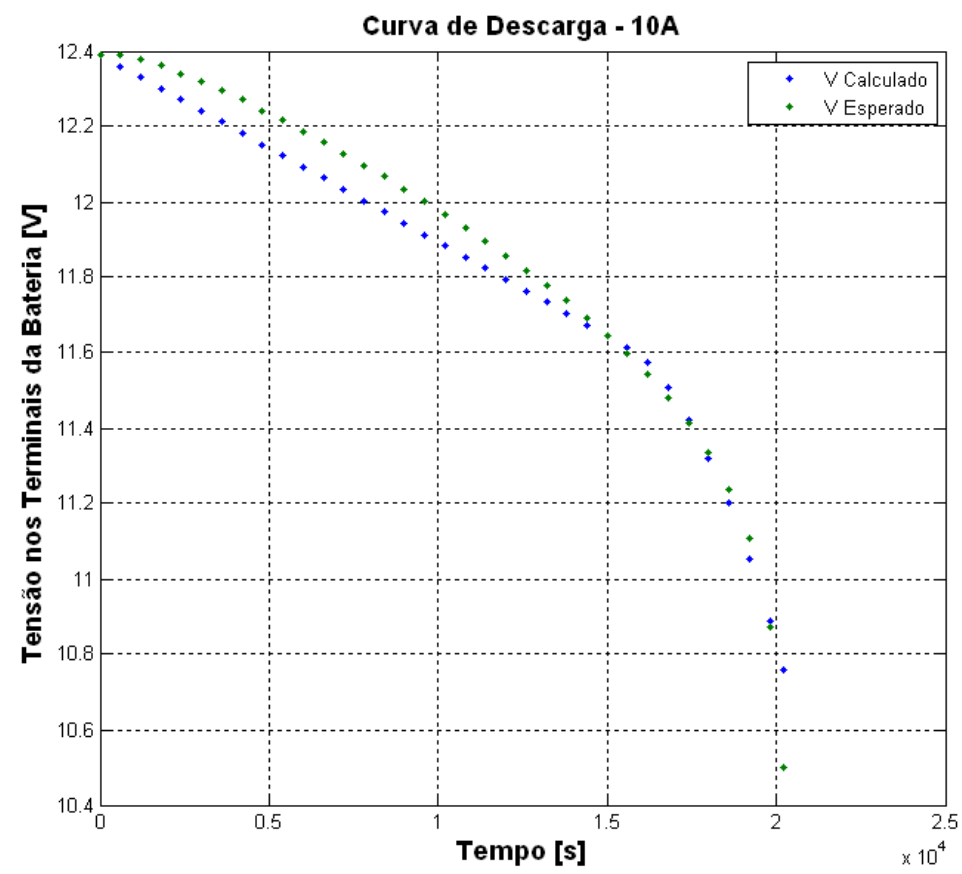

Gráfico 4.10 - Variação da tensão nos terminais da bateria em função do tempo para uma bateria de chumbo-ácido submetida ao processo de descarga constante $10 \mathrm{~A}$ - Comparação entre valor calculado pela metodologia descrita na subseção 4.4 e valor medido experimentalmente.

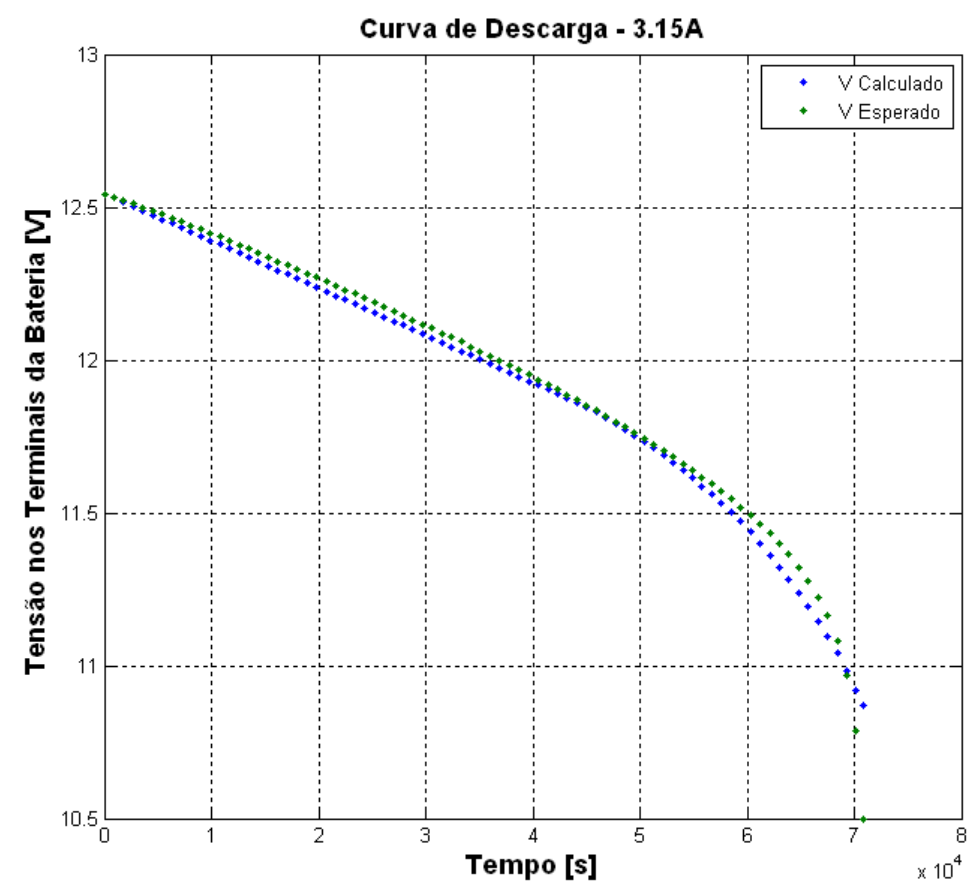

Gráfico 4.11 - Variação da tensão nos terminais da bateria em função do tempo para uma bateria de chumbo-ácido submetida ao processo de descarga constante $3,15 \mathrm{~A}$ - Comparação entre valor calculado pela metodologia descrita na subseção 4.4 e valor medido experimentalmente. 
Nos gráficos 4.8 a 4.11 nota-se que a metodologia para a resolução da equação da bateria apresentou bons resultados visto que o desvio entre as curvas teóricas e experimentais são pequenos. Isso mostra o bom potencial da metodologia adotada e que as simplificações feitas no modelo, conforme explicado na subseção 4.2, foram adequadas para a modelagem da descarga da bateria. Nota-se também que o valor do erro ficou abaixo de $1 \%$ para os quatro valores de descarga apresentados. Apesar de não ter sido fixado um valor limite esperado para o erro, os valores encontrados atenderam a expectativa que era de obter curvas teóricas e experimentais similares.

\subsubsection{Variação dos parâmetros do modelo da bateria em função da corrente de descarga}

Usando os valores obtidos para cada parâmetro do conjunto $\left[\begin{array}{lllll}A_{0} & R_{10} & \tau_{1} & k\end{array}\right]$ e também para o parâmetro $R_{00}$, é possível estimar como esses parâmetros variam em função da corrente de descarga $i_{2}$. O objetivo de conhecer essa variação é para tornar possível a obtenção dos parâmetros para qualquer outro valor de corrente de descarga, para os quais não se tem disponível a curva de descarga obtida a partir de dados experimentais e, conseqüentemente, para os quais não será possível a aplicação da metodologia para a resolução da equação da bateria conforme figura 4.11. Os gráficos 4.12 a 4.16 mostram essa variação e a equação da curva que mais se aproxima. 


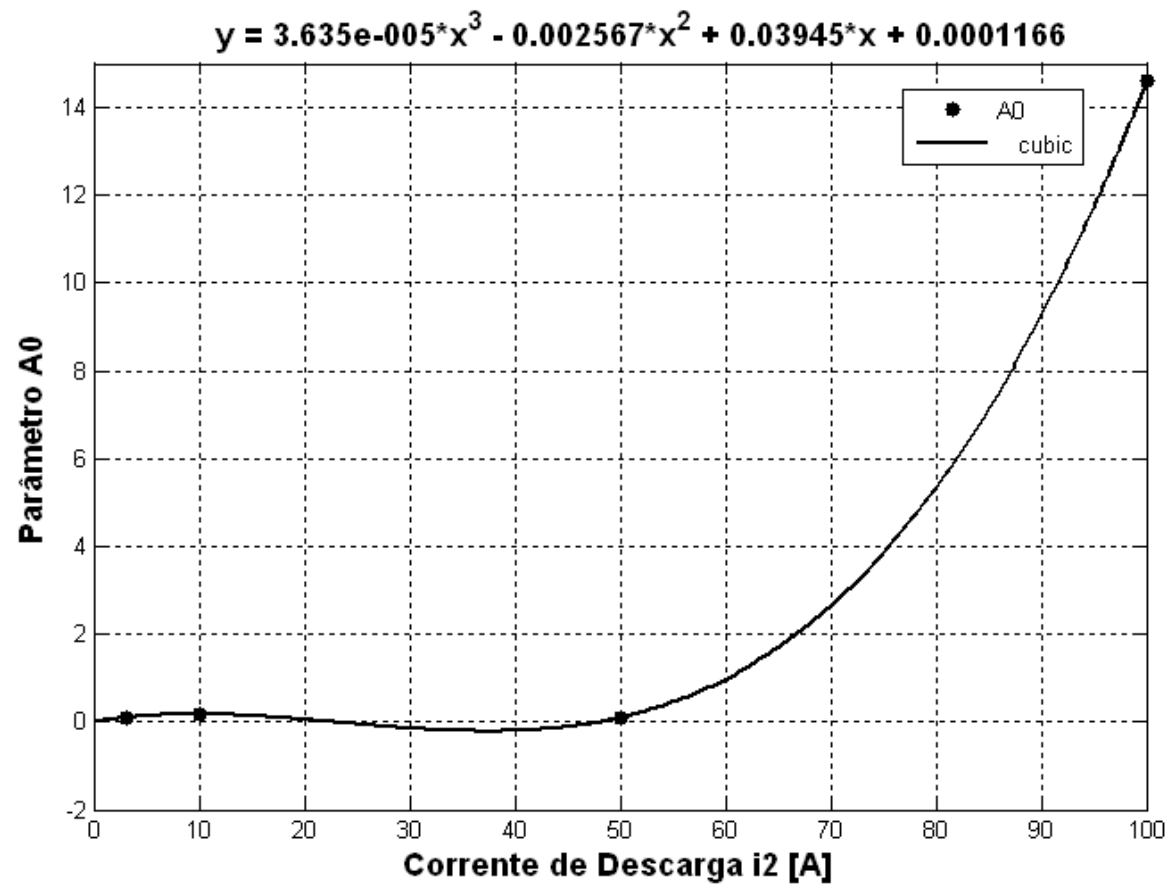

Gráfico 4.12 - Variação do parâmetro $A_{0}$ em função da corrente de descarga $i_{2}$ com curva de aproximação cúbica.

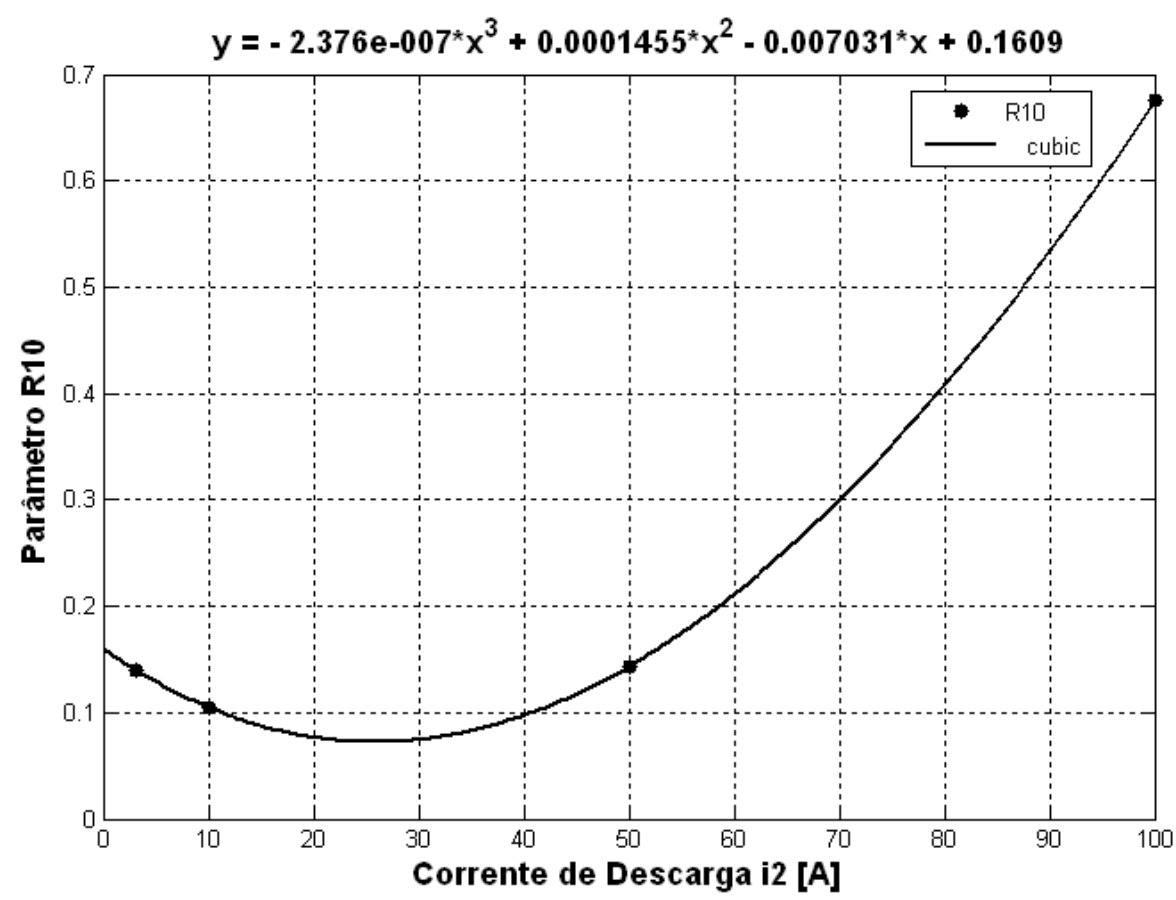

Gráfico 4.13 - Variação do parâmetro $R_{10}$ em função da corrente de descarga $i_{2}$ com curva de aproximação cúbica. 


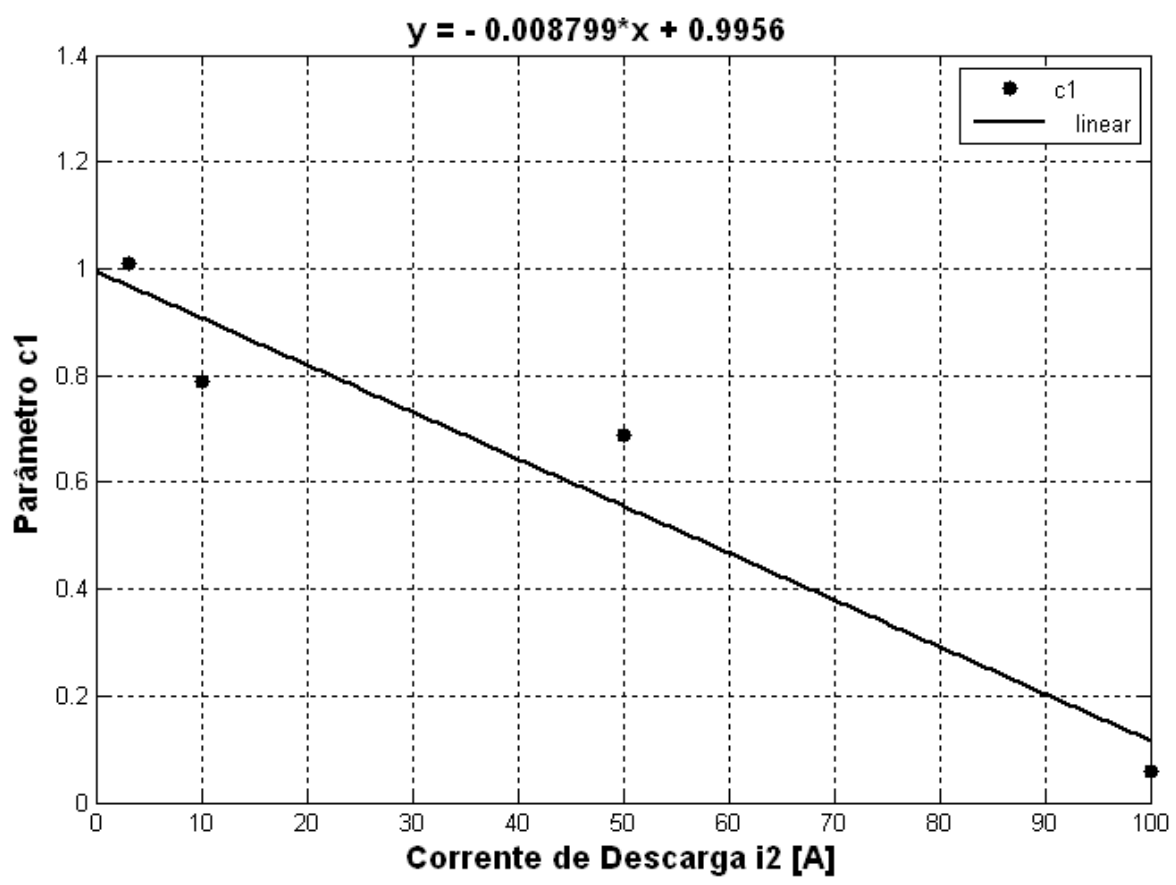

Gráfico 4.14 - Variação do parâmetro $\tau_{1}$ em função da corrente de descarga $\dot{i}_{2}$ com curva de aproximação linear.

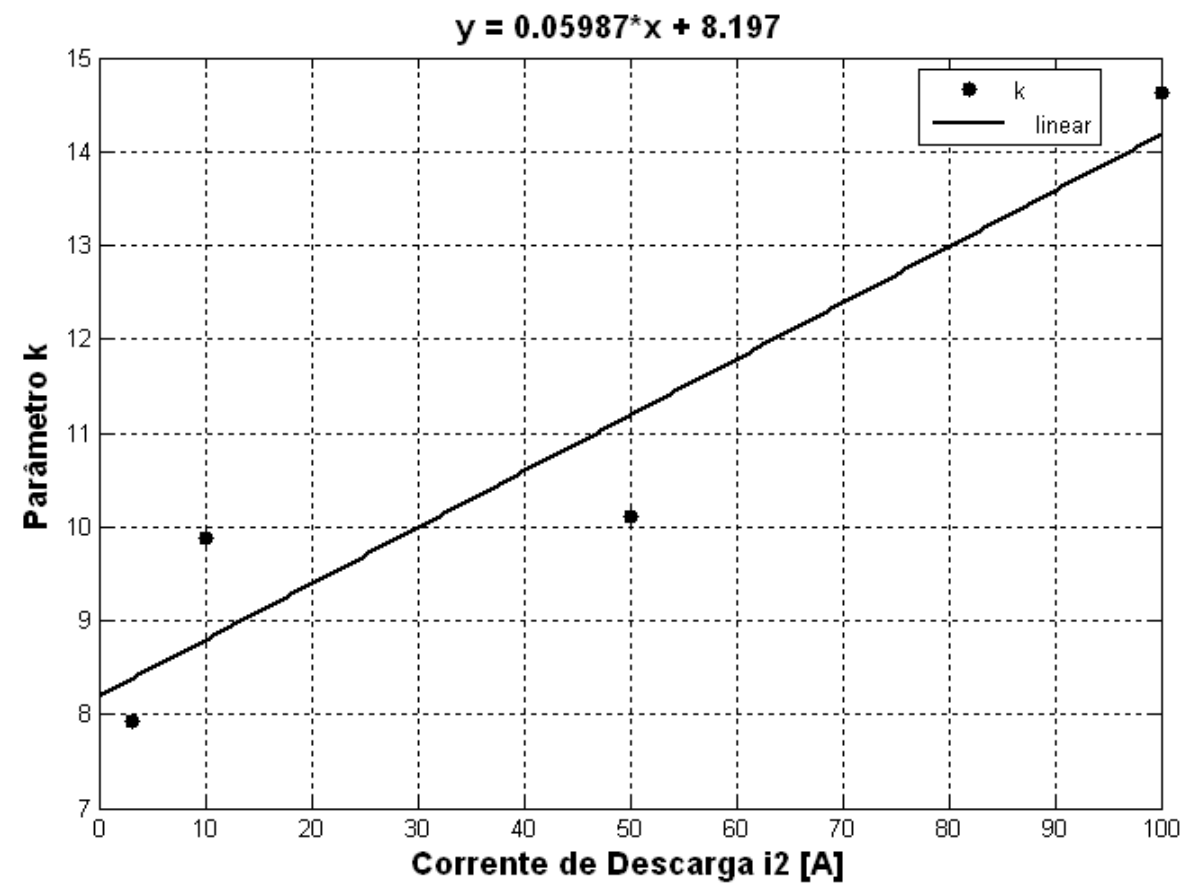

Gráfico 4.15 - Variação do parâmetro $k$ em função da corrente de descarga $i_{2}$ com curva de aproximação linear. 


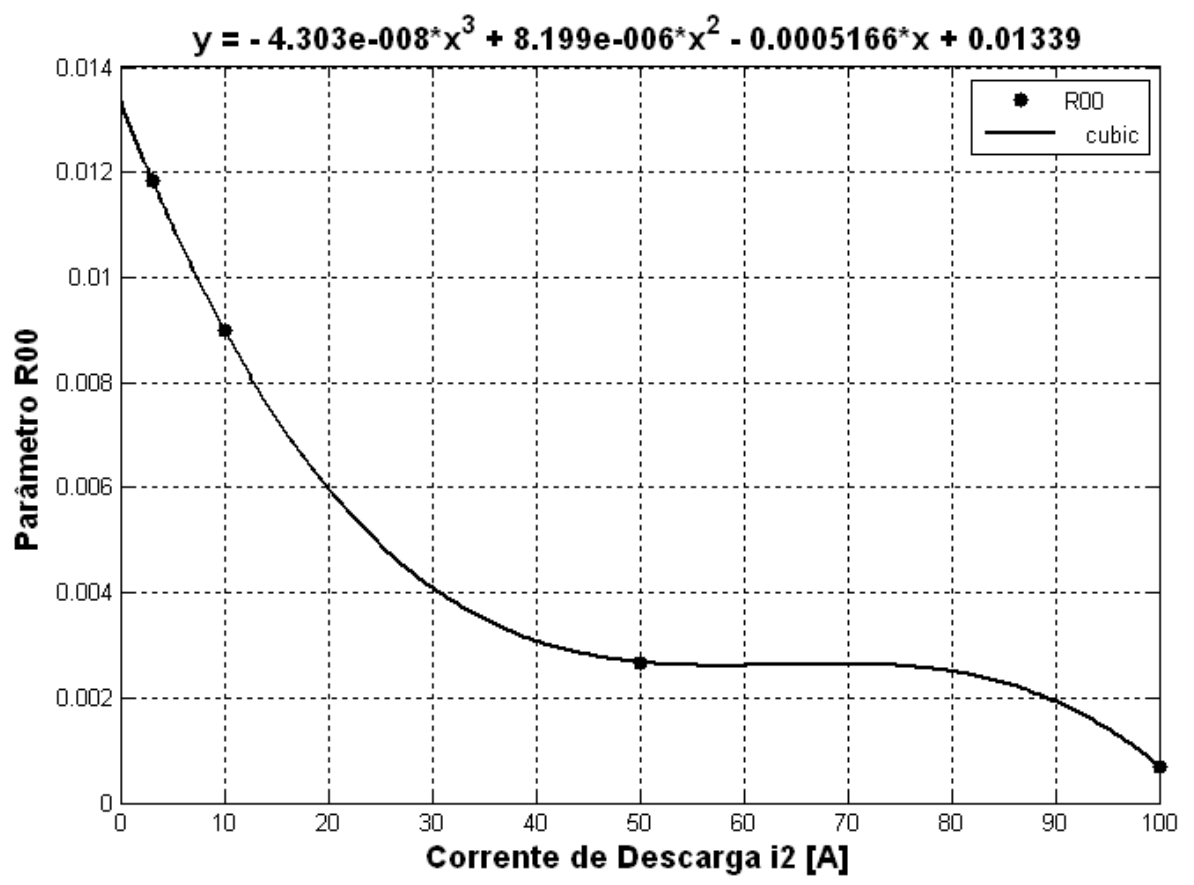

Gráfico 4.16 - Variação do parâmetro $R_{00}$ em função da corrente de descarga $i_{2}$ com curva de aproximação cúbica.

Por conta da limitação no número de curvas de descarga experimentais, foram utilizadas apenas quatro curvas, foi utilizada a aproximação cúbica para os parâmetros $\left[\begin{array}{lll}A_{0} & R_{10} & R_{00}\end{array}\right]$ mesmo sabendo que seria uma aproximação ótima. Já para os parâmetros $\left[\begin{array}{ll}\tau_{1} & k\end{array}\right]$ a aproximação linear foi escolhida como a mais adequada considerando a disposição dos valores dos parâmetros para cada valor de corrente utilizado.

\subsubsection{Exemplo de utilização do modelo da bateria}

O modelo da bateria de 63Ah, apresentado e estimado nas subseções 4.2 à 4.5.1, será aplicado a título de exemplo, conforme metodologia ilustrada na figura 4.15. 


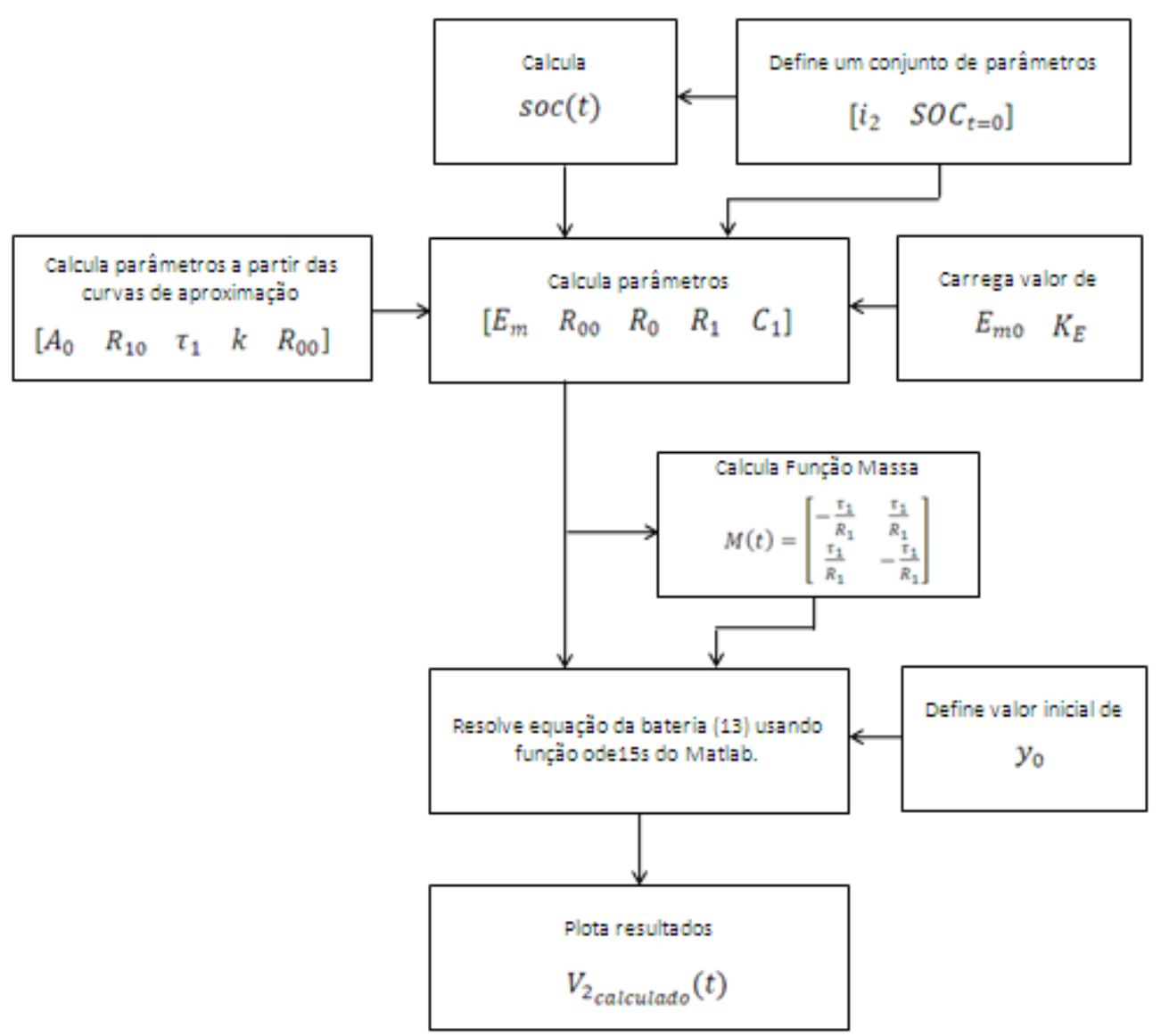

Figura 4.16 - Fluxo da metodologia para a resolução da equação da bateria para um valor de corrente de descarga qualquer.

Usando essa metodologia, a curva de tensão nos terminais da bateria em função do tempo pode ser calculada para um dado valor de corrente de descarga $i_{2}$. Como exemplo, a curvas de descarga para 15A, 20A, 30A, 60A e 70A foram calculadas e ilustradas nos gráficos 4.17 e 4.18. Como não estão disponíveis as curvas de descarga experimentais para esses valores de corrente, não é possível comparar o valor calculado com o valor esperado, a partir dos dados experimentais. Por isso, foram adicionadas as curvas de 10A, 50A e 100A nos gráficos 4.17 e 4.18 apenas para mostrar que os valores calculados encontram-se dentro da escala e do formato esperados. 


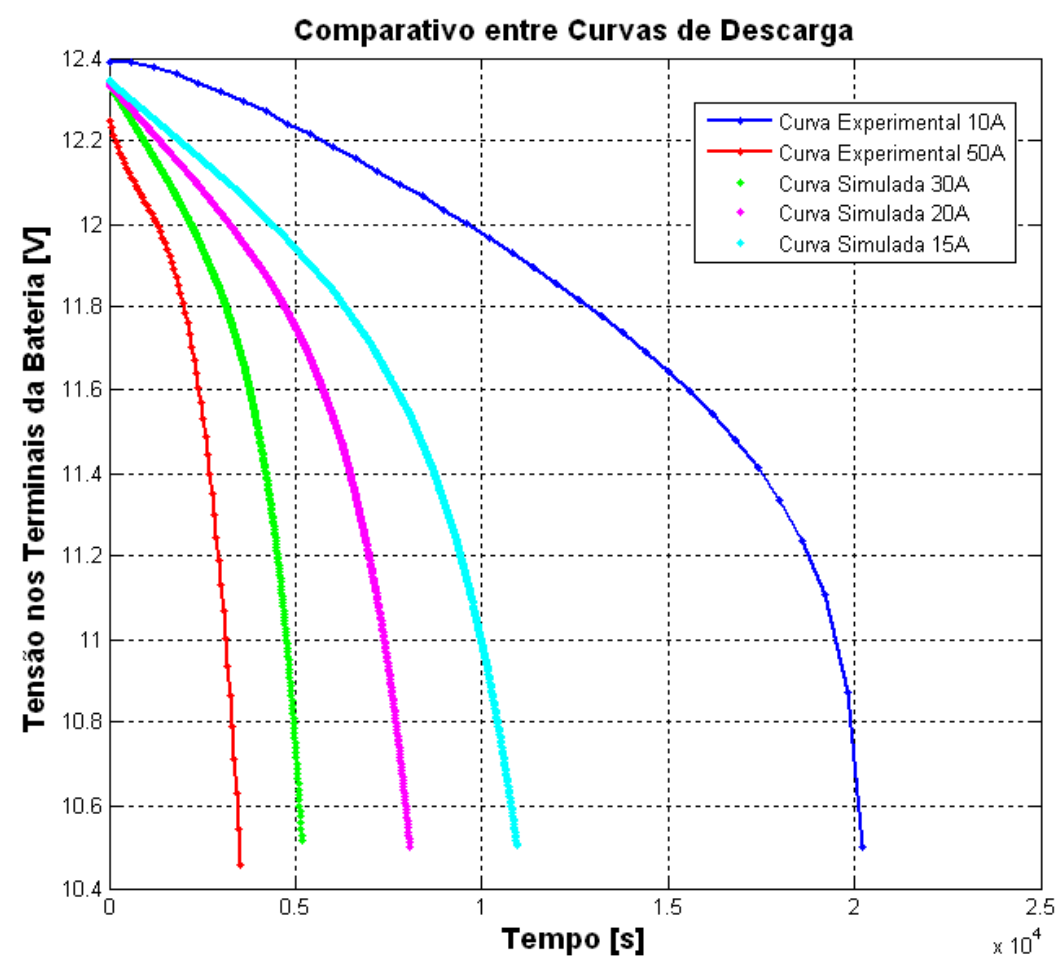

Gráfico 4.17 - Comparativo entre curvas de descarga experimentais de 10A e 50A e curvas de descarga calculadas de 15A, 20A e 30A.

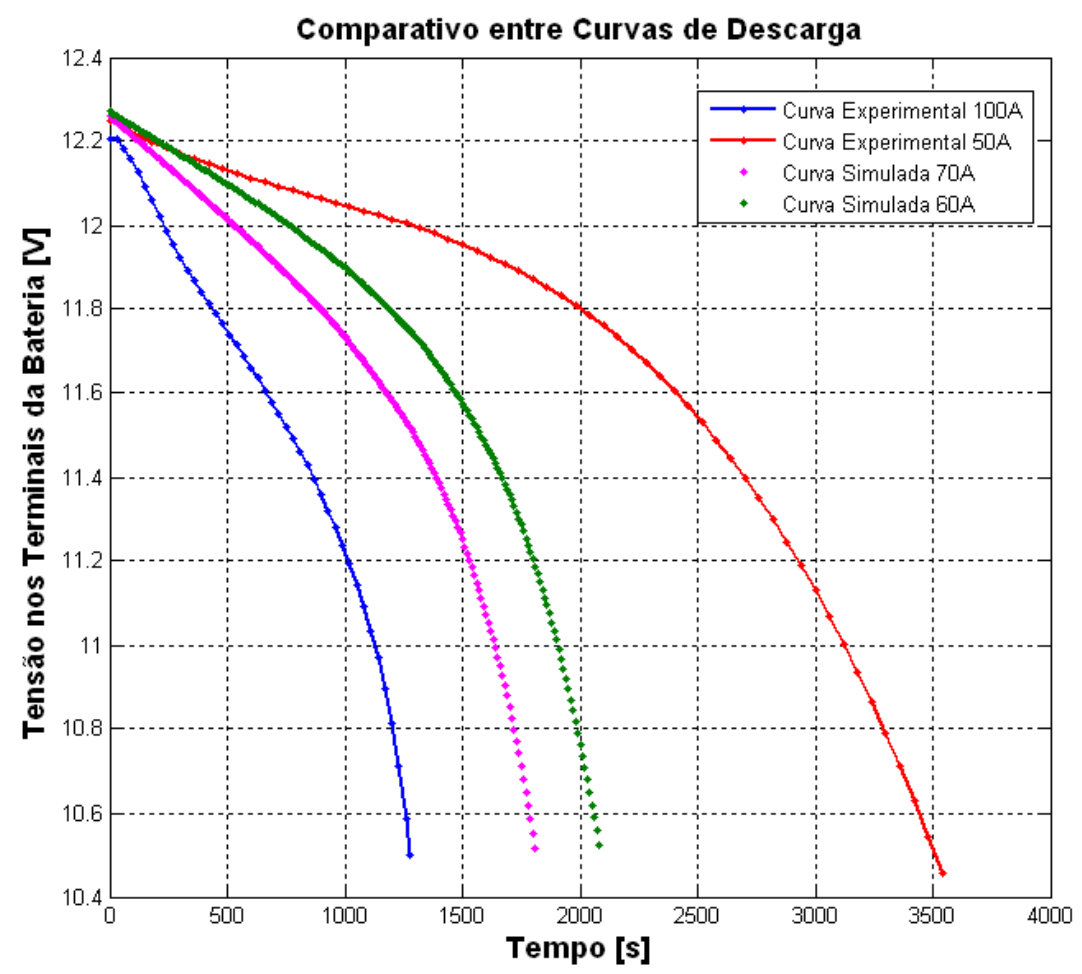

Gráfico 4.18 - Comparativo entre curvas de descarga experimentais de 50A e 100A e curvas de descarga calculadas de 60A e 70A. 
As curvas mostradas nos gráficos 4.17 e 4.18 mostram, do ponto de vista qualitativo, que é possível a obtenção das curvas de descarga para valores de corrente préestabelecidas. 


\section{Conclusão}

A motivação para a execução desse trabalho, que foi a proposta de um método de simulação para o teste de Cold Crank, foi bastante desafiadora e ousada dada a complexidade do tema e a quantidade limitada de trabalhos já publicados sobre o assunto, que apresentem detalhes de como o processo de simulação foi elaborado. $\mathrm{Na}$ fase de qualificação do trabalho, foi apresentada uma proposta de modelo de bateria e também uma proposta de modelo de motor de partida, com o intuito de transformar a motivação do trabalho em seu objetivo final. Entretanto, a proposta precisou ser dividida em partes menores e menos complexas para possibilitar sua execução. Essa redução permitiu um aprimoramento no modelo de bateria porém fez com que o modelo do motor de partida fosse abandonado, podendo é claro ser retomado na continuação desse tema.

O objetivo dessa primeira parte, que foi o estudo do modelo matemático da bateria, foi alcançado apesar das dificuldades encontradas, que foram:

- a quantidade limitada de curvas de descarga experimentais, que prejudicou no levantamento da curva de aproximação da variação dos parâmetros em função da corrente de descarga;

- a falta de conhecimento prévio sobre os limites mínimo e máximo dos parâmetros, que fez com que a metodologia para a resolução da equação da bateria fosse aplicada muitas vezes para descobrir os limites mais apropriados;

- a falta de conhecimento prévio sobre o método de otimização mais adequado para o problema, que também fez com que a metodologia para a resolução da equação da bateria fosse aplicada muitas vezes para descobrir o método mais adequado.

A pesquisa bibliográfica sobre a bateria permitiu um maior conhecimento sobre 0 componente e suas características. $O$ estudo dos diversos modelos matemáticos mostrou que o uso de um modelo relativamente simples é suficiente para representar a dinâmica de funcionamento da bateria durante o processo de 
descarga. Usando apenas dois resistores, um capacitor e uma fonte de tensão, foi possível representar esse componente sem a necessidade de aprofundar numa análise físico-química, facilitando assim o trabalho de modelagem para o engenheiro eletricista e para os demais estudiosos e profissionais que não possuem formação acadêmica na área de Química.

A idéia do uso da curva OCV $\times$ SOC foi bastante importante para a evolução do trabalho. E tem como vantagem ser uma informação cotidiana fornecida pelo fabricante de baterias para empresas do ramo automotivo e de uso comum entre os engenheiros de produto que definem a especificação da bateria necessária em cada aplicação.

Os resultados finais mostraram que as simplificações feitas no modelo de bateria usado como base (modelo de Jackey) foram corretas. Bem como a consideração do instante inicial para o cálculo da resistência $R_{00}$ foi uma importante definição para reduzir o número de parâmetros desconhecidos.

O software Matlab® contribuiu substancialmente uma vez que ofereceu as ferramentas apropriadas para a resolução da equação diferencial e para a otimização do melhor conjunto de parâmetros, de forma simples e funcional.

Adicionalmente, a pesquisa bibliográfica sobre o motor de partida, que é o outro principal componente do sistema de partida, e sobre o motor a combustão, que é a carga do sistema, foi iniciada para facilitar trabalhos futuros sobre o tema. Informações como princípio de funcionamento e principais propriedades estão disponíveis no apêndice A para futuras consultas.

\subsection{Sugestões de trabalhos futuros}

Para se ter uma melhor estimativa da variação dos parâmetros $\left[\begin{array}{llll}A_{0} & R_{10} & \tau_{1} & k\end{array}\right]$ e $R_{00}$, recomenda-se os seguintes estudos adicionais, que podem ser realizados por futuros interessados no tema: 
1) Aplicação da metodologia para a resolução da equação da bateria usando-se curvas de descarga experimentais usando correntes da ordem de centenas de ampères.

2) Aplicação da metodologia para a resolução da equação da bateria usando-se curvas de descarga experimentais levantadas sob temperaturas ambientes negativas (de $-10^{\circ} \mathrm{C}$ a $-30^{\circ} \mathrm{C}$ ).

3) Estudo da influência do envelhecimento da bateria na definição dos parâmetros.

Para dar continuidade à proposta de simulação do teste de Cold Crank, recomendase que as partes já definidas na descrição dos objetivos desse trabalho e listadas abaixo sejam pesquisadas por futuros interessados no tema:

1. Estudo do modelo do motor de partida;

2. Estudo do modelo do motor a combustão;

3. União dos modelos de forma a representar a dinâmica de funcionamento do sistema de partida juntamente com a carga, que é o motor a combustão;

4. Validação do modelo através da comparação com resultados obtidos de experimentos práticos. 
REFERÊNCIAS BIBLIOGRÁFICAS

(Battery Space) Battery Space. Lead Acid Batteries. Disponível em: $<$ http://www.batteryspace.com/leadacidbatteries.aspx>. Acesso em 18.out.2010.

(Bocchi; Ferracin; Biaggio, 2000) Bocchi, N.; Ferracin, L. C.; Biaggio, S. R. Pilhas e Baterias: funcionamento e impacto ambiental. Revista Química Nova na Escola, $\quad n . \quad 11,2000 . \quad$ Disponível em $<$ http://qnesc.sbq.org.br/online/qnesc11/v11a01.pdf>. Acesso em 20.jan.2010.

(CADEX, 2003) CADEX ELECTRONICS INC. Battery University. 2003. Disponível em: <http://www.batteryuniversity.com/index.htm>. Acesso em 09.fev.2010.

(Caselitz; Juchem, 1998) Caselitz, P.; Juchem, R. Computer aided design of battery management systems for automobiles - A model for Lead Acid Batteries. SAE no 980309, 1998.

(DELCO REMY BRASIL) DELCO REMY BRASIL. Manual de Treinamento.

(Duval, 1995) Duval, H. Computer model of the lead/acid starter battery in automobiles. Elsevier - Journal of Power Sources, n. 53, p. 351-357, 1995.

(Esfahanian; Torabi; Mosahebi, 2008) Esfahanian, V.; Torabi, F.; Mosahebi, A. An innovative computation algorithm for simulation of lead-acid batteries. Elsevier - Journal of Power Sources, n. 176, p. 373-380, 2008.

(GENERAL MOTORS, 1998) GENERAL MOTORS. GMI-L-6-3: Cold Crank and Cranking Tests on Spark Ignition Engines. São Paulo, 1998. 17 p.

(GUO, 2010) Guo, S. The application of genetic algorithms to parameter estimation in lead-acid battery equivalent circuit models. 2010. $137 \mathrm{p}$. Dissertação (Mestrado) - School of Electronic, Electrical \& Computer Engineering, University of Birmingham, Birmingham, 2010. 
(Jackey, 2007) Jackey, R. A. A simple, effective lead-acid battery modeling process for electrical system component selection. SAE $n \div$ 2007-01-0778, 2007.

(Johnston, 1996) Johnston, R. H. A history of automobile electrical systems. Automotive Engineering Magazine, 1996.

(Kiehne, 2000) Kiehne, H.A. Battery technology handbook. ISBN 0-8247-42494, 2000.

(Kreith; Goswami, 2005) Kreith, F.; Goswami, D. Y. The CRC Handbook of Mechanical Engineering. $2^{\text {nd }}$ ed. CRC Press, 2005.

(Linden, 2002) Linden, D.; Reddy, T.B. Handbook of Batteries. $3^{\text {rd }}$ ed., McGrawHill, 2002.

(Martins, 1999) Martins, R. A. Alessandro Volta e a invenção da pilha: dificuldades no estabelecimento da identidade entre o galvanismo e a eletricidade. ISSN 1415-6814, 1999.

(MATLAB, 2008) MatLab® R2008b versão 7.7.0.471 - Documentação de Ajuda.

(PETROBRAS, 2009) PETROBRAS. Lubrificantes Automotivos. Disponível em: <http://www.br.com.br/wps/portal/PortalDeConteudo $>$. Acesso em 15.set.2009.

(BOSCH, 1988) ROBERT BOSCH. Automotive Electric-Electronic Systems. $1^{\text {st }}$ ed. SAE, 1988.

(BOSCH, 2005) ROBERT BOSCH. MANUAL de Tecnologia Automotiva. Tradução de Helga Madjderey, Gunter W. Prokesch, Euryale de Jesus Zerbini, Suely Pfeferman. 25 ${ }^{\text {th }}$ ed. São Paulo: Edgard Blücher, 2005.

(BOSCH, 2007) ROBERT BOSCH. Manual de Baterias. 2007. Disponível em: $<$ http://www.bosch.com.br/br/autopecas/produtos/baterias/downloads/Manual de Baterias Bosch 6008 FP1728 04 2007.pdf>. Acesso em 31.jan.2010.

(Schintag; Reimann; Krüger, 2001) Schintag, P.; Reimann, W.; Krüger, I. Battery Simulation. SAE nำ 2001-01-0776, 2001. 
(Xiao; Shi; He, 2010) Xiao, B.; Shi, Y.; He, L. A Universal State-of-Charge Algorithm for Batteries. In: Design Automation Conference (DAC), 47., 2010, Califórnia, Estados Unidos. ISSN 0738-100X, p. 687-692. Disponível em: $<$ http://ieeexplore.ieee.org/search/freesrchabstract.jsp?tp=\&arnumber $=5523225 \&$ queryText\%3Da+universal+state+of+charge+algorithm+for+batteries\%26opened Refinements\%3D*\%26searchField\%3DSearch+All>. Acesso em 04.ago.2010.

(Zhong; Henein; Bryzik, 2007) Zhong, L.; Henein, N. A.; Bryzik, W. Simulation of diesel engines cold-start. SAE n² 2007-01-0933, 2007. 


\section{APÊNDICE A - ANÁLISE DAS PRINCIPAIS CARACTERÍSTICAS DOS DO MOTOR A COMBUSTÃO E MOTOR DE PARTIDA}

\section{1 - Motor a combustão}

O motor de combustão interna (IC - Internal Combustion - Combustão Interna) é a fonte de energia usada com mais freqüência para veículos automotivos. Eles geram energia a partir da conversão de energia química em energia mecânica. Essa conversão ocorre em duas etapas. Na primeira etapa o calor é gerado a partir da combustão de um líquido que precisa de oxigênio para realizar a queima. $\mathrm{Na}$ segunda etapa o calor aumenta a pressão de um meio, através de compressão, que gera trabalho enquanto é expandido (BOSCH, 2005).

O líquido usado, combustível, é normalmente da família dos hidrocarbonetos e 0 oxigênio usado é obtido do ar de admissão do motor. Quando essa conversão de energia ocorre dentro de um cilindro fechado, o processo é chamado de combustão interna. O próprio gás gerado a partir da combustão do líquido (combustível) é usado como meio que realiza o trabalho. Quando a conversão ocorre fora desse cilindro, o processo é chamado de combustão externa (BOSCH, 2005).

Para garantir o trabalho mecânico contínuo, esse processo deve ser cíclico e o gás deve expandir e retornar à sua condição inicial (ciclo de combustão). Na combustão externa, o processo é fechado porque o gás consegue voltar à sua condição inicial. $\mathrm{Na}$ combustão interna, o gás é alterado durante sua expansão e seu retorno à condição inicial não é possível. Para dar continuidade ao ciclo, será preciso eliminar o gás e adicionar uma nova quantidade de combustível para a queima. Por isso é chamado de ciclo aberto, pois precisa de troca de carga $(\mathrm{BOSCH}, 2005)$.

A mistura de ar+combustível pode ser formada fora da câmara de combustão. Nesse caso, ela será bastante homogênea quando a combustão for iniciada. Caso o 
combustível seja introduzido diretamente na câmara de combustão, a mistura ar+combustível será realizada dentro da câmara e será heterogênea (BOSCH, 2005).

A ignição para iniciar a combustão pode ser externa, a partir de uma centelha elétrica, chamada de Spark Ignition (Ignição por Faísca), ou pode ocorrer através da auto-ignição, situação na qual a mistura ar+combustível se inflama à medida que se aquece durante sua compressão, chamada Compression Ignition (Ignição por Compressão) usada em motores diesel. A taxa de compressão dos motores do tipo Compression Ignition é muito maior do que a taxa dos motores Spark Ignition, para que a alta temperatura requerida na auto-ignição seja atingida (Kreith; Goswami, 2005).

A segunda etapa do processo de conversão de energia, aumento da pressão do gás a partir do calor gerado pela combustão, pode ser realizada, idealmente, seguinte um dos seguintes ciclos termodinâmicos (Kreith; Goswami, 2005):

- Ciclo Otto (adição de calor através de volume constante): modela o funcionamento de um motor Spark Ignition.

- Ciclo Diesel (adição de calor através de pressão constante): modela o funcionamento de um motor Compression Ignition.

O ciclo Otto apresenta as seguintes etapas: $1 \rightarrow 2$ : compressão isentrópica ${ }^{2} ; 2 \rightarrow 3: 0$ calor é adicionado a volume constante; $3 \rightarrow 4$ : expansão isentrópica; $4 \rightarrow 1$ : rejeição de calor a volume constante. A figura 1.1 (extraído de Kreith; Goswami, 2005) apresenta o diagrama pressão - volume que representa essas etapas.

\footnotetext{
${ }^{2}$ Transformação isentrópica significa que a entropia do sistema permanece constante, ou seja, o equilíbrio termodinâmico permanece constante (sem acréscimo ou dissipação de calor e sem atrito).
} 


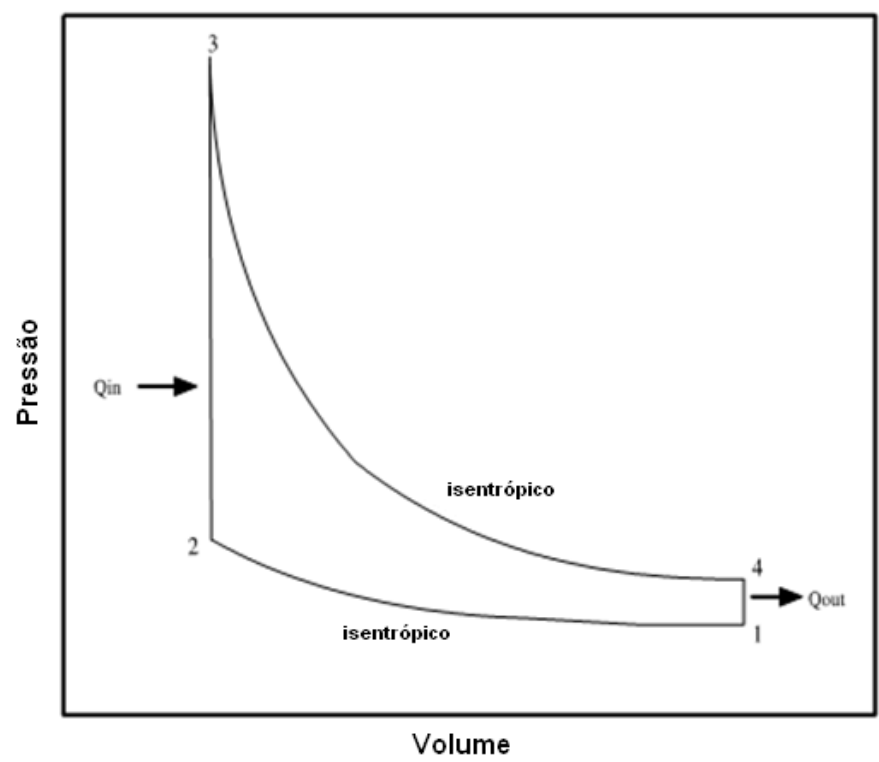

Figura 1.1 - Diagrama pressão-volume de um ciclo ideal Otto de um motor de combustão interna (extraído de Kreith; Goswami, 2005).

Já o ciclo diesel apresenta as seguintes etapas: $1 \rightarrow 2$ : compressão isentrópica; $2 \rightarrow 3$ : o calor é adicionado a pressão constante; $3 \rightarrow 4$ : expansão isentrópica até o máximo volume; $4 \rightarrow 1$ : rejeição de calor a volume constante. A eficiência térmica (relação entre calor de entrada e trabalho gerado) do ciclo diesel é menor do que o ciclo Otto. A figura 1.2 (extraído de Kreith; Goswami, 2005) apresenta o diagrama pressão volume que representa essas etapas.

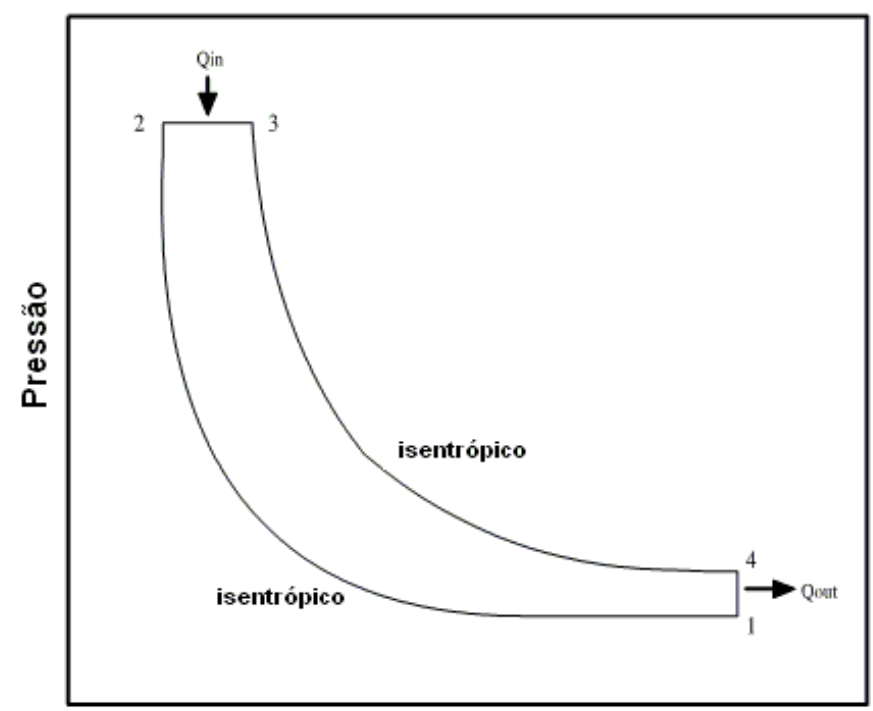

Volume 
Figura 1.2 - Diagrama pressão-volume de um ciclo ideal Diesel de um motor de combustão interna (extraído de Kreith; Goswami, 2005).

Os principais tipos de motor de combustão interna são (BOSCH, 2005):

- Motor com pistão alternativo;

- Motor com pistão rotativo;

- Motor de ignição por centelha;

- Motor diesel;

- Motor híbrido;

Os motores de combustão interna podem ainda serem classificados por uma série de outras características, tais como (Kreith; Goswami, 2005):

- Motor quatro tempos x Motor dois tempos;

- Motor recíproco x Motor rotativo;

- Através do tipo de coletor (aspirated x turbocharged / supercharged);

- Através do número e arranjo dos cilindros;

- Através do método de resfriamento (ar x água);

- Através do sistema de combustível.

\section{2 - Óleo lubrificante para motores}

Os óleos são usados para lubrificar os componentes em movimento entre si. Os tipos mais usados são óleos minerais aditivados, óleos sintéticos e óleos semisintéticos. A qualidade depende da origem, da refinação do óleo base e da aditivação. Os aditivos são classificados de acordo com sua função que pode ser melhorar a viscosidade, melhorar o ponto de solidificação, inibir a oxidação e corrosão, reduzir emissões, reduzir formação de depósitos, entre outras (BOSCH, 2005).

Os principais critérios para a homologação de um óleo são conteúdo de cinzas de sulfetos, conteúdo de zinco, efeito protetor contra desgaste, capacidade de limpeza e de remoção de sujeiras e compatibilidade com juntas (BOSCH, 2005). 
A classificação pode ser feita segundo uma das normas abaixo (PETROBRAS, 2009):

- SAE (Society of Automotive Engineers - Sociedade de Engenheiros Automotivos): classificação mais antiga que define faixas de viscosidade, não considera os requisitos de desempenho e é a mais popular conhecida no Brasil.

- API (American Petroleum Institute - Instituto Americano de Petróleo): define os grupos de desempenho que os óleos devem atender.

- Classe S - Serviços (para motores Otto): SF, SG, SH, SJ, SL;

- Classe C - Comercial (para motores Diesel): CC, CD, CD, CF, CG-4, $\mathrm{CH}-4$.

- ACEA (Association des Constructeurs Européens de l'Automobile Associação dos Fabricantes Europeus de Automóveis): classificação européia que associa testes da API, ensaios de fornecedores europeus e ensaios de laboratório.

- NMMA (National Marine Manufacturers Association - Associação Nacional dos Fabricantes Navais): classifica os óleos lubrificantes usados em embarcações marítimas de forma geral.

- JASO (Japanese Automobile Standards Organization - Organização Japonesa de Normas Automotivas): classifica os óleos lubrificantes para motores a dois tempos.

Conforme a SAE, os óleos são classificados em, conforme ilustra gráfico 1.1 (BOSCH, 2005):

- Óleos de verão: SAE 30, 40, 50, etc.

- Óleos de inverno (W = winter = inverno): SAE 10W, 5W, 0W, etc.

- Óleos multi-viscosos (inverno e verão): SAE 10W-60, 5W-30, etc. 


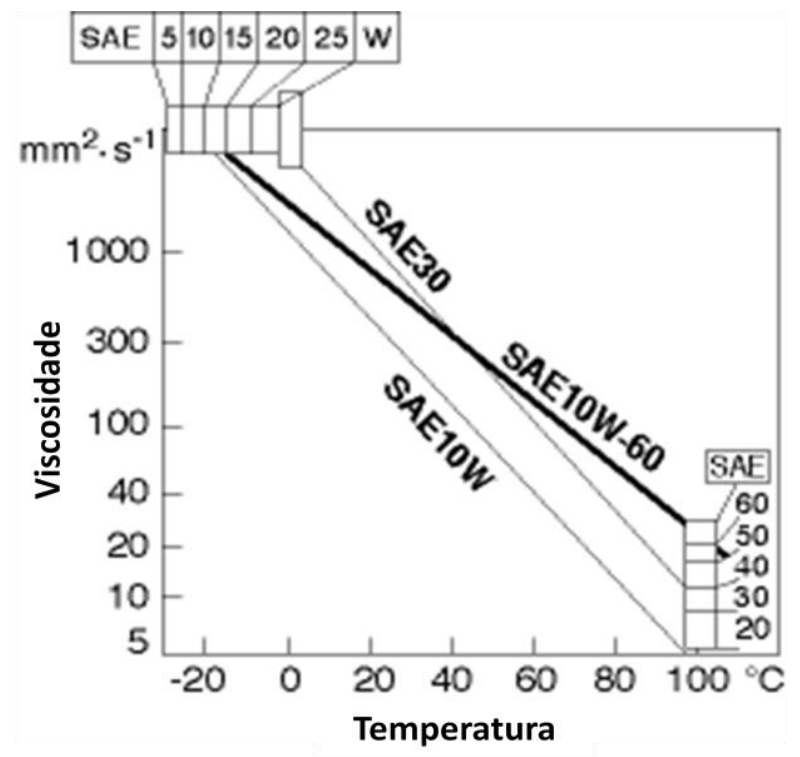

Gráfico 1.1 - Variação da viscosidade em função da temperatura dos óleos lubrificantes classificados segundo a norma SAE (extraído de BOSCH, 2005).

\section{2 - Motor de partida}

O motor de partida, também conhecido como motor de arranque, é utilizado para ajudar o motor à combustão a vencer as resistências ao início de seu funcionamento. São elas: torque resultante da compressão, atrito dos pistões e atrito dos mancais. A função do motor de partida é dar o impulso inicial ao motor, durante a combustão inicial, através de uma velocidade mínima de rotação de seu eixo até que o próprio motor consiga sustentar seu funcionamento $(\mathrm{BOSCH}, 1988)$.

A rotação mínima requerida depende das características do motor a combustão (tipo de motor, número de cilindros, taxa de compressão, atrito dos mancais, tipo de óleo lubrificante que está sendo utilizado, etc.) e da temperatura ambiente (BOSCH, 1988).

Os motores elétricos (CC, AC ou Trifásico), hidráulicos e pneumáticos podem ser usados como motores de partida e devem atender aos seguintes requisitos (BOSCH, 1988):

- Estar sempre pronto para funcionar; 
- Potência de partida suficiente a diferentes temperaturas;

- Vida útil longa para resistir a um alto número de partidas;

- Projeto robusto para suportar vibração, corrosão, ciclos de temperatura, sujeira, etc.

- Ser leve e de tamanho reduzido;

- Livre de manutenção ou com manutenções obrigatórias distantes umas das outras.

O motor de partida elétrico $\mathrm{CC}$ é composto por três partes principais, ilustradas na figura 2.1 (extraído de $\mathrm{BOSCH}, 1988$ ):

1. Motor elétrico;

2. Chave solenóide;

3. Unidade de engate do pinhão.

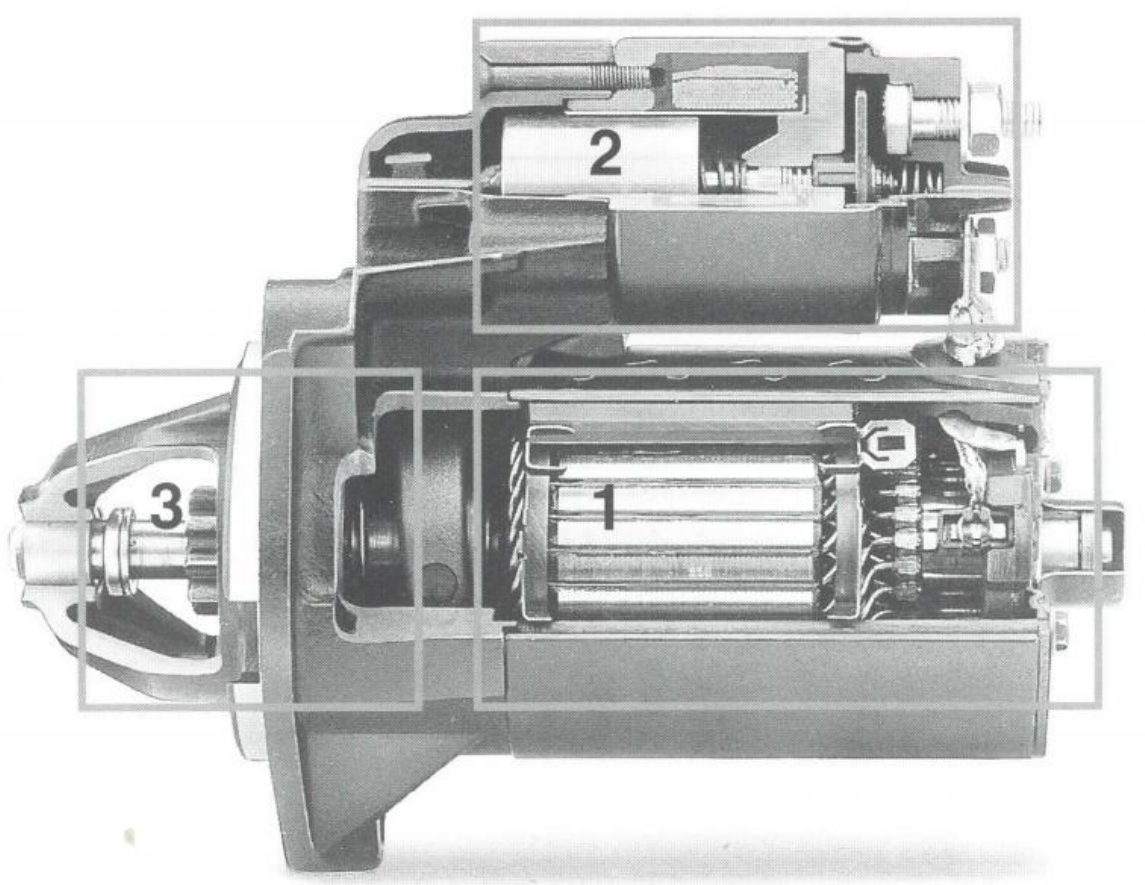

Figura 2.1 - Sub-componentes de um motor de partida elétrico CC: 1 - motor elétrico, 2 chave solenóide, 3 - unidade de engate do pinhão (extraído de $\mathrm{BOSCH}, 1988$ ).

A função do motor elétrico é converter a corrente elétrica em movimento de rotação.

É composto pelo induzido (ou armadura), enrolamento de campo, escovas e comutador, conforme ilustra a figura 2.2 (extraído de $\mathrm{BOSCH}, 1988$ ). 


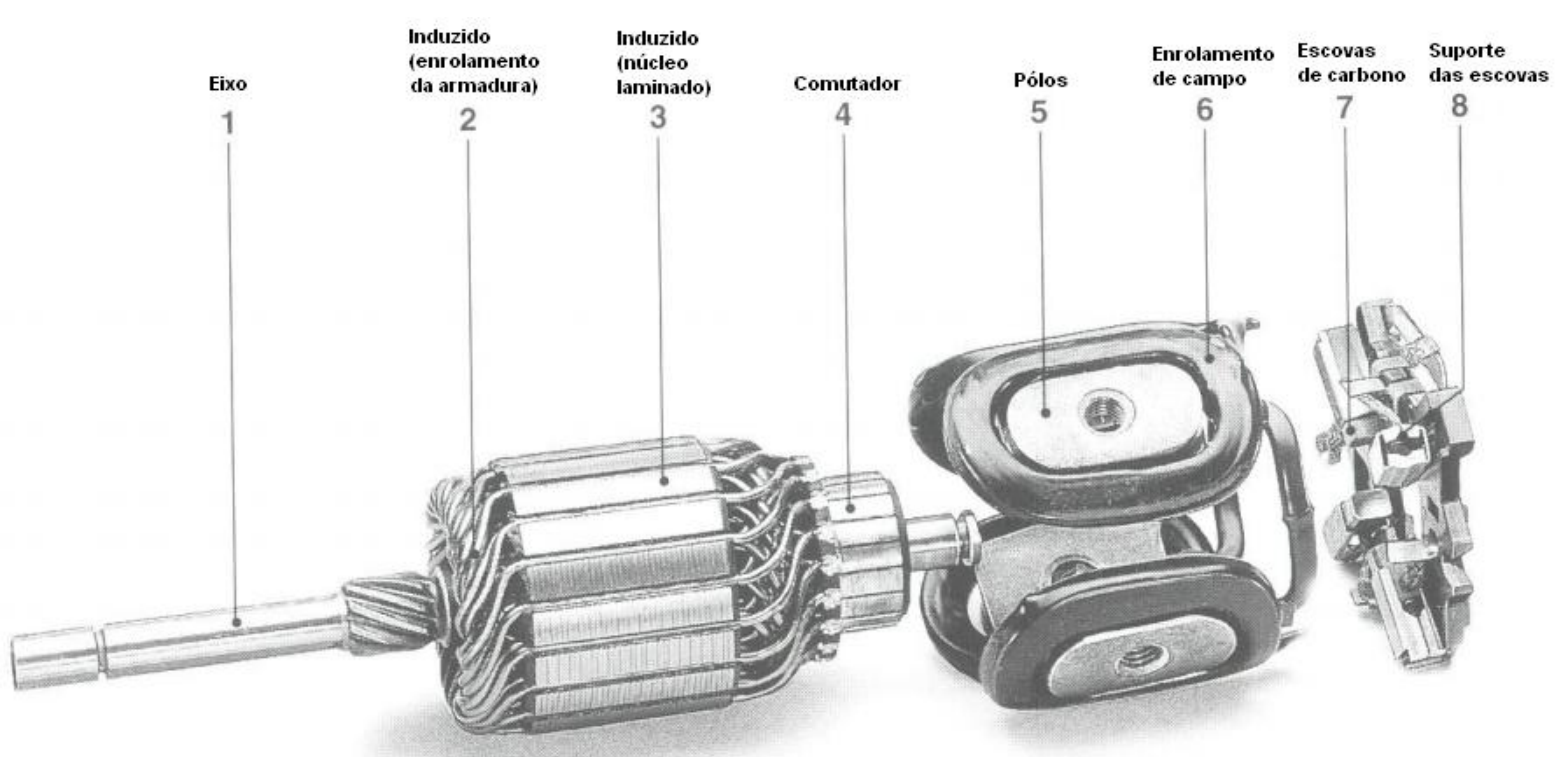

Figura 2.2 - Sub-componentes de um motor elétrico de um motor de partida elétrico CC (extraído de BOSCH, 1988).

O enrolamento de campo produz o campo magnético através de um ímã permanente ou através de um eletroímã. A forma como é conectado ao induzido determina se o motor é série, paralelo ou composto, ilustrado na figura 2.3 (extraído de $\mathrm{BOSCH}, 1988)$. Como o motor série possui alto torque inicial, é comumente usado no projeto de motores de partida $(\mathrm{BOSCH}, 1988)$.

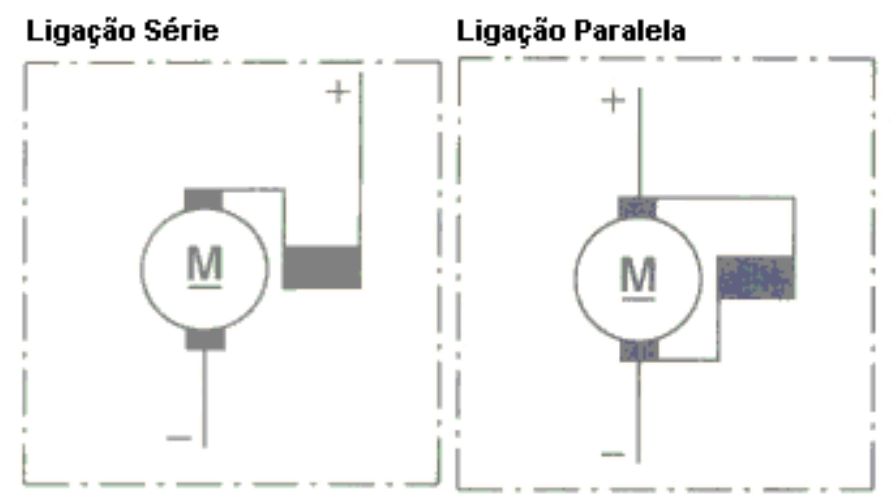


Ligação Composta

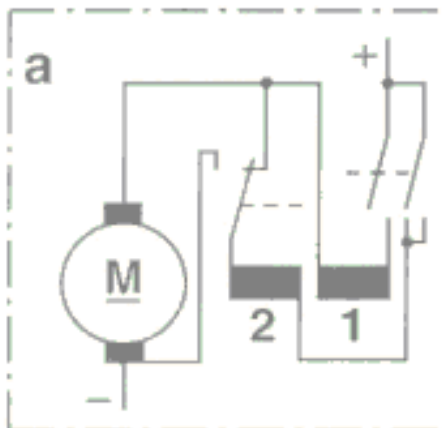

a) Apenas o enrolamento paralelo está conectado ao induzido (condição de corrente de armadura limitada)

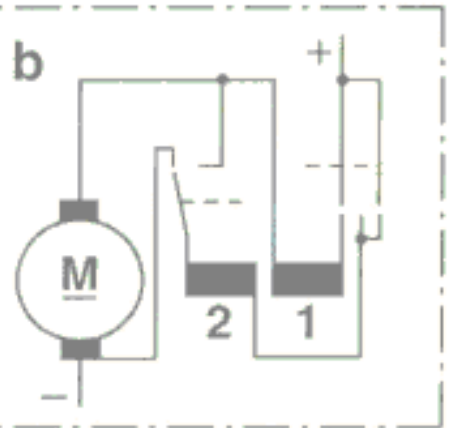

b) Ambos os enrolamentos estão conectados ao induzido (condição de corrente de armadura máxima)

Figura 2.3 - Ligação entre o enrolamento de campo e o induzido (ou armadura) de um motor elétrico CC: série, paralela ou composta (extraído de BOSCH, 1988).

A chave solenóide, ilustrada na figura 2.4 (extraído de $\mathrm{BOSCH}, 1988$ ), é composta por um relé e um solenóide de engate. Possui duas funções: fechar o circuito principal energizando o enrolamento de campo e o induzido (através das escovas) para criar o movimento de rotação e empurrar o pinhão para conectar-se à cremalheira (roda dentada) do motor a combustão $(\mathrm{BOSCH}, 1988$; DELCO REMY BRASIL).

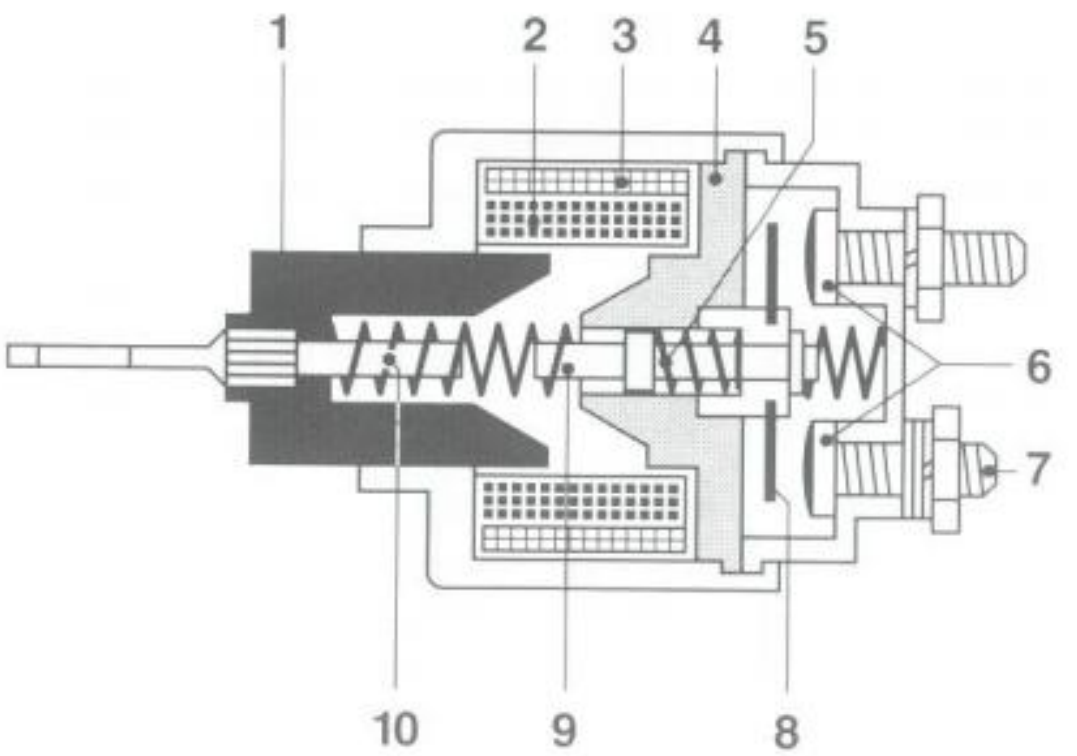

1 - Armadura

2 - Bobina pull-in

3 - Bobina hold-in

4 - Armadura do solenóide

5 - Contato mola

6 - Contatos

7 - Terminal

8 - Contato móvel

9 - Pino de comutação

10 - Mola de retorno

Figura 2.4 - Sub-componentes de uma chave solenóide de um motor de partida elétrico CC (extraído de BOSCH, 1988) 
A unidade de engate do pinhão, ilustrada na figura 2.5 (extraído de $\mathrm{BOSCH}, 1988$ ), é responsável pela coordenação do movimento de impulso da chave solenóide e do movimento de rotação do motor elétrico e pela transferência desses movimentos para o pinhão. A função do pinhão é conectar-se à cremalheira do motor a combustão através de uma alta relação de polias, que torna possível vencer o alto torque resistente de partida usando um pequeno motor de partida com alta velocidade. $O$ contato entre o pinhão e a engrenagem da cremalheira do motor é automaticamente desfeito após a rotação mínima de partida ser atingida, para proteger o motor de partida, através da roda livre. Esse mecanismo desfaz o contato quando o pistão tem uma velocidade maior que a velocidade de rotação do induzido (BOSCH, 1988).

Essa unidade pode ser projetada de três formas diferentes, influenciados pela potência de saída e pelas dimensões físicas desejadas, e determina o tipo de motor de partida (BOSCH, 2005):

- Motor de partida com fuso de avanço;

- Motor de partida com fuso de avanço e alavanca de comando;

- Motor de partida com avanço do pinhão por haste deslizante. 


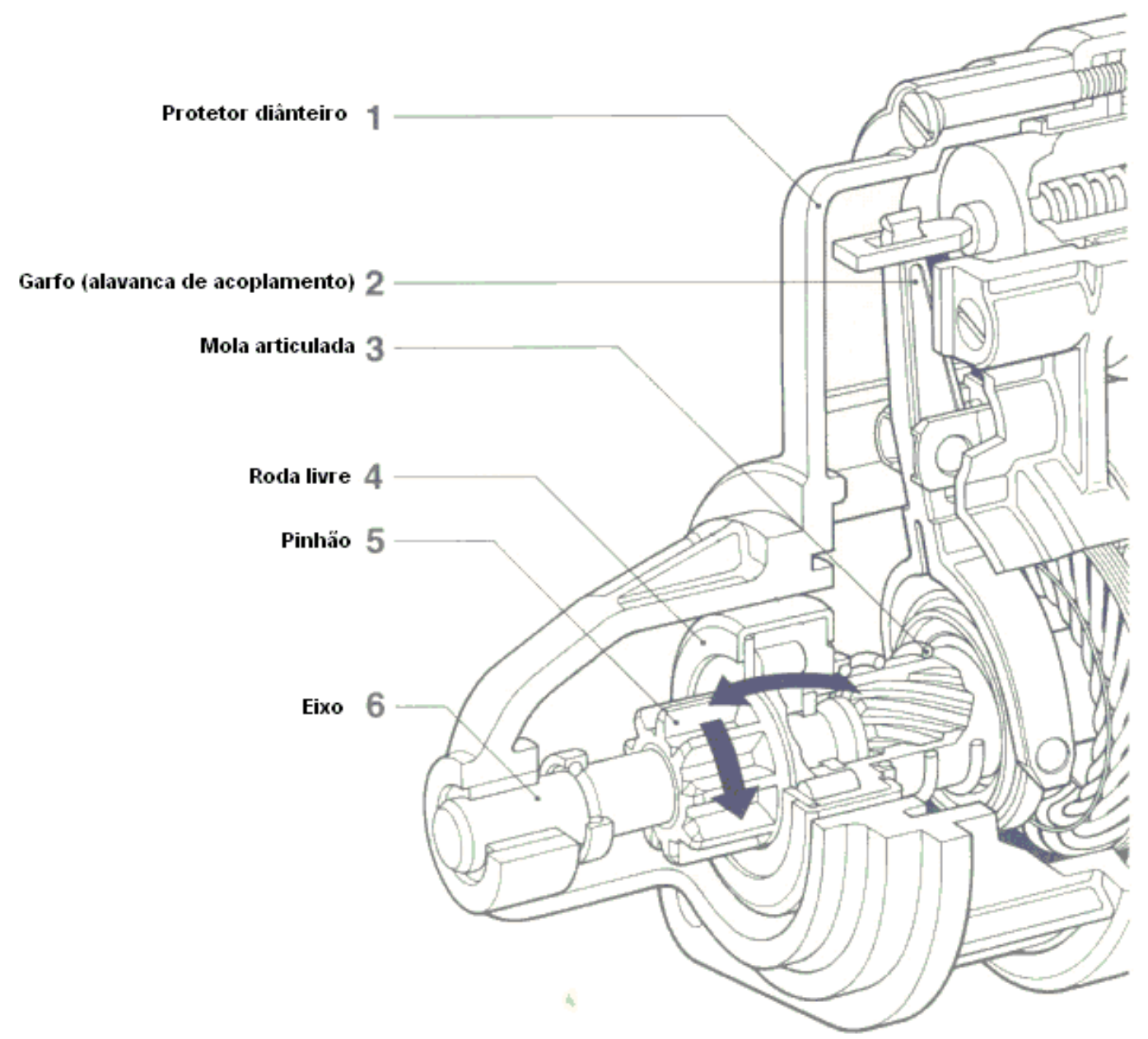

Figura 2.5 - Sub-componentes de uma unidade de engate do pinhão de um motor de partida elétrico CC (extraído de BOSCH, 1988)

O motor de partida elétrico CC série com fuso de avanço e alavanca de comando tornou-se padrão mundial.

O garfo, acionado pela chave solenóide, empurra o pinhão na direção da cremalheira. No final do curso do pinhão, a ponte de contatos do solenóide fecha a corrente principal do motor de partida e o induzido começa a girar. Se um dente do pinhão encontra um vão da cremalheira (posição dente-vão ilustrada pela figura 2.6 a) (extraído de $\mathrm{BOSCH}, 1988$ ), o pinhão engrena até onde atuar o movimento do solenóide. O induzido desloca o pinhão completamente para dentro da cremalheira, conforme figura 2.7 (extraído de $\mathrm{BOSCH}, 1988$ ). Se o dente coincide com um dente da cremalheira (posição dente-dente ilustrada pela figura 2.6 b) (extraído de $\mathrm{BOSCH}, 1988)$, o solenóide, através do garfo, comprime a mola de retorno. O induzido gira o pinhão na frente da cremalheira até que um dente do pinhão 
encontre um vão livre da cremalheira e a mola de retorno comprimida empurra o pinhão e a roda livre para frente. Daí o induzido desloca o pinhão completamente para dentro da cremalheira, conforme figura 2.7 (extraído de $\mathrm{BOSCH}, 1988$ ). Com a ultrapassagem da velocidade do motor a combustão em relação à velocidade do motor de partida, a roda livre auxilia o desengate (BOSCH, 1988; $\mathrm{BOSCH}, 2005)$.

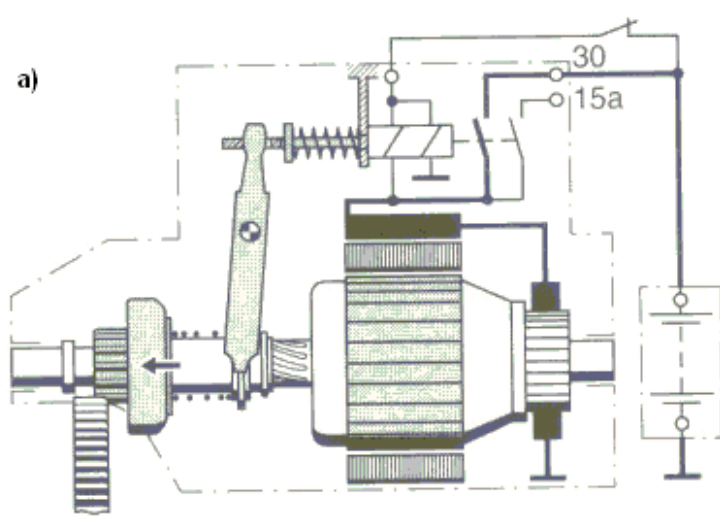

a) Posição dente-vão: encontro entre um dente do pinhão e um vão da cremalheira.

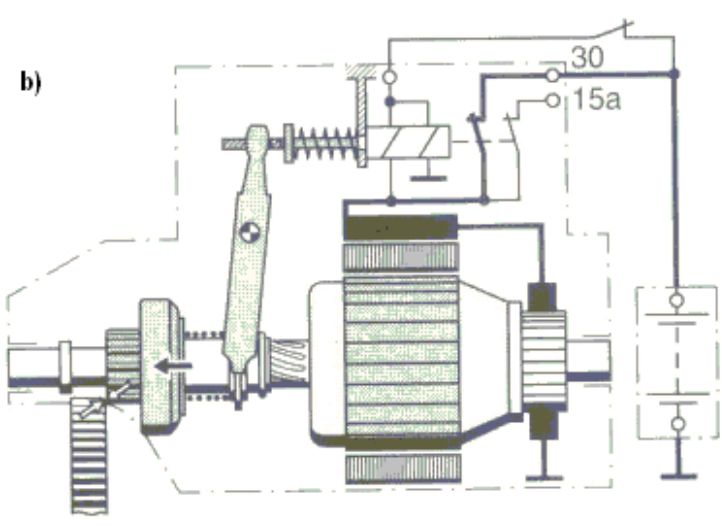

b) Posição dente-dente: encontro entre um dente do pinhão e um dente da cremalheira

Figura 2.6 - Deslocamento da unidade de engate do pinhão de um motor de partida elétrico CC com fuso de avanço e alavanca de comando (extraído de $\mathrm{BOSCH}, 1988$ ).

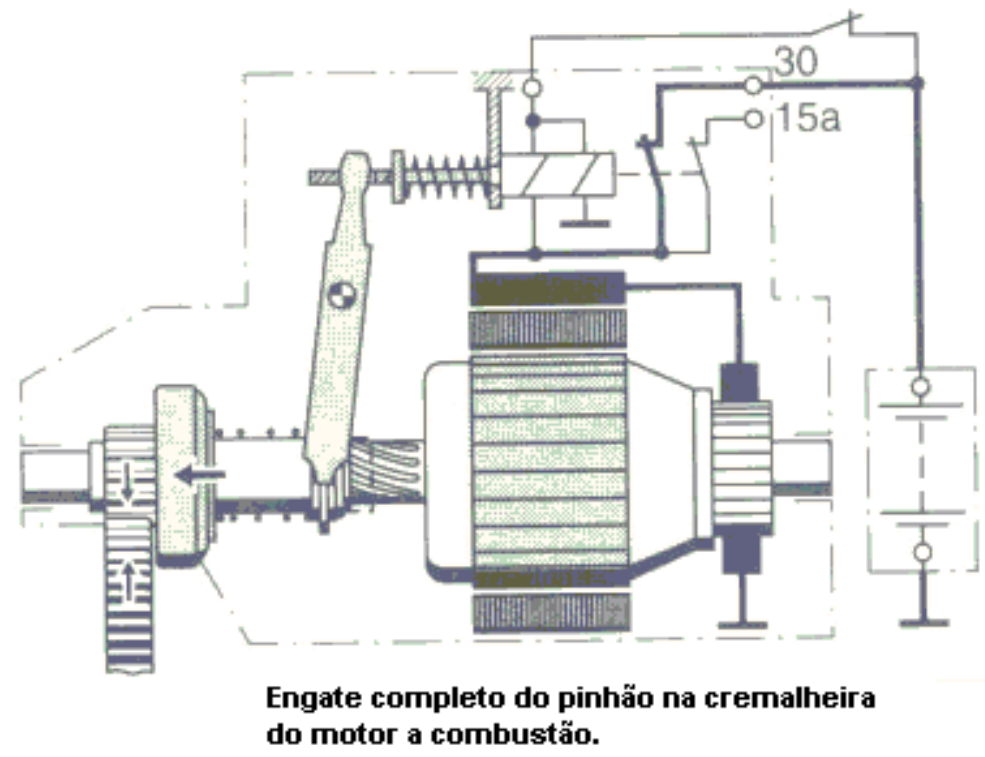

Figura 2.7 - Deslocamento da unidade de engate do pinhão de um motor de partida elétrico CC com fuso de avanço e alavanca de comando (extraído de $\mathrm{BOSCH}, 1988$ ). 


\section{1 - Propriedades}

As características mais importantes do motor de partida são (BOSCH, 1988):

- Tensão de operação: determinado pela bateria.

- Potência de saída: determinado pelo motor a combustão / torque de partida.

- Direção de rotação: determinado pela posição de instalação e direção de operação do motor à combustão.

- Tamanho do motor de partida (diâmetro): é função da potência requerida.

As especificações de desempenho do motor de partida dependem do tipo e geometria do motor à combustão. No gráfico 2.1 tem-se um exemplo de curvas típicas de desempenho de um motor de partida elétrico CC.

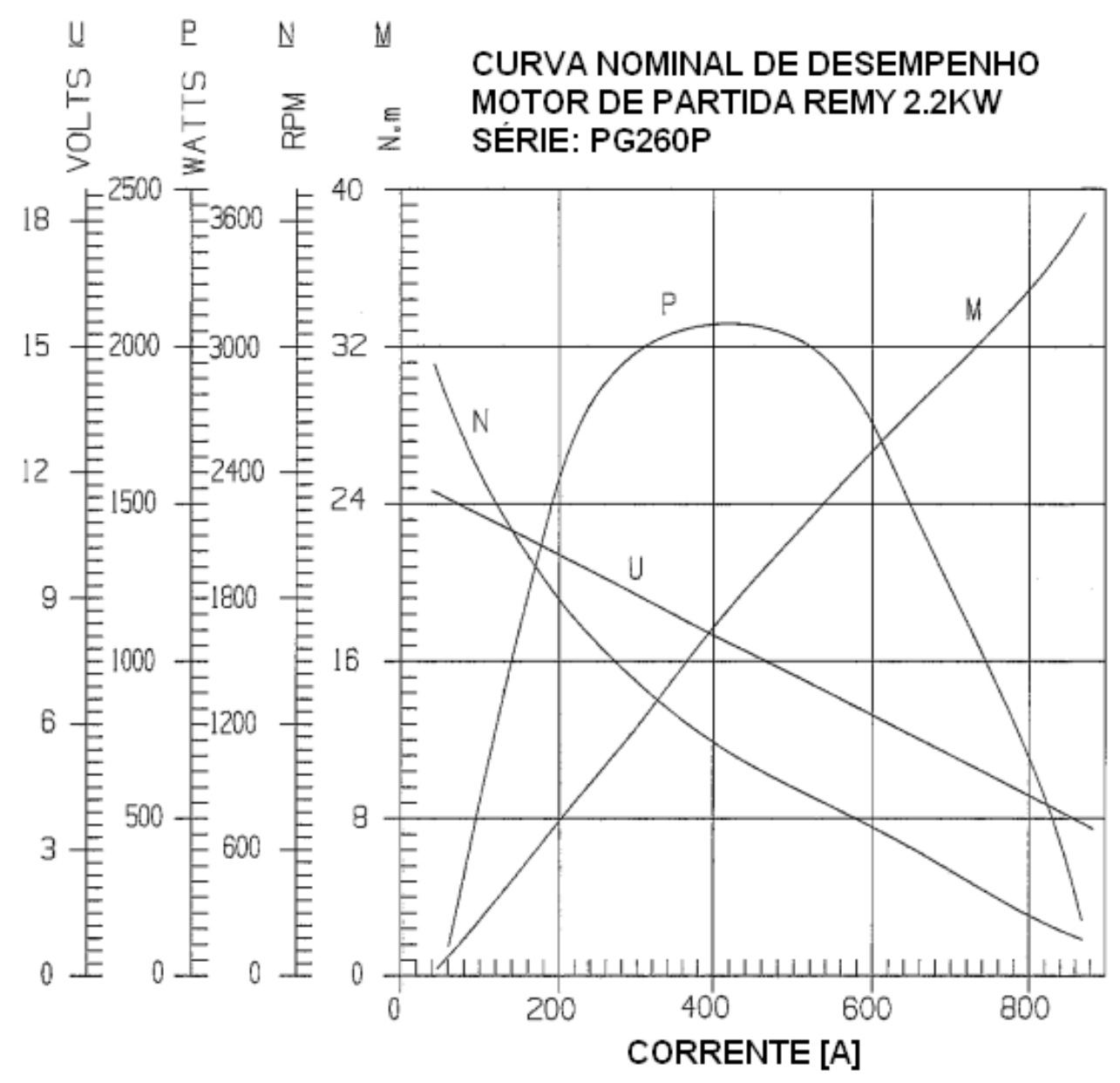

Gráfico 2.1 - Exemplo de curvas típicas de desempenho de um motor de partida elétrico CC de 2.2KW Série PG260P da Delco Remy usado pela General Motors 
APÊNDICE B - DESENVOLVIMENTO DA EQUAÇÃO DA BATERIA

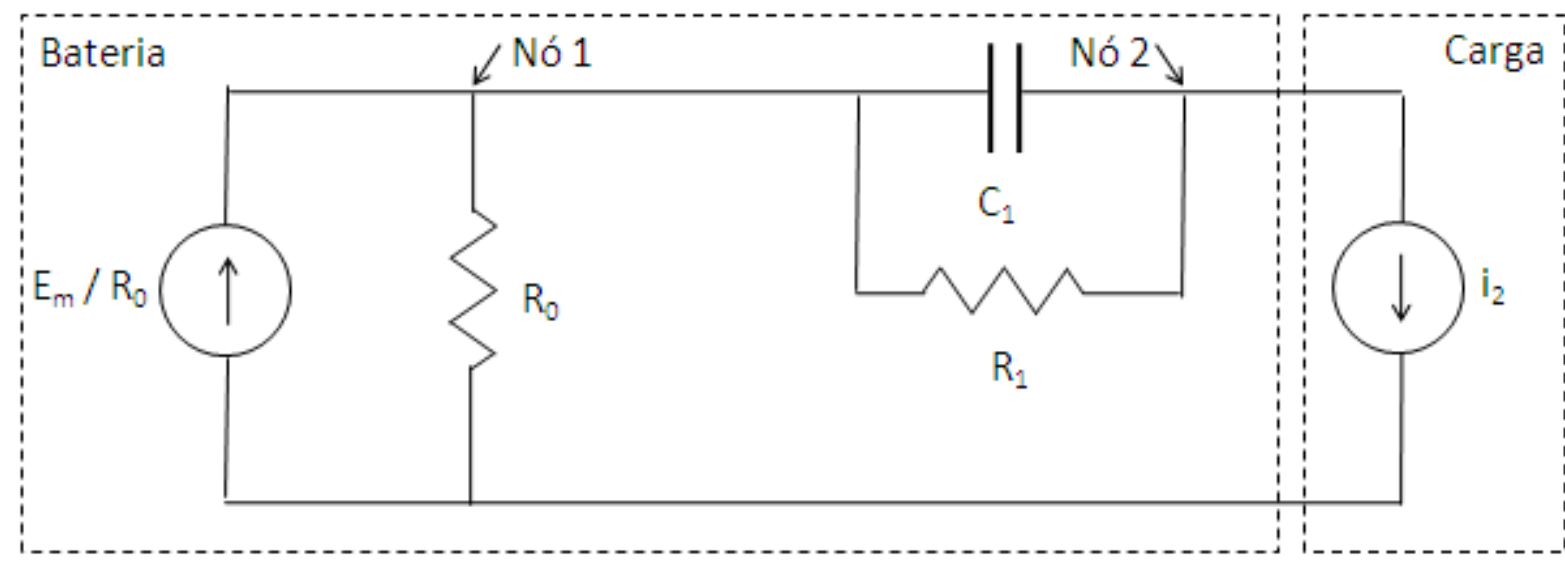

$N$ ó $1 \rightarrow \frac{E_{m}}{R_{0}}-\frac{V_{1}}{R_{0}}-\frac{\left(V_{1}-V_{2}\right)}{R_{1}}-C_{1} \frac{d}{d t}\left(V_{1}-V_{2}\right)=0$

$N$ ó $2 \rightarrow \frac{\left(V_{1}-V_{2}\right)}{R_{1}}+C_{1} \frac{d}{d t}\left(V_{1}-V_{2}\right)-i_{2}=0$

Nó $1 \rightarrow-C_{1} \frac{d}{d t}\left(V_{1}-V_{2}\right)=-\frac{E_{m}}{R_{0}}+\frac{V_{1}}{R_{0}}+\frac{\left(V_{1}-V_{2}\right)}{R_{1}}$

$N$ ó $2 \rightarrow C_{1} \frac{d}{d t}\left(V_{1}-V_{2}\right)=i_{2}-\frac{\left(V_{1}-V_{2}\right)}{R_{1}}$

Nó $1 \rightarrow-C_{1} \frac{d}{d t} V_{1}+C_{1} \frac{d}{d t} V_{2}=-\frac{E_{m}}{R_{0}}+\frac{V_{1}}{R_{0}}+\frac{V_{1}}{R_{1}}-\frac{V_{2}}{R_{1}}$

$N$ ó $2 \rightarrow C_{1} \frac{d}{d t} V_{1}-C_{1} \frac{d}{d t} V_{2}=i_{2}-\frac{V_{1}}{R_{1}}+\frac{V_{2}}{R_{1}}$

$\left[\begin{array}{cc}-C_{1} & C_{1} \\ C_{1} & -C_{1}\end{array}\right]\left[\begin{array}{l}\dot{V}_{1} \\ \dot{V}_{2}\end{array}\right]=\left[\begin{array}{c}-\frac{E_{m}}{R_{0}} \\ i_{2}\end{array}\right]+\left[\begin{array}{cc}\left(\frac{1}{R_{0}}+\frac{1}{R_{1}}\right) & \frac{-1}{R_{1}} \\ \frac{-1}{R_{1}} & \frac{1}{R_{1}}\end{array}\right]\left[\begin{array}{l}V_{1} \\ V_{2}\end{array}\right]$ 


\section{APÊNDICE C - ALGORITMO PARA CÁLCULO DA EQUAÇÃO DA BATERIA}

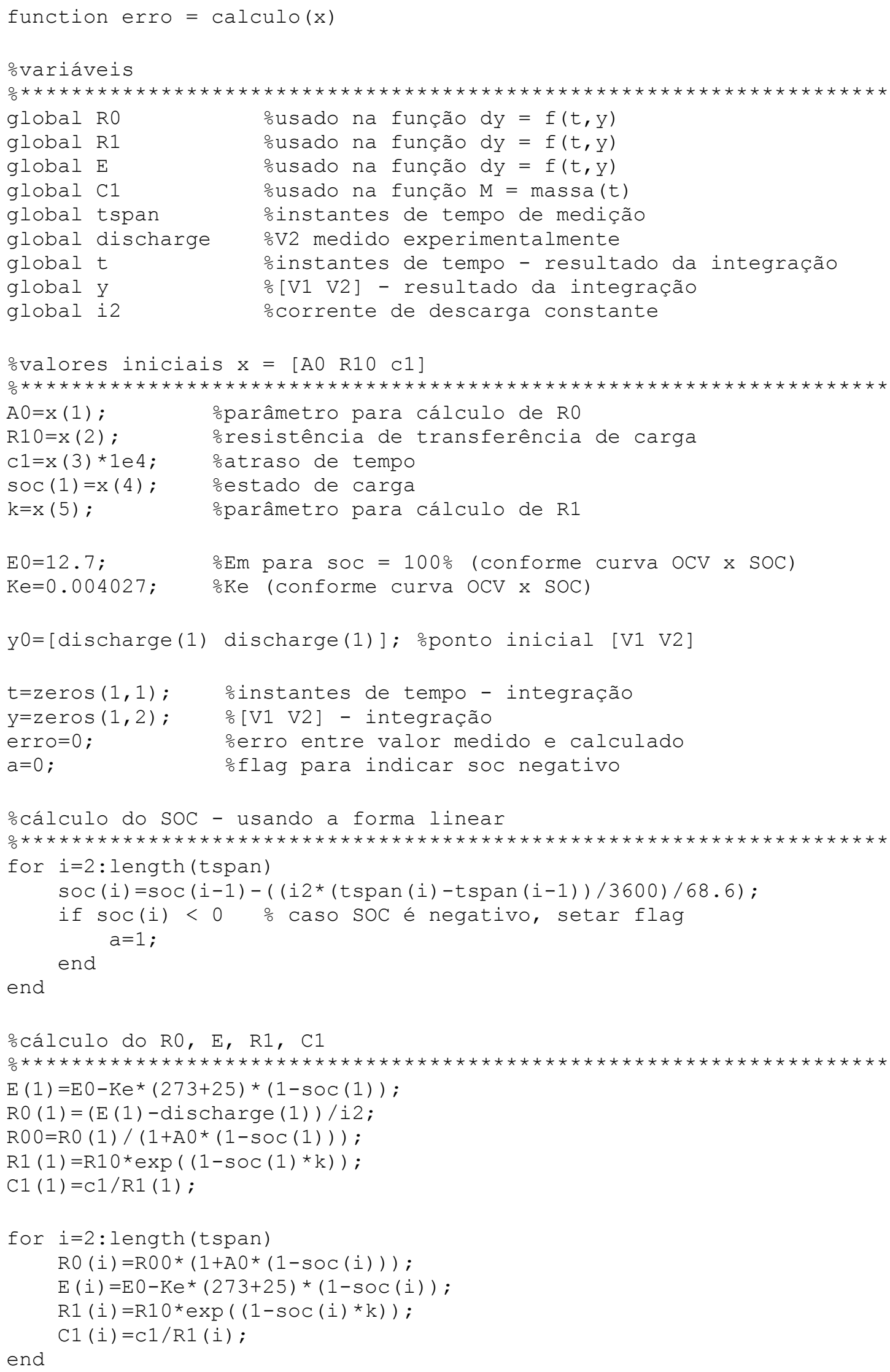




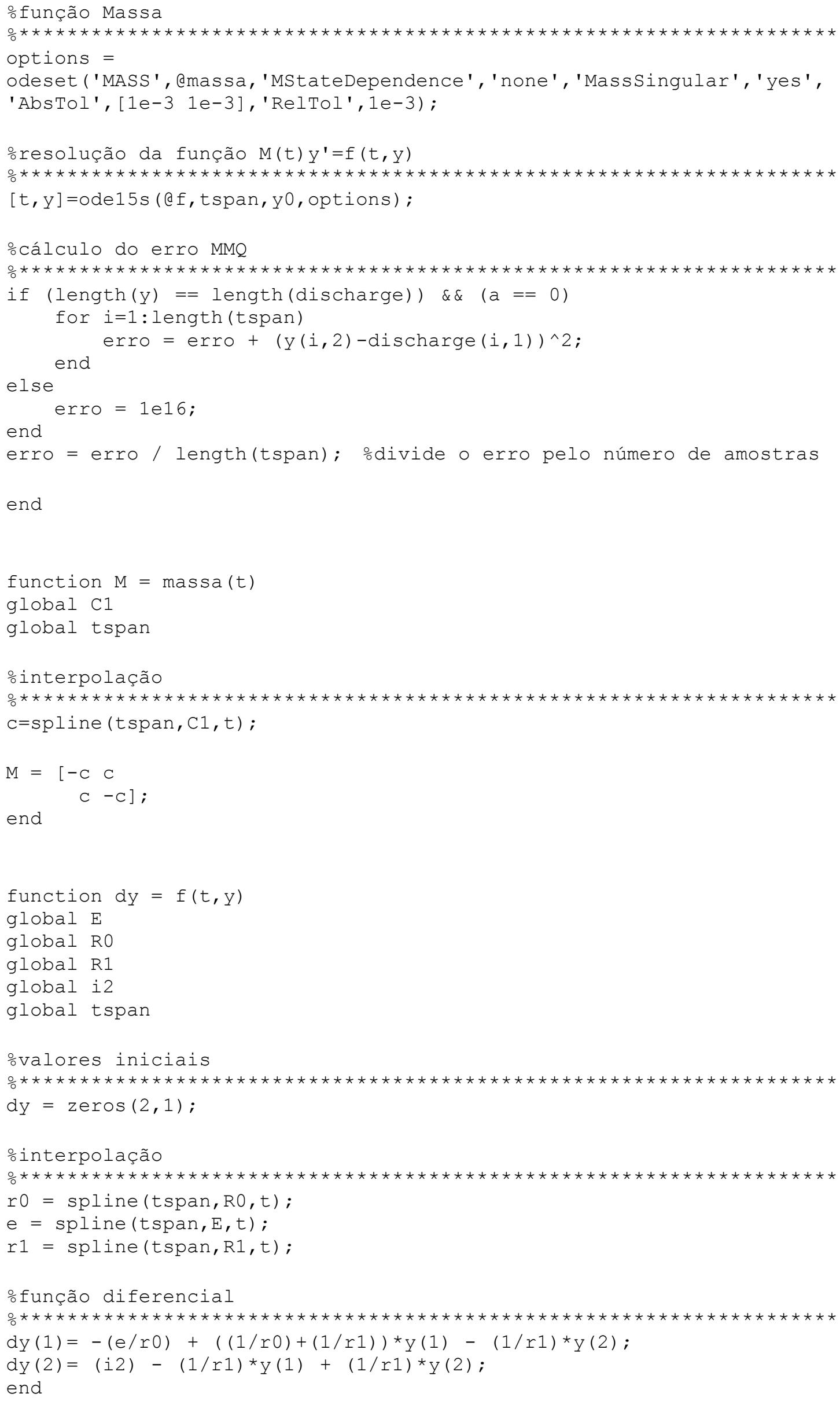

end

function $d y=f(t, y)$

global E

global R0

global R1

global i2

global tspan

ovalores iniciais

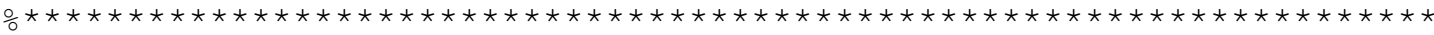
$\mathrm{dy}=\operatorname{zeros}(2,1)$;

ointerpolação

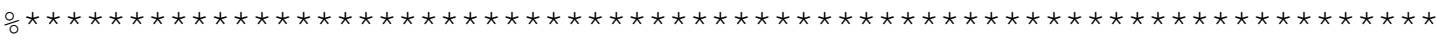
rO = spline (tspan, R0, t);

$e=$ spline (tspan, E, t);

$r 1=\operatorname{spline}(\operatorname{tspan}, \mathrm{R} 1, \mathrm{t})$;

ㅇunção diferencial

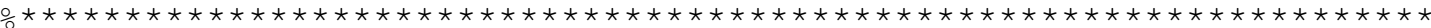

$\mathrm{dy}(1)=-(\mathrm{e} / \mathrm{r} 0)+((1 / \mathrm{r} 0)+(1 / \mathrm{r} 1)){ }^{*} \mathrm{y}(1)-(1 / \mathrm{r} 1) * \mathrm{y}(2)$;

$\mathrm{dy}(2)=(\mathrm{i} 2)-(1 / \mathrm{r} 1){ }^{*} \mathrm{y}(1)+(1 / \mathrm{r} 1){ }^{*} \mathrm{y}(2)$;

end 